\title{
Bruno Jardim
}

\section{Atuadores Elásticos em Série Aplicados no Desenvolvimento de um Exoesqueleto Para Membros Inferiores}

Dissertação apresentada à Escola de Engenharia de São Carlos da Universidade de São Paulo, como parte dos requisitos para obtenção do título de Mestre em Engenharia Mecânica

Área de Concentração: Dinâmica de Máquinas e Sistemas Orientador: Prof. Dr. Adriano A. G. Siqueira 


\section{Sumário}

Resumo vii

$\begin{array}{ll}\text { Abstract } & \text { ix }\end{array}$

Publicações

Lista de Figuras $\quad$ xiii

1 Introdução 1

1.1 Motivação . . . . . . . . . . . . . . . . . . . . . . . 1

1.2 Revisão bibliográfica . . . . . . . . . . . . . . . . . . . . 3

1.3 Descrição do trabalho . . . . . . . . . . . . . . . . . . . . . . . 14

1.4 Disposição dos capítulos . . . . . . . . . . . . . . . . . . 14

2 Atuadores Elásticos em Série $\quad 15$

2.1 Princípio de funcionamento . . . . . . . . . . . . . . . . . . . . 17

2.2 Modelagem do atuador . . . . . . . . . . . . . . . . . . . . . . 19

2.3 Montagem . . . . . . . . . . . . . . . . . . . . . . 22

2.3 .1 Componentes . . . . . . . . . . . . . . . . . . 23

2.3 .2 Cálculo da constante elástica . . . . . . . . . . . . . . . . . 23

2.3.3 Potenciômetro linear deslizante . . . . . . . . . . . . . . . 25

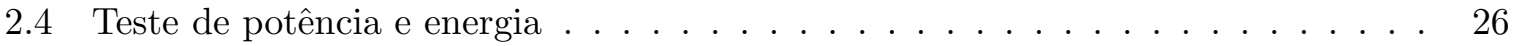

3 Controle de Atuadores Elásticos em Série $\quad 31$

3.1 Driver de potência. . . . . . . . . . . . . . . . . . 31

3.2 Controle de posição . . . . . . . . . . . . . . . . . . . . . . . . 34

3.3 Controle de força $\ldots \ldots \ldots \ldots \ldots \ldots \ldots$

3.4 Controle de impedância . . . . . . . . . . . . . . . . . . . . . . . 38

4 Órtese Tornozelo-Pé Ativa $\quad 41$ 
4.1 Desenho de conjunto do exoesqueleto . . . . . . . . . . . . . . . . . 41

4.2 Projeto e construção de uma Órtese Tornozelo-Pé Ativa . . . . . . . . . . . . . . 47

4.2 .1 Requisitos ....................... 47

4.2 .2 Características ...................... . . 47

4.2.3 Projeto........................... . . 47

4.3 Modelagem cinemática da órtese . . . . . . . . . . . . . . . . . . . . 52

4.4 Análise da articulação do tornozelo . . . . . . . . . . . . . . . . 53

5 Resultados $\quad 59$

5.1 Controle de posição . . . . . . . . . . . . . . . . . . . . . . 59

5.2 Controle de força . . . . . . . . . . . . . . . . . . . . . 62

5.3 Controle de impedância - OTPA . . . . . . . . . . . . . . . . . . 71

$\begin{array}{llr}6 & \text { Conclusão } & 77\end{array}$

$\begin{array}{lr}\text { Referências Bibliográficas } & 79\end{array}$

A Lista de Materiais $\quad 85$ 
À minha mãe, Maria Cecília Jardim, que sempre me motivou a acreditar nos meus sonhos e me ensinou o valor da educação.

Ao meu filho, Ítalo, que me dá força para vencer os desafios e buscar novos sonhos.

A todos que sonham e trabalham por um mundo melhor. 
Ao orientador e amigo Prof. Dr. Adriano Almeida Gonçalves Siqueira, pela confiança depositada, orientação, tempo dedicado a este trabalho e pelas inestimáveis experiências transmitidas em nossas conversas.

Aos professores e funcionários do Departamento de Engenharia Mecânica da Escola de Engenharia de São Carlos, pelas contribuições durante o mestrado.

Aos técnicos do Departamento de Engenharia Mecânica por contribuir com o desenvolvimento do projeto.

Aos alunos de Iniciação Científica, Heitor de Araujo Martins, Guilherme Machado Lara Silveira, Danilo Santos, Paulo Roberto Chiarolanza Vilela e Tiago Furlan Winter, pela dedicação ao projeto.

Aos amigos do Rotary Club de Campinas, especialmente ao Sr. Carlos Roberto de Mattos Rocha que muito contribuiu para minha formação.

Aos amigos do Departamento de Engenharia Mecânica pela amizade, paciência, companheirismo e colaborações durante a realização das disciplinas e deste trabalho.

À minha noiva Maria Helena por estar sempre ao meu lado.

Ao Conselho Nacional de Desenvolvimento Científico e Tecnológico (CNPq) pela concessão da bolsa de mestrado. 


\section{Resumo}

Esta dissertação apresenta o projeto e a construção de atuadores elásticos em série para o acionamento das juntas de um exoesqueleto para membros inferiores, baseado em uma órtese comercial. Inicialmente, considerou-se como dispositivo de testes a parte do exoesqueleto referente à junta do tornozelo, ou seja, a construção de uma órtese tornozelo-pé ativa. Atuadores elásticos em série são considerados neste trabalho, pois tais dispositivos apresentam características ideais para a sua utilização em órteses ativas: controle de força, controle de impedância (possibilidade de impedância baixa), absorção de impactos, baixo atrito e largura de banda que se aproxima da movimentação muscular. Um primeiro protótipo do atuador elástico em série foi construído e resultados experimentais de controle de força, impedância e posição foram obtidos com sucesso, através de uma interface de acionamento e controle entre o atuador, os sensores (encoders e sensores de força) e o computador. Também foi construída uma órtese tornozelopé ativa acionada pelo atuador elástico em série construído, sendo apresentados os primeiros resultados experimentais obtidos com este dispositivo.

Palavras-chave: Atuadores elásticos em série, exoesqueleto, controle de impedância, reabilitação. 


\section{Abstract}

This dissertation deals with the design and construction of series elastic actuators for driving the joints of an exoskeleton for lower limbs, based on a commercial orthosis. Initially, it was considered the construction of the exoskeleton's ankle joint, that is, the construction of an active ankle-foot orthosis. Series elastic actuators are considered in this work since these devices have ideal characteristics for use in active orthoses: force control, impedance control (possibility of low impedance), impact absorption, low friction and bandwidth that approximates the muscle movement. A first prototype of the series elastic actuator was constructed and experimental results of force, impedance, and position control were successfully obtained trough of a control interface between the actuators, the sensors (encoders and force sensors) and the computer. Also, an active ankle-foot orthosis, driven by the series elastic actuator, was constructed and the first experimental results achieved with this device are presented.

Keywords: Series elastic actuators, exoskeleton, impedance control, rehabilitation. 


\section{Publicações}

- SiqueirA, A. A. G.; JARDiM, B.; VILELA, P. R. C.; WINTER, T. F. (2008). Analysis of Gait-Pattern Adaptation Algorithms Applied in an Exoskeleton for Lower Limbs. In: Proceedings of the 16th Mediterranean Conference on Control and Automation, Ajaccio, Corsica, France, p. 920-925.

- JARDIM, B.; SIQUEIRA, A. A. G. (2008). Desenvolvimento de Atuadores Elásticos em Série para Acionamento de uma Órtese Tornozelo-Pé Ativa. In: Anais do Congresso Brasileiro de Automática, CBA2008, Juiz de Fora, Brasil, p. 1-6.

- JARDim, B.; MARTINS, H. A.; SIQUEIRA, A. A. G. (2009). Controle de Impedância Aplicado em uma Ó rtese Tornozelo-Pé Ativa. In: Anais do $2^{\circ}$ Encontro Nacional de Engenharia Biomecânica, Florianópolis, Brasil, p. 1-2. (Aceito para apresentação) 


\section{Lista de Figuras}

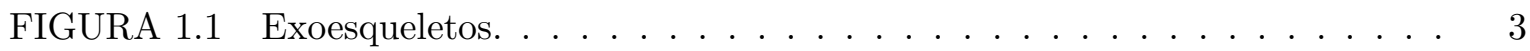

FIGURA 1.2 Sarcos - Raytheon . . . . . . . . . . . . . . . . . 5

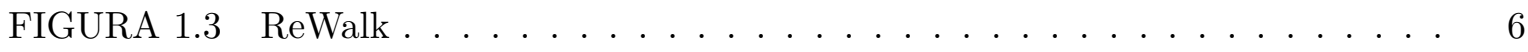

FIGURA 1.4 Reciprocating Gait Orthosis . . . . . . . . . . . . . 7

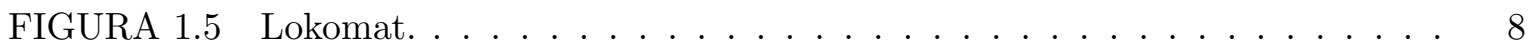

FIGURA 1.6 Órtese Para sustentação do joelho . . . . . . . . . . . . . 9

FIGURA 1.7 Órtese em Conjunto com Sensores IMU - Universidad Politécnica de

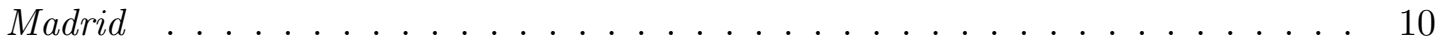

FIGURA 1.8 Órtese atuada por Músculos Artificias Pneumáticos - Laboratório de Bioengenharia - UFMG . . . . . . . . . . . . . . . . 11

FIGURA 1.9 Órtese Tornozelo-pé Ativa - MIT f . . . . . . . . . . . . . 12

FIGURA 1.10 Exoesqueleto quase-passivo para membros inferiores - MIT . . . . . . . 12

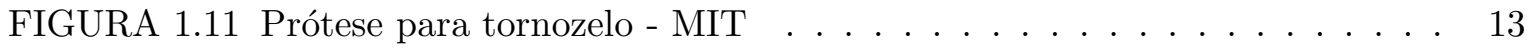

FIGURA 1.12 MIT - Prótese Tornozelo-Pé Ativa . . . . . . . . . . . . . . . . . . 13

FIGURA 2.1 Robôs que utilizam o AES para movimentar suas juntas - MIT Leg Laboratory . . . . . . . . . . . . . . . . . . . . . . . 17

FIGURA 2.2 Atuador Elástico em Série . . . . . . . . . . . . . . . . . . . 17

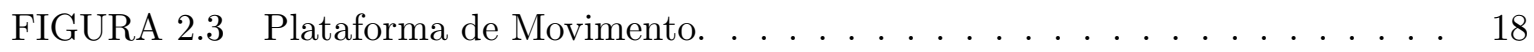

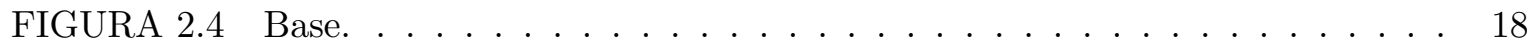

FIGURA 2.5 Funcionamento do Atuador Elástico em Série - MIT Leg Laboratory . . 19 
FIGURA 2.6 Modelo do Atuador Elástico em Série . . . . . . . . . . . . . . . . . . 19

FIGURA 2.7 Comportamento em malha aberta para diferentes valores de B . . . . . 22

FIGURA 2.8 Atuador Elástico em Série . . . . . . . . . . . . . . . . . 23

FIGURA 2.9 Peças - AES $\ldots \ldots \ldots \ldots \ldots \ldots \ldots$

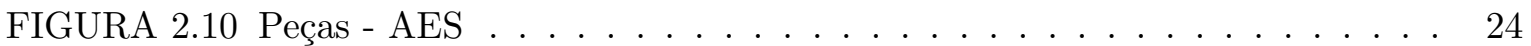

FIGURA 2.11 Atuador Elástico em Série - Configuração Final . . . . . . . . . . . . 24

FIGURA 2.12 Curva Para Obter o Coeficiente Elástico das Molas . . . . . . . . . . 25

FIGURA 2.13 Curva experimental para obter a relação de linearidade do potenciômetro 27

FIGURA 2.14 Aparato Experimental f . . . . . . . . . . . . . . . . 28

FIGURA 2.15 Energia liberada à carga - AES . . . . . . . . . . . . . . . . 29

FIGURA 3.1 EPOS $70 / 10$ Position Controller . . . . . . . . . . . . . . . . . 32

FIGURA 3.2 Parâmetros de Controle EPOS - Interface de ajuste do controlador interno do driver - Modo automático para a sintonia do PID . . . . . . . . . . . . 33

FIGURA 3.3 Interface de Controle - Borland Builder $C++\ldots \ldots \ldots$

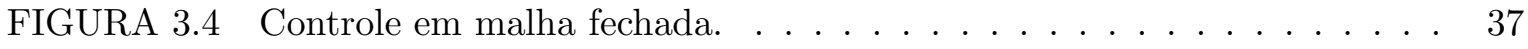

FIGURA 4.1 Órtese adquirida para o projeto de pesquisa. . . . . . . . . . . . . . . 42

FIGURA 4.2 Desenho de conjunto do exoesqueleto. . . . . . . . . . . . . . . . 44

FIGURA 4.3 Desenho de conjunto do exoesqueleto: vista lateral e posterior. . . . . . 45

FIGURA 4.4 Mecanismos de acionamento da articulação do quadril. . . . . . . . . . 45

FIGURA 4.5 Mecanismos de acionamento da articulação do joelho. . . . . . . . . . . 46

FIGURA 4.6 Mecanismos de acionamento da articulação do tornozelo. . . . . . . . . . 46

FIGURA 4.7 Órtese tornozelo-pé projetada em CAD . . . . . . . . . . . . . 48

FIGURA 4.8 Órtese Tornozelo-Pé Ativa $\ldots \ldots \ldots \ldots \ldots$

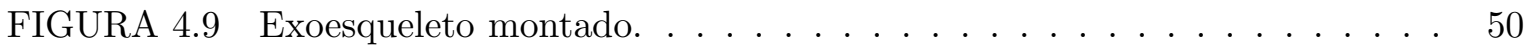

FIGURA 4.10 Comparação entre as duas bases utilizadas. . . . . . . . . . . . . . . 51 
FIGURA 4.11 Palmilha flexível com sensores SIC . . . . . . . . . . . . . . 52

FIGURA 4.12 Modelagem Cinemática - OTPA . . . . . . . . . . . . . . 52

FIGURA 4.13 Posições do tornozelo - MIT . . . . . . . . . . . . . . . . . . 54

FIGURA 4.14 Etapas do caminhar - tornozelo - MIT . . . . . . . . . . . . 55

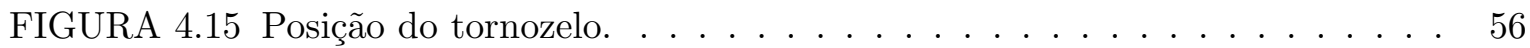

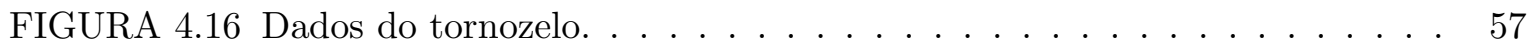

FIGURA 5.1 Controle de Posição com trajetória senoidal e frequência de $0.2 \mathrm{~Hz} \quad \ldots \quad$. 60

FIGURA 5.2 Controle de Posição com frequência de $0.6 \mathrm{~Hz} \ldots \ldots \ldots$. . . . . . . 61

FIGURA 5.3 Controle de Posição com freqência de $0.7 \mathrm{~Hz} \quad \ldots \ldots \ldots$. . . . . . . 61

FIGURA 5.4 Controle de Posição, trajetória de uma pessoa saudável caminhando . . 62

FIGURA 5.5 Interface de Controle $\ldots \ldots \ldots \ldots \ldots$

FIGURA 5.6 Sintonia de PID . . . . . . . . . . . . . . . . . . . . . 64

FIGURA 5.7 Resposta a um degrau de amplitude $200 N \ldots \ldots$. . . . . . . . 66

FIGURA 5.8 Resposta a um degrau de amplitude $-200 N \ldots \ldots \ldots 6$

FIGURA 5.9 Resposta a um degrau de amplitude $-300 N \ldots \ldots \ldots 7$

FIGURA 5.10 Resposta a um degrau de amplitude $-400 N \ldots \ldots \ldots$. . . . . 67

FIGURA 5.11 Retornar ao valor zero $(\Delta x=0) \ldots \ldots \ldots \ldots$

FIGURA 5.12 Controle de Força - Carga Livre . . . . . . . . . . . . . . . . . . . . 69

FIGURA 5.13 Controle de Força - Carga Livre . . . . . . . . . . . . . . . . . . . . 69

FIGURA 5.14 Controle de Força - Degrau $200 N \ldots \ldots$. . . . . . . . . 70

FIGURA 5.15 Controle de Força - Degrau $-100 N \ldots \ldots \ldots$. . . . . . . 71

FIGURA 5.16 Interface para Controle de Impedância ～. . . . . . . . . . . . . . . . 72

FIGURA 5.17 Interface para Controle de Impedância ～. . . . . . . . . . . . . . . 73

FIGURA 5.18 OTPA - Mola Virtual . . . . . . . . . . . . . . . . . 74

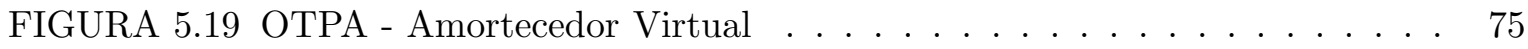

FIGURA 5.20 OTPA - Mola e Amortecedor Virtuais . . . . . . . . . . . . . . 75 


\section{Capítulo 1}

\section{Introdução}

\subsection{Motivação}

Há milhões de pessoas no mundo com deficiência no caminhar, necessitadas de dispositivos que as auxiliem em sua reabilitação ou que as assistam permanentemente. Segundo o mais recente Censo do IBGE (2003), existem cerca de 8 milhões de pessoas com alguma deficiência motora no Brasil . Entretanto, muitos dos métodos de reabilitação e assistência empregados atualmente dependem do julgamento de pessoal especializado, requerem constante ajuste e demandam grande esforço do paciente. Muitas pesquisas estão sendo desenvolvidas, tanto nas universidades como na indústria, na área de robôs humanóides e locomoção bípede. Dentre as diversas pesquisas sobre robôs bípedes, umas das áreas promissoras é o desenvolvimento de exoesqueletos. Em zoologia, chama-se exoesqueleto à cutícula resistente, mas flexível, que cobre o corpo de muitos animais e protistas, fornecendo proteção para os órgãos internos e suporte para os músculos. Na área militar, exoesqueletos são utilizados para aumentar a capacidade física dos soldados, fazendo com que eles possam carregar pesos que uma pessoa normal não conseguiria. Outras possibilidades de utilização de exoesqueletos são: equipes de resgate e de emergência podem usá-los em áreas de entulhos e terrenos acidentados onde veículos com rodas não conseguem se locomover; bombeiros podem carregar equipamentos pesados para o interior de prédios em chamas ou retirar pessoas de lá mais rapidamente; fisioterapeutas podem usá-los na reabilitação de pacientes com lesão medular, que perderam total ou parcialmente a movimentação dos membros inferiores. Neste caso, denominada engenharia de reabilitação, é dado enfoque à utilização de equipamentos mecânicos e eletromecânicos para ajudar na recuperação de pacientes com deficiências motoras nos membros inferiores. A ideia é fazer com 
que o paciente tenha interação com o exoesqueleto, de forma que este forneça potência somente quando necessário, ou seja, o usuário é forçado a treinar seus músculos e suas movimentações de forma gradativa. Este tipo de interação necessita de atuadores com rigidez controlável, para gerar movimentos antropomórficos e evitar lesões ao usuário e danos ao equipamento. Portanto, neste trabalho é dado enfoque ao desenvolvimento de Atuadores Elásticos em Série, pois tais dispositivos apresentam características ideais para este tipo de equipamento: controle de força e impedância (possibilidade de impedância baixa), absorção de impactos, baixo atrito e largura de banda que se aproxima da movimentação muscular. 


\subsection{Revisão bibliográfica}

\section{Exoesqueletos}

Vários centros de pesquisa vêm construindo exoesqueletos ao redor do mundo. Segundo GUIZZO E GOLDSTEIN (2005), os mais avançados exoesqueletos já construídos são o HAL5, da Universidade de Tsukuba do Japão, e os exoesqueletos da Universidade da Califórnia, Berkeley, e da Sarcos Research Corp., ambos nos Estados Unidos.

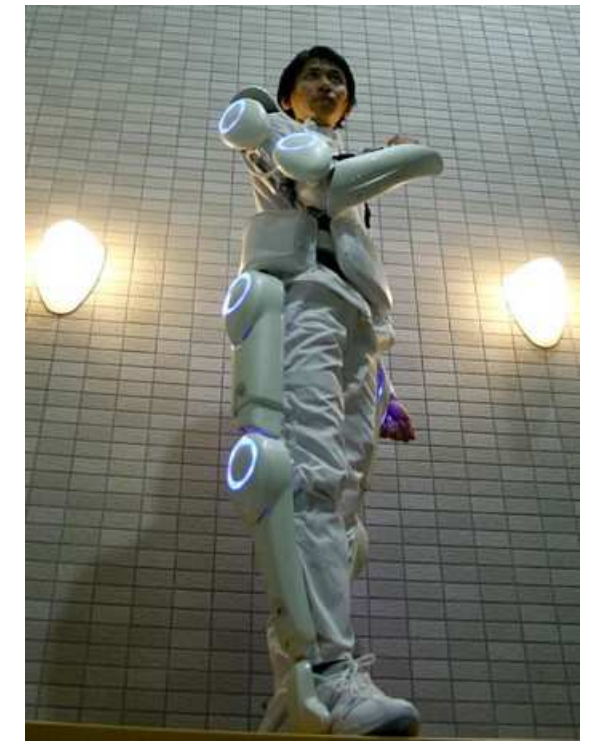

(a) HAL-5

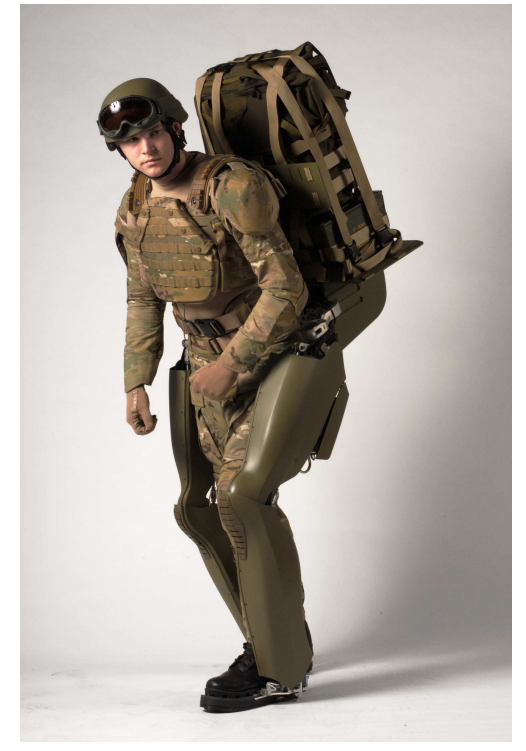

(b) BLEEX 2

Figura 1.1: Exoesqueletos.

O HAL-5 (Hybrid Assistive Limb), desenvolvido pelo Prof. Yoshiyuki Sankai da Universidade de Tsukuba, apresentado primeiramente na 2005 World Expo, é a quinta geração de exoesqueletos projetados para auxiliar pessoas com deficiência, Figura 1.1(a). A estrutura do HAL-5, composta de ligas níquel molibdênio e duralumínio, é fixada na parte externa do usuário e protegida por uma envoltória de plástico. Além de permitir que o usuário permaneça em pé, caminhe e suba escadas, o exoesqueleto possibilita carregar até $40 \mathrm{~kg}$ a mais que o usuário normalmente conseguiria por até 10 minutos. Ao utilizar o HAL-5 o usuário não necessita carregar uma mochila contendo o computador e os sistemas de comunicação sem fio, estes componentes são dispostos em um pequeno compartimento anexado ao cinto. A fonte de energia utilizada para acionar pequenos motores DC nos ombros, cotovelos, joelhos e quadril, provém de baterias híbridas níquel-metal e de lítio que funcionam por 2 horas e 40 minutos. Dois sistemas de controle 
são utilizados para acionar o exoesqueleto: o primeiro, chamado sistema bio-cibernético (termo cunhado pelo Prof. Sankai), monitora as correntes elétricas do corpo do usuário, conhecidas como sinais mioelétricos, e acionam os motores quando o usuário pretende realizar algum movimento, através de um controle assistido de potência (HAYASHI et al. , 2005; LEE E SANKAI , 2002); o segundo faz com que o usuário e o exoesqueleto movam-se de forma suave e sincronizada, denominado controle por sequência de fases, ele gera uma sequência de movimento assistidos pela transição de movimentos fundamentais chamados de fase, (KIM E SANKAI , 2005,b). A calibração do sistema pode levar até dois meses para cada pessoa e o custo total do equipamento chega a US\$ 13800,00 .

Os projetos de pesquisa da Universidade da Califórnia, Berkeley, e da Sarcos Research Corp., são financiados pela Agência de Defesa dos EUA (Defense Advanced Research Projects Agency, DARPA) desde 2001 com um custo total de US\$ 50 milhões. Em outubro de 2003 foi apresentado o BLEEX 1, em sua exposição o usuário caminhava com velocidade de até 2 milhas por hora, carregando uma carga de aproximadamente $35 \mathrm{~kg}$. O Prof. Kazerooni, diretor do Berkeley Robotics and Human Engineering Laboratory, mostrou que o projeto abordou quatro tecnologias: a concepção da arquitetura do exoesqueleto, algorítmos de controle, uma rede local (LAN) para o controle e uma unidade de potência e energia para os atuadores, sensores e computadores.

Uma nova versão deste projeto foi construída e algumas melhorias foram realizadas. Enquanto o BLEEX 1 possui uma estrutura volumosa com os atuadores hidráulicos e componentes eletrônicos dispostos nas pernas, o BLEEX 2, Figura 1.1(b), possui uma estrutura mais enxuta pesando apenas $14 \mathrm{~kg}$, sem a exposição de cabos, circuitos e atuadores, (GUIZZO E GOLDSTEIN , 2005). O BLEEX 2 utiliza atuadores hidráulicos acionados por uma bomba ligada a um pequeno motor a gasolina. Mais de 40 sensores junto com os atuadores formam uma rede local (LAN) que funciona como o sistema nervoso humano. Os sensores constantemente disponibilizam informações ao computador central que calcula o que é necessário fazer para distribuir o peso de tal forma que o usuário não sinta o peso excedente (ZOSS et al. , 2005; KAZEROONI , 2005; KIM et al. , 2004).

O BLEEX 2, concluído em 2005, é capaz de transportar aproximadamente $70 \mathrm{~kg}$ à velocidade de 5 milhas por hora. A sua arquitetura o faz ser altamente manobrável, robusto, leve e durável, podendo transcender as limitações humanas. O controlador apresenta grande sensibilidade ao controle de força e torque, permitindo ao usuário diversas manobras.

O grupo de pesquisa da Sarcos Research Corp., liderado pelo roboticista Stephen Jacobsen, 
tem trabalhado no que pode ser o mais poderoso exoesqueleto jamais construído. Numa apresentação realizada em 2005, um usuário conseguiu carregar $85 \mathrm{~kg}$ sem sentir a carga total. Assim como o BLEEX, sensores de força, desenvolvido pela Sarcos, em contato com o corpo do usuário fornecem informações para que o controle do exoesqueleto seja feito de forma harmônica com o movimento do usuário. A unidade de potência deste sistema também é um motor de combustão interna. Segundo Jacobsen, uma dificuldade neste projeto foi a construção das servoválvulas que controlam o fluxo do fluido hidráulico até os atuadores. Elas devem ser pequenas, resistentes a altas pressões e eficientes para preservar a potência. Este mesmo grupo de pesquisa desenvolveu um exoesqueleto denominado Raytheon, Figuras 1.2(a) e 1.2(b) que também tem a finalidade de prover mais força e potência aos soldados. Detalhes técnicos a respeito deste projeto ainda não foram publicados.

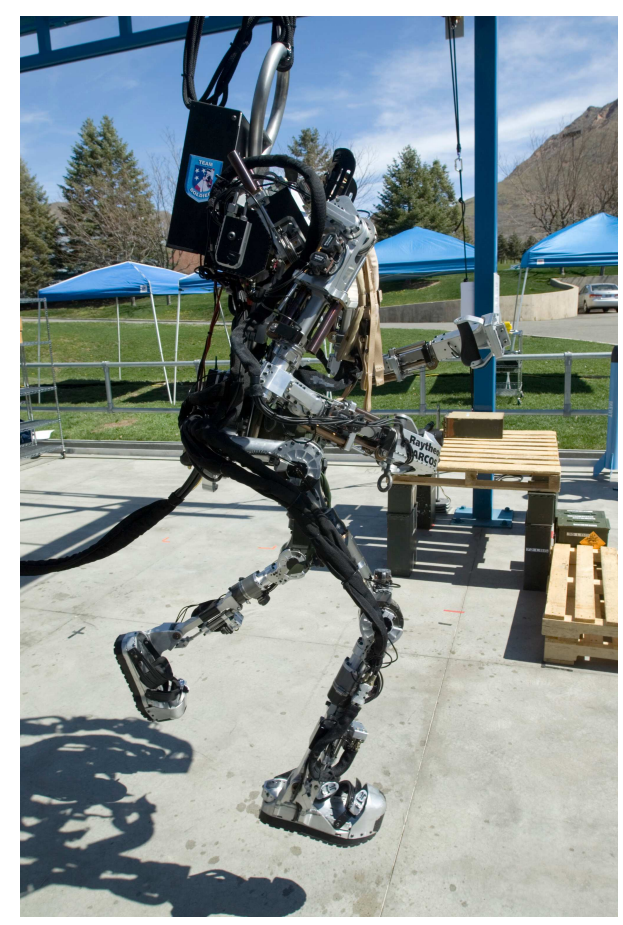

(a) Vista lateral

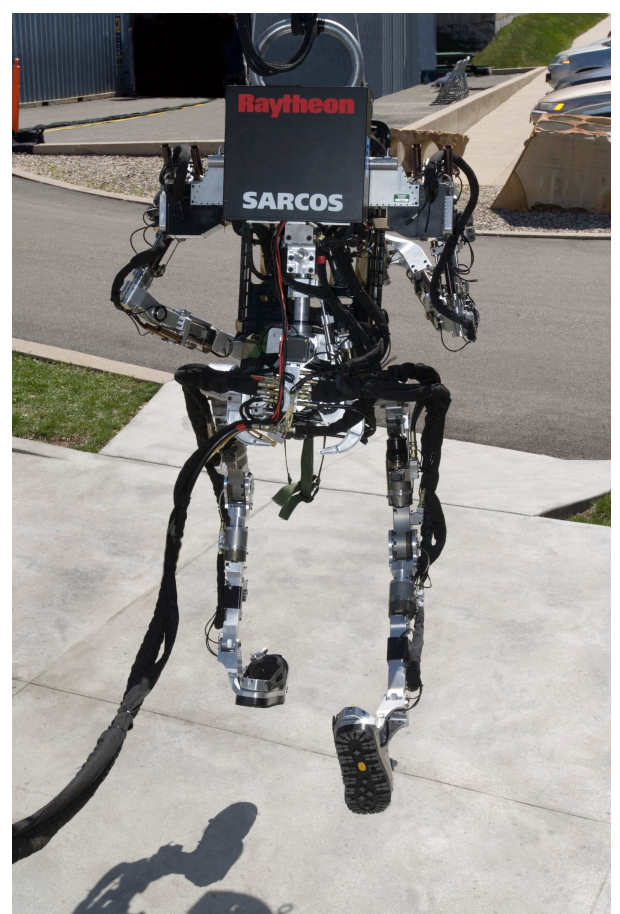

(b) Vista Traseira

Figura 1.2: Sarcos - Raytheon

Uma empresa israelense chamada Argo Medical Technologies, especializada em tecnologia aplicada em medicina, desenvolveu um exoesqueleto que ajudará na locomoção de paraplégicos, auxiliando-os a caminhar, subir escadas, sentar, descer terrenos íngremes e até mesmo dirigir. O dispositivo leva o nome de ReWalk, Figura 1.3 e foi desenvolvido pelo Dr. Amit Goffer, diretor da Argo. Foram investidos neste projeto US\$ 30 milhões. O exoesqueleto traz um leve 


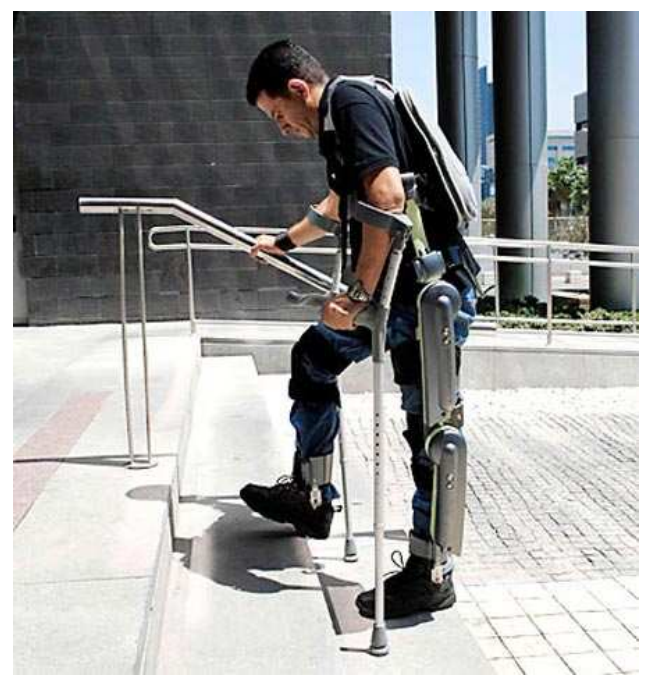

Figura 1.3: ReWalk

suporte para os braços, integrado a uma armadura que conta com motores de corrente contínua, baterias recarregáveis, uma série de sensores e um sistema de controle que se comunica com um computador. O exoesqueleto ReWalk detecta os movimentos da parte superior do corpo e, a partir daí, o processo de caminhada é iniciado. Para auxiliar na estabilidade e segurança do procedimento, o paciente faz uso de muletas, sendo que o exoesqueleto pode ser usado durante o dia inteiro, além de substituir outros aparelhos dentro de casa ou no centro de reabilitação.

Pensando somente na reabilitação de pacientes com deficiências na sua mobilidade, foram desenvolvidos dispositivos denominados órteses, para dar sustentabilidade ao corpo do usuário. Alguns permitem somente que este permaneça em pé sem precisar do auxílio de cadeira de rodas. O termo órtese refere-se aos aparelhos ou dispositivos ortopédicos de uso externo, destinados a alinhar, prevenir ou corrigir deformidades ou melhorar a função das partes móveis do corpo. Exemplos de uma órtese do tipo Reciprocating Gait Orthosis, RGO, são mostradas nas Figuras 1.4(a) e $1.4(\mathrm{~b})$.

Algumas pesquisas sobre órteses propõem a utilização de estimulação elétrica funcional dos músculos do paciente para reduzir os esforços necessários para o caminhar (JASPERS et al. , 1996; PÉREZ-ORIVE E MAYAGOITIA , 1994; TO et al. , 2005). Em TO et al. (2005), é descrito um sistema de controle que coordena o travamento das juntas do joelho e do calcanhar de uma órtese, enquanto a estimulação neuromuscular funcional é utilizada para controlar as juntas desbloqueadas. Apenas resultados simulados são apresentados. As órteses híbridas possuem algumas desvantagens em comparação com órteses mecânicas simples: a colocação e retirada dos eletrodos leva tempo e o custo é alto, o usuário precisa apertar um botão toda vez que 


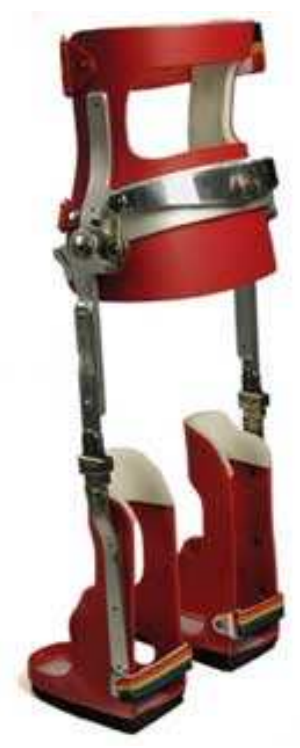

(a) Órtese $R G O$.

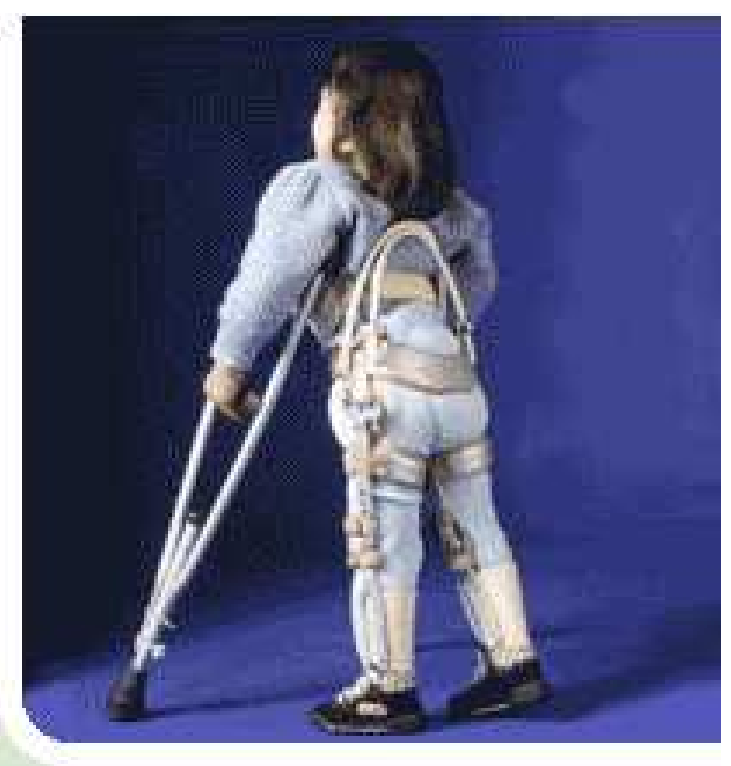

(b) Usuário vestindo uma $R G O$

Figura 1.4: Reciprocating Gait Orthosis

quiser realizar um passo a frente, (JASPERS et al. , 1996) e a rápida redução da força dos músculos devido à fadiga destes (TO et al. , 2005).

Poucos artigos descrevem a utilização de atuadores elétricos ou hidráulicos para acionar as articulações de órteses (JASPERS et al. , 1995; OHTA et al. , 2003). Em JASPERS et al. (1995), um mecanismo ativo foi projetado para promover a flexão da junta do joelho durante a fase de balanço. O mecanismo é eletricamente controlado e consiste de um pequeno motor DC com redutor, um came e um seguidor, sendo acionado em sincronia com a estimulação neuromuscular no início do passo. A introdução de atuadores elétricos na articulação do quadril e no joelho, foram realizadas em OHTA et al. (2003), no qual um atuador linear foi desenvolvido combinando um motor DC e uma engrenagem cremalheira e pinhão, e que aciona o mecanismo de reciprocação de uma órtese $R G O$. O dispositivo é acionado por baterias recarregáveis $N I-H$, pesando apenas $1,4 \mathrm{~kg}$.

Em JASPERS et al. (1996), um sistema de detecção da intenção do caminhar de um usuário utilizando uma órtese híbrida, composição de uma órtese com um sistema de estimulação neuromuscular, é proposto com informações apenas dos sensores de pressão montados sobre os pés. É utilizada uma máquina de estado finita que reflete os carregamentos dos membros durante um passo. 
A utilização da robótica na reabilitação de pacientes com disfunção de mobilidade está se tornando cada vez mais comum, principalmente devido à importância dos exercícios de reabilitação funcional (FERRIS et al. , 2005). Estes estimulam a parte remanescente intacta do sistema nervoso central a reconhecer e a reaprender funções perdidas (plasticidade neural).

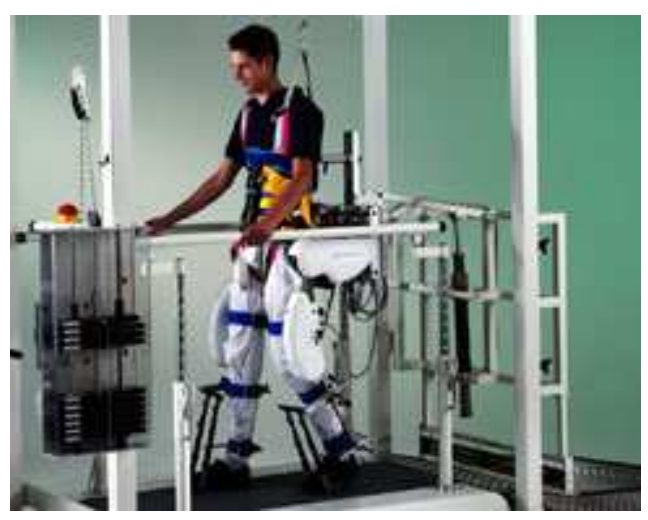

Figura 1.5: Lokomat.

Em JEZERNIK et al. (2003), uma órtese robótica, denominada Lokomat, é utilizada na reabilitação de pacientes com lesão medular e que sofreram acidente vascular cerebral (AVC), Figura 1.5. O dispositivo é instalado em uma esteira rolante e o paciente se locomove sobre a esteira utilizando um compensador de peso. O treinamento regular de pacientes é realizado impondo um padrão de marcha fixo através de um controle de posição das articulações da órtese robótica. Porém, é importante garantir que o paciente esteja efetivamente andando, e não apenas tendo a sua perna movida passivamente pelo aparelho de locomoção. Esta idéia levou ao desenvolvimento de algoritmos de adaptação do padrão de marcha (JEZERNIK et al. , 2004; RIENER et al. , 2005). Estes algoritmos possibilitam ao paciente ter a capacidade de alterar o padrão de marcha conforme o seu grau de locomoção voluntária. Na área de reabilitação, assistida pela robótica, usualmente três algoritmos de adaptação do padrão de marcha são utilizados. O primeiro deles produz uma adaptação do padrão de marcha estimando primeiramente os torques de interação homem-robô e então adaptando as trajetórias angulares de modo a reduzir tais torques de interação. O segundo algoritmo relaciona o torque de interação homem-robô com a mudança necessária de aceleração das trajetórias angulares. No terceiro algoritmo, o controle de impedância gera uma relação entre os torques de interação e os desvios de posição permitidos. Este procedimento permite adaptação direta das trajetórias angulares através do desvio de posição medido ou dos torques de interação estimados. 
Um outro exoesqueleto utilizado para aumento de força e resistência do usuário é proposto em PRATT et al. (2004). Denominado RoboKnee, ele atua na junta do joelho, determinando a intenção do usuário através das forças de reação do solo e da posição da junta do joelho e aplicando forças quando necessário, Figuras 1.6(a) e 1.6(b). Para garantir baixa impedância ao usuário e aplicação de força apropriada, atuadores elásticos em série são utilizados para o acionamento do dispositivo. Tais atuadores foram desenvolvidos primeiramente para o controle dos robôs bípedes Flamingo (PRATT et al. , 1997) e M2 (PALUSKA , 2000), e estão sendo utilizados também no desenvolvimento do exoesqueleto descrito em WALSH et al. (2006). Basicamente, um atuador elástico em série é composto de um motor elétrico ou hidráulico ligado em série ao efetuador através de molas, (ROBINSON et al. , 1999; PRATT E WILLIAMSON , 1995). Com um controle de força apropriado, é possível alterar a impedância do atuador de acordo com a necessidade do usuário. Os atuadores elásticos são vendidos comercialmente pela Yobotics (www.yobotics.com), no valor de US\$ 8000,00.

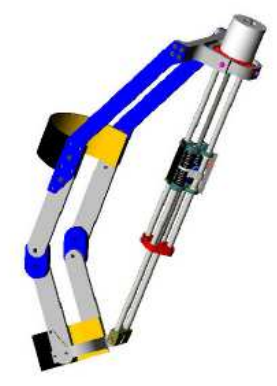

(a) RoboKnee

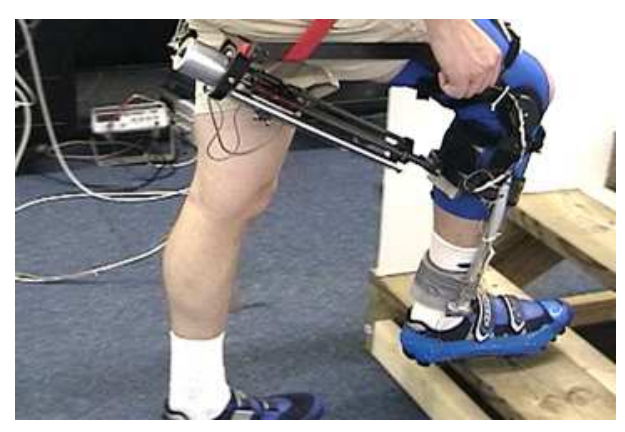

(b) Usuário vestindo o RoboKnee

Figura 1.6: Órtese Para sustentação do joelho

Em MORENO et al. (2006) e MORENO et al. (2007) são apresentados a concepção e implementação de sensores inerciais (IMU) do inglês, (Inertial Measurement Unit), aplicados em órteses e próteses para membros inferiores. A Figura 1.7(a) mostra a órtese, desenho em CAD, em conjunto com o sensor e a Figura 1.7(b), um usuário vestindo-a.

O sensor é composto por dois acelerômetros e um giroscópio, micro usinados. O giroscópio funciona devido a força de Coriolis, medida relativa a variação de momento angular, através de sensores capacitivos. O dispositivo é calibrado pelas medidas de encoders durante o treinamento até obter valores com precisão desejada. O mecanismo é semipassivo, sendo que no acionamento das juntas são utilizados dispositivos que funcionam com molas e amortecedores. 


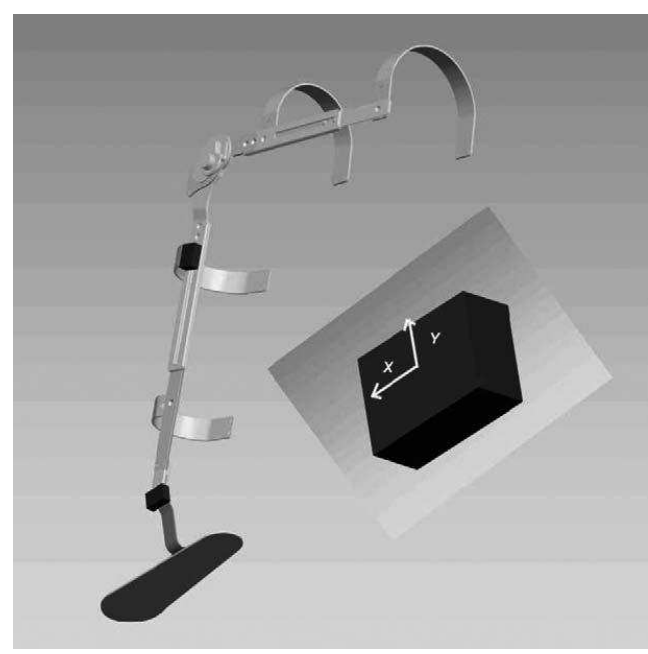

(a) Sensores IMU Aplicados à uma Órtese Para Membros Inferiores

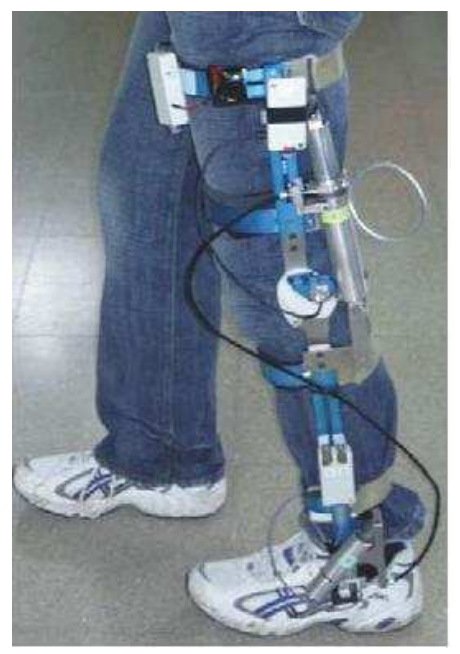

(b) Usuário vestindo a Órtese

Figura 1.7: Órtese em Conjunto com Sensores IMU - Universidad Politécnica de Madrid

O mecanismo de acionamento do joelho possui um elemento elástico de constante $K_{2}$, ativado quando ocorre o contato do calcanhar com o solo, e outro de constante $K_{1}$, ativado quando a fase de suporte termina. A alternância entre os dois elementos elásticos é feita através de um solenóide linear. O funcionamento do dispositivo de acionamento da junta do tornozelo é baseado em 2 molas de constantes diferentes, uma para cada etapa da marcha: $K_{3}$ armazena energia e controla a dorsiflexão, movimento de levantar o pé, enquanto $K_{4}$ possui a rigidez necessária para a flexão plantar, movimento de abaixar o pé, e evita que o pé arraste no solo durante a fase de balanço. Neste caso não há a utilização qualquer dispositivo ativo.

Os autores de MORENO et al. $(2006,2007)$ concluem que os dados fornecidos pelos sensores são suficientes para proporcionar o controle de impedância das juntas da órtese, para as fases de balanço e de suporte do caminhar.

O grupo de pesquisa do Laboratório de Bioengenharia da Universidade Federal de Minas Gerais (UFMG) desenvolveu uma órtese para auxiliar e prover sustentação à marcha de pacientes com deficiência motora nos membros inferiores. O dispositivo, Figura 1.8, é atuado no quadril através de um músculo artificial pneumático. O mecanismo é controlado pelo usuário e medidas da posição angular do quadril permitem que a movimentação seja voluntária, (PINOTTI et al. , 2008). Foi realizado um teste com um paciente, vítima de poliomelite, no qual resultados satisfatórios para a melhoria do ciclo da marcha do paciente foram obtidos com uma configuração adequada da órtese e utilização de barras paralelas. 


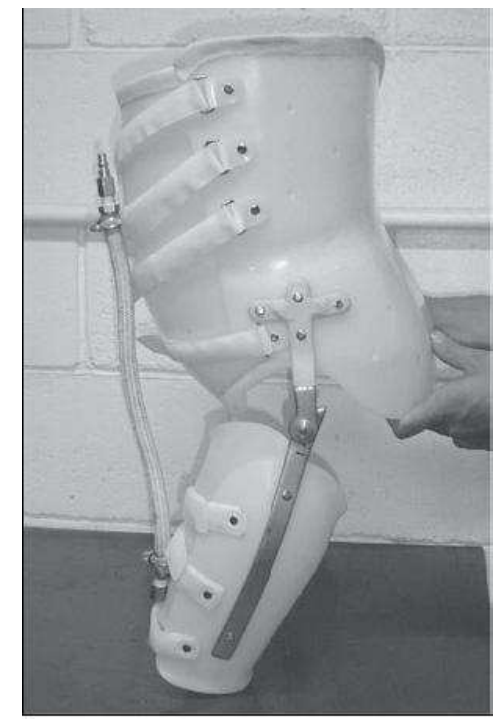

Figura 1.8: Órtese atuada por Músculos Artificias Pneumáticos - Laboratório de Bioengenharia - UFMG

O Grupo de Biomecatrônica do MIT (MIT-Harvard Division of Health Sciences and Technology), liderado pelo pesquisador Hugh Herr, também vem desenvolvendo projetos que contribuem significativamente para a reabilitação de pacientes com lesões medulares e amputações de membros inferiores. De acordo com DOLLAR E HERR (2008), 4.7 milhões de pessoas, nos EUA, poderiam ser beneficiadas com uma órtese ativa para membros inferiores.

Uma primeira versão de Órtese Tornozelo-Pé Ativa, OTPA, foi desenvolvida em JAUKOVIC (1981), o dispositivo consistia de um motor DC acoplado à órtese para prover a extensão/flexão da junta. Baseado nessa idéia, em BLAYA E HERR (2004) foi desenvolvida uma órtese para auxiliar pacientes com a patologia denominada pé-caído, resultado de trauma grave, esclerose ou paralisia cerebral. A órtese é montada a partir de uma AFO (ankle foot orthosis), na qual é adicionado um atuador elástico em série, permitindo o controle de impedância. Com este dispositivo, Figura 1.9, é possível variar a impedância da junta durante a fase de flexão plantar e permitir baixas impedâncias durante a fase de balanço.

Ensaios clínicos mostraram que esta órtese pode melhorar o caminhar de pacientes com tal patologia, pé caído, aumentando a velocidade do caminhar, fazendo com que os pacientes parem de arrastar os pés e permitindo aos mesmos mais segurança durante a fase de suporte. $\mathrm{O}$ dispositivo é relativamente compacto e de baixa potência elétrica.

Em ENDO et al. (2007) foi desenvolvido um exoesqueleto para membros inferiores, quasepassivo. O dispositivo não tem atuadores, apenas molas no tornozelo e quadril e um mecanismo 


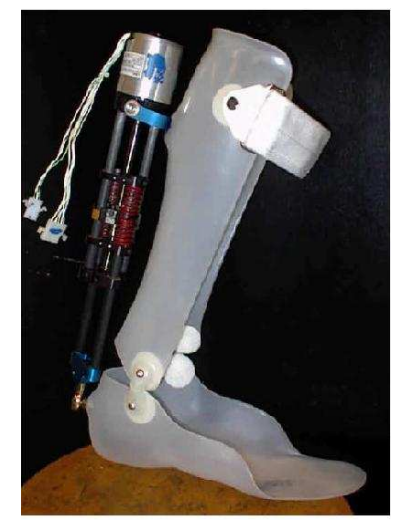

Figura 1.9: Órtese Tornozelo-pé Ativa - MIT

de amortecimento variável no joelho. A Figura 1.10, mostra o protótipo do mecanismo e sua implementação. O exoesqueleto foi projetado para transferir o peso da mochila diretamente para o solo e permitir a movimentação normal da perna. Os dados provenientes dos sensores são processados em um PC104 e a corrente é enviada ao módulo de amplificadores para prover potência ao joelho.
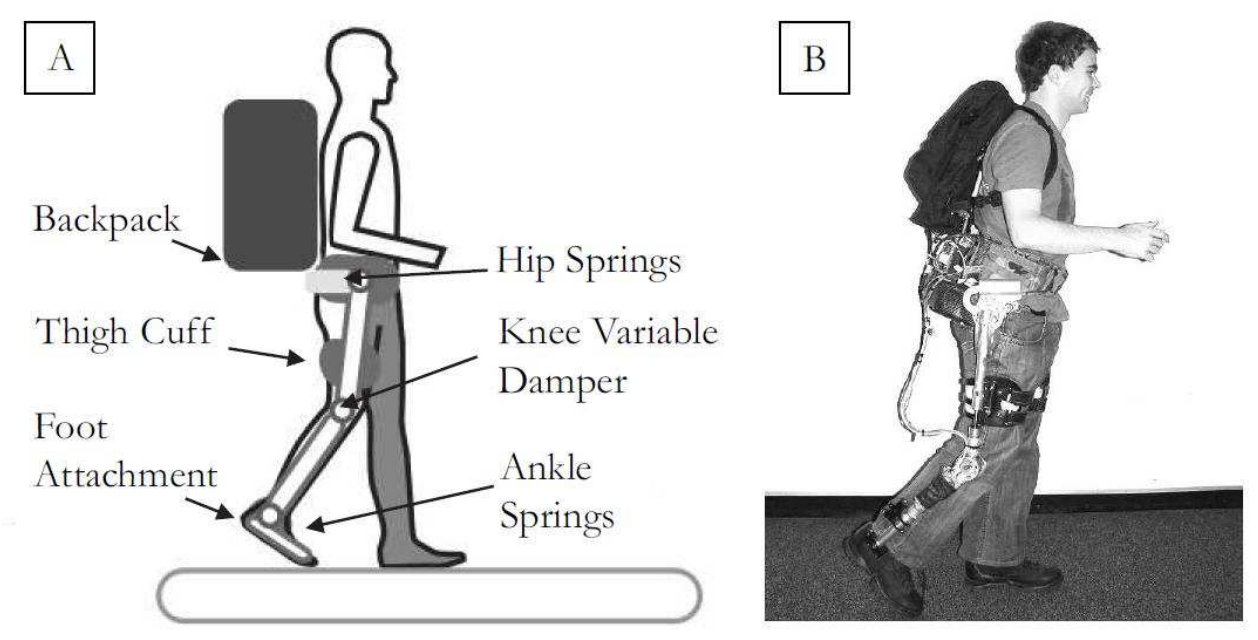

Figura 1.10: Exoesqueleto quase-passivo para membros inferiores - MIT

Para pessoas com deficiências, com parte dos membros inferiores amputados, o grupo desenvolveu próteses para o tornozelo (SAMUEL E HERR , 2006). Na Figura 1.11 é mostrada uma prótese para amputação abaixo do joelho, ela apresenta controle de impedância, possibilitando ao usuário a propulsão necessária, fornecida pela potência gerada na junta do tornozelo em uma das etapas da marcha. O controle de impedância é realizado por um atuador elástico em série.

O grupo de pesquisa está trabalhando no desenvolvimento de uma prótese mais compacta 


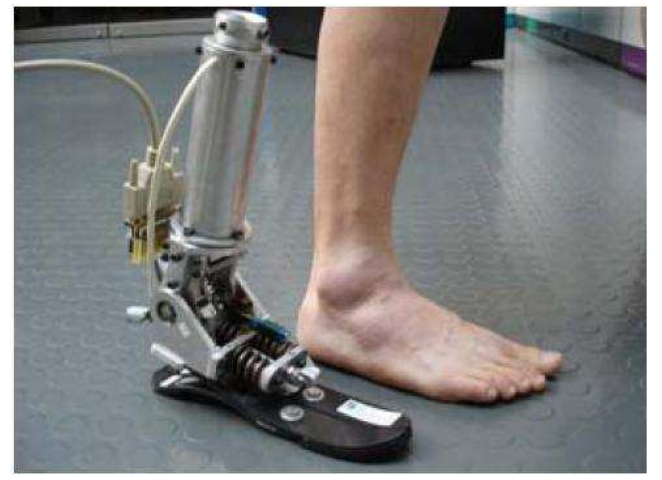

Figura 1.11: Prótese para tornozelo - MIT

e mais confortável para o usuário, denominada MIT Powered Ankle-Foot Prosthesis, Figura 1.12(a). Esta prótese produz potência e trabalho necessários para o caminhar. Sua arquitetura é definida por uma mola unidirecional, configurada em paralelo com um atuador elástico, que pode ter controle de força e impedância. O mecanismo tem o mesmo peso e tamanho de um tornozelopé humano e pode prover mais torque e potência do que o biológico. Esta prótese foi projetada para realizar um caminhar antropomórfico proporcionando mais conforto e estabilidade aos usuários, Figura 1.12(b). Para avaliar estas características, foram medidas as taxas de consumo de oxigênio durante a caminhada de um usuário. Os resultados divulgados mostram que com esta prótese o usuário teve uma economia de $7 \%$ a $20 \%$ comparada com outras próteses convencionais.

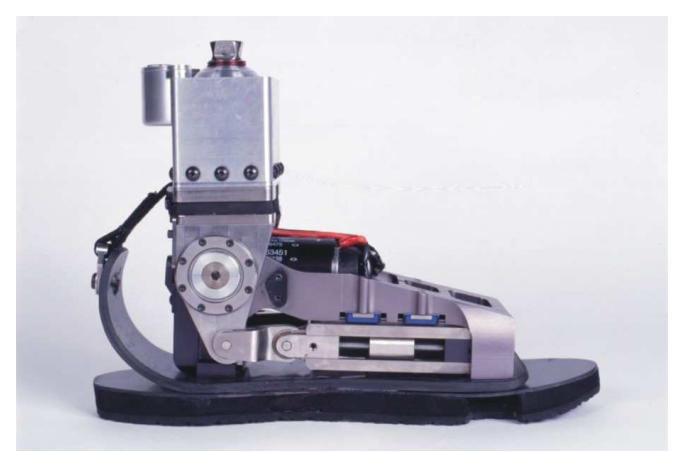

(a) Prótese

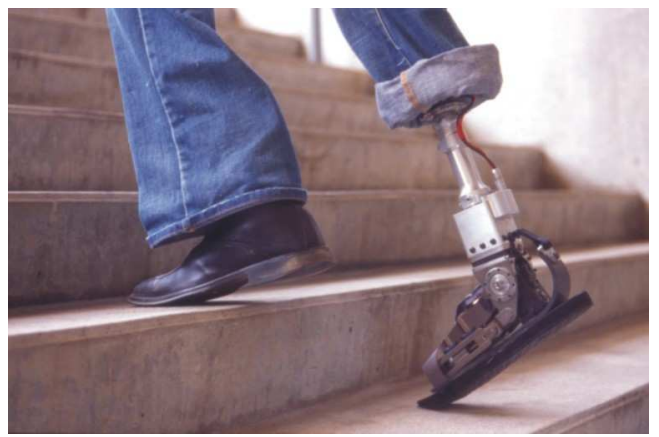

(b) Usuário Utilizando a Prótese

Figura 1.12: MIT - Prótese Tornozelo-Pé Ativa

Neste trabalho, são apresentados o projeto e a construção de um atuador elástico em série para o acionamento das juntas de um exoesqueleto para membros inferiores, baseado em uma órtese comercial. Também foi construída uma órtese tornozelo-pé ativa acionada pelo atuador elástico em série, sendo os resultados experimentais de controle de força, impedância e posição obtidos com sucesso. 


\subsection{Descrição do trabalho}

Esta dissertação de mestrado está dividida em duas partes: projeto e construção do Atuador Elástico em Série (SEA), e projeto e construção de uma OTPA.

A primeira parte mostra o desenvolvimento de um primeiro protótipo do atuador elástico em série para o acionamento das juntas de um exoesqueleto para membros inferiores. São apresentados o projeto do atuador, a descrição da montagem, a modelagem matemática, os controladores implementados, a descrição do driver de potência utilizado e os resultados experimentais obtidos com o dispositivo, referentes aos controladores implementados: controle de posição, controle de força e controle de impedância.

Na segunda parte são apresentados o desenho do exoesqueleto já com os atuadores posicionados em cada junta, e os mecanismos de acionamento das mesmas. Também são descritos os mecanismos de acionamento da junta do tornozelo, o sensor utilizado para obter o instante em que o pé toca o solo, a modelagem cinemática do mecanismo, análise clínica da junta do tornozelo e por fim são apresentados os resultados experimentais, referentes aos controladores implementados no protótipo da OTPA.

\subsection{Disposição dos capítulos}

No Capítulo 2 é descrita a modelagem do Atuador Elástico em Série bem como a análise dos parâmetros que a compõem.

No Capítulo 3 é abordado o projeto dos métodos de controle de força e de impedância do mecanismo.

No Capítulo 4 é apresentado o projeto da Órtese Tornozelo - Pé Ativa (OTPA).

No Capítulo 5 os controladores propostos são implementados no atuador e na órtese.

No Capítulo 6 são apresentadas as conclusões. 


\section{Capítulo 2}

\section{Atuadores Elásticos em Série}

Atuador é um elemento que produz movimento, atendendo a comandos que podem ser manuais ou automáticos. Como exemplo, pode-se citar atuadores de movimento induzidos por cilindros pneumáticos ou hidráulicos e motores elétricos.

A interface entre um atuador e a carga é tradicionalmente projetada para ser a mais rígida possível, (PRATT E WILLIAMSON , 1995). Aumentando a rigidez, pode-se melhorar a precisão, a estabilidade e a largura de banda do controle de posição. No entanto, esse tipo de interface apresenta alguns problemas: atrito, folgas, oscilações do torque e ruídos.

De acordo com PRATT E PRATT (1998), para diversas aplicações como robôs bípedes ou braços robóticos, com interface homem-máquina, é necessário ter uma interface com impedância controlável. Neste caso, contatos inesperados e distúrbios externos não causam danos ao dispositivo nem ao ambiente no qual ele se encontra.

Atualmente, tecnologias para controle de força apresentam formas típicas que utilizam controle de corrente: atuação direta, por meio de engrenagens ou por meio de correia de transmissão.

$\mathrm{Na}$ atuação direta, um servomotor é ligado diretamente à carga, de forma que o torque de saída é proporcional a corrente elétrica no motor. A medida da corrente é realimentada no sistema de controle de força. Entretanto, os servomotores são ineficientes quando operados em velocidades baixas e torques elevados, sendo necessário aumentar sua potência, e consequentemente, aumentar seu tamanho e peso, tornando inviável sua aplicação em robôs. Este tipo de atuador é muito limitado e, em robótica, pode somente ser utilizado nas bases não móveis do robô.

Uma possível solução para esse problema é diminuir o tamanho e peso dos motores. Para 
manter baixas velocidades e elevados torques, introduz-se um sistema de redução no atuador. Um redutor, desprezadas as perdas na transmissão, é capaz de prover à carga, um torque tantas vezes maior que o do motor quanto for a relação de redução. Porém, a redução por engrenagens traz alguns inconvenientes como atrito, folgas (backlash) e aumento da inércia. Uma vez que o fator de redução é muito grande, a impedância aumenta e o controle de força torna-se impreciso. Substituindo as engrenagens por correia, as folgas e o atrito são reduzidos consideravelmente.

Ainda para o caso de um atuador com redutor por engrenagens, pode-se minimizar o atrito e os efeitos de inércia via controlador, através da medida da força por uma célula de carga. Entretanto, uma célula de carga apresenta instabilidades. No caso de um movimento linear muito rápido, ela pode gerar um pulso de força muito elevado. Para manter a estabilidade do sistema é necessário manter os ganhos do controlador baixos. Com isso, o controle é muito lento, não respondendo a forças de pequenas amplitudes.

Para superar essas deficiências, alguns pesquisadores desenvolveram um experimento no qual controlavam, com o sistema em malha fechada de força, um motor elétrico com redução em série com um sistema de molas, (ROBINSON et al. , 1999; PRATT E WILLIAMSON , 1995). Os autores de PRATT E WILLIAMSON (1995) denominaram esta configuração como Atuador Elástico em Série, denominado neste trabalho por AES.

A ideia mais básica desse tipo de atuador é colocar uma mola entre a transmissão e a carga, ou seja, em série entre o motor e a carga. A mola tem duas funções importantes, filtrar impactos, distúrbios externos, folgas e atrito e também determinar a força aplicada à carga pelo efetuador. Este tipo de atuador foi implementado nos robôs mostrados nas Figuras 2.1(a), 2.1(b) e 2.1(c).

O robô COG, mostrado na Figura 2.1(a) utiliza o AES para movimentar as juntas do seu braço, que possui 6 graus de liberdade. O robô Spring Flamingo, Figura 2.1(b), é bípede e planar, utilizando o AES para atuar no joelho, quadril e tornozelo, totalizando 6 graus de liberdade (3 para cada perna). Em terreno plano ele pode caminhar numa velocidade de $1,25 \mathrm{~m} / \mathrm{s}$. Na Figura 2.1(c) é mostrado o robô tridimensional M2; ele possui 12 graus de liberdade (3 para cada quadril, um para cada joelho e 2 para cada tornozelo).

A segurança na interação dos atuadores com o ambiente ou com usuários depende diretamente de baixa impedância, (SENSINGER E WEIR , 2006). Em SENSINGER E WEIR (2006) foram investigados diferentes métodos para melhorar o controle de impedância dos atuadores elásticos: tipos de motores eletromagnéticos, redução da inércia do sistema, modulação passiva da impedância, variação da rigidez da série elástica e controle do torque. 


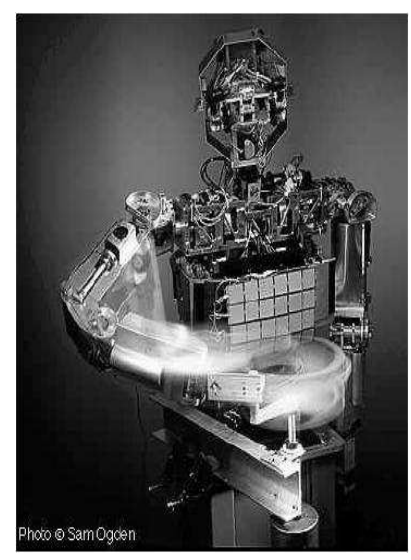

(a) COG

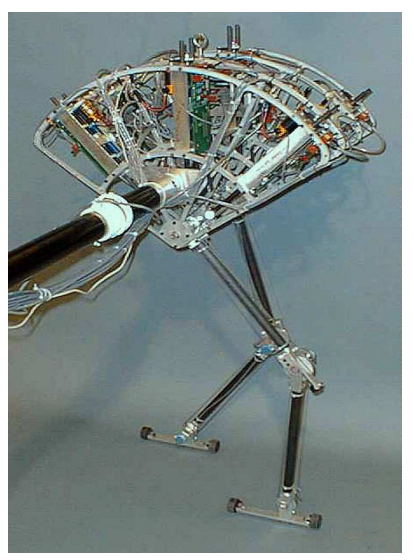

(b) Spring Flamingo

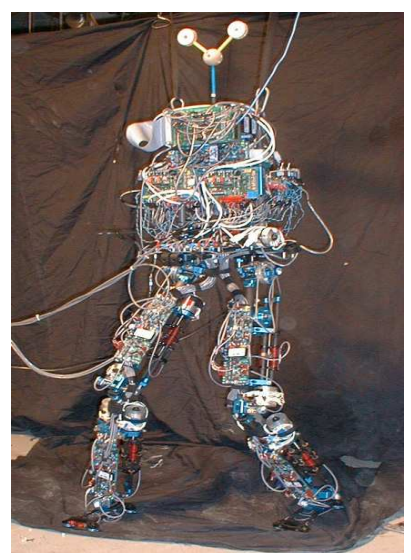

(c) M2

Figura 2.1: Robôs que utilizam o AES para movimentar suas juntas - MIT Leg Laboratory

Os resultados experimentais obtidos são provenientes de dois tipos de sensores de força, combinados com dois tipos de controles internos: potenciômetro linear, célula de carga, controle de posição e controle de velocidade. Diminuindo a rigidez do sistema é possível aumentar os ganhos do controlador, tornando-o mais confiável e preciso. A inclusão do controle interno de posição em combinação com o sensor de força, célula de carga, faz com que o ganho do controlador e a largura de banda sejam aumentados e o controle de força responde com maior precisão.

\subsection{Princípio de funcionamento}

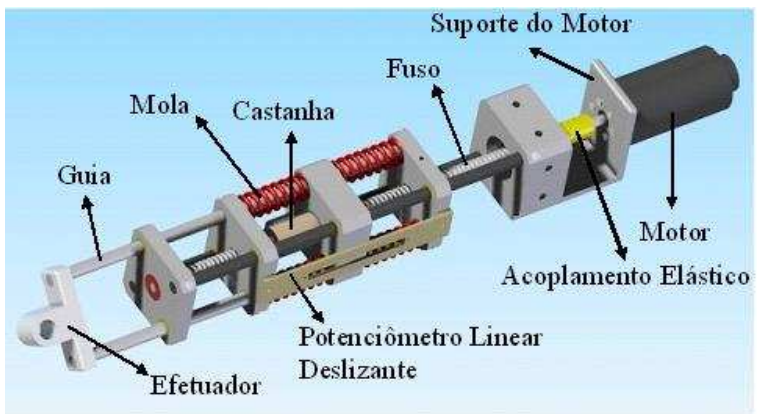

Figura 2.2: Atuador Elástico em Série

Para entender o funcionamento do AES, Figura 2.2, o dispositivo foi dividido em duas partes: Plataforma de Movimento e Base. A primeira parte (Plataforma de Movimento) é composta 


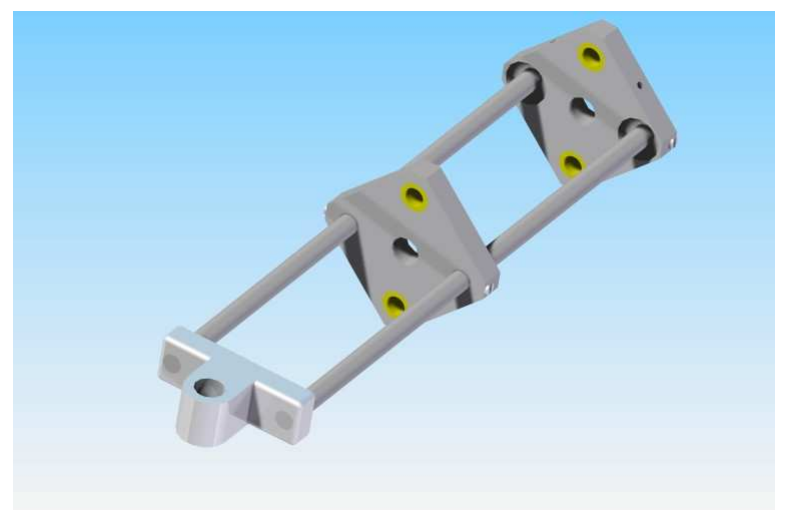

Figura 2.3: Plataforma de Movimento.

por duas peças de suporte, fixas a duas guias e a um efetuador, como mostrado na Figura (2.3). A Base, Figura (2.4), é composta por: motor, suporte para o mesmo, mancal, rolamentos, fuso, duas guias, e castanha de esferas recirculantes.

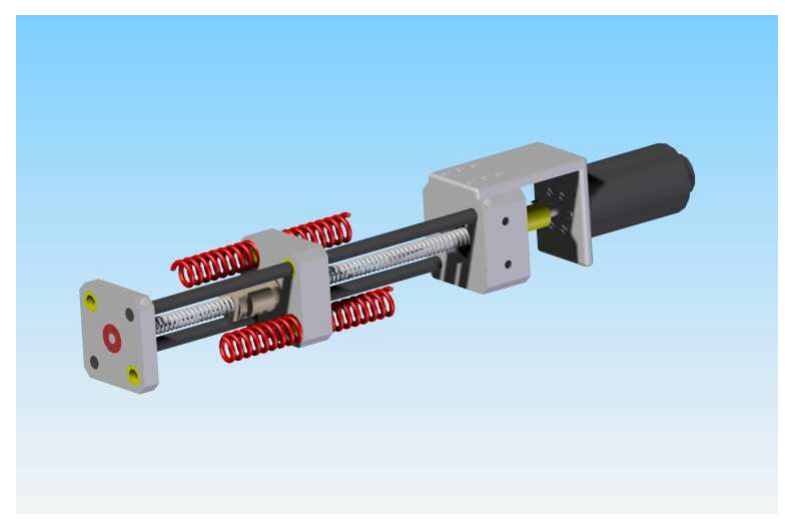

Figura 2.4: Base.

Um motor DC está fixo ao fuso através de acoplamento elástico. A castanha de esferas recirculantes converte o movimento rotacional do fuso em movimento linear. Quando o motor é acionado, a castanha move-se para frente ou para trás fazendo com que a peça de suporte a qual ela está fixa comprima um par de molas (série elástica). As molas pressionam uma das plataformas do Plataforma de Movimento e transmitem a força para o conjunto, que por sua vez movimenta a carga através do efetuador.

Este esquema de movimentação está representado na Figura 2.5. Nela pode-se notar que se uma força positiva é aplicada ao efetuador, o primeiro par de molas é comprimido. Quando se aplica uma força negativa, o segundo par de molas sofre deformação. Nos dois casos em que há 
presença de força no efetuador, quando este estiver destravado, haverá movimentação do mesmo.
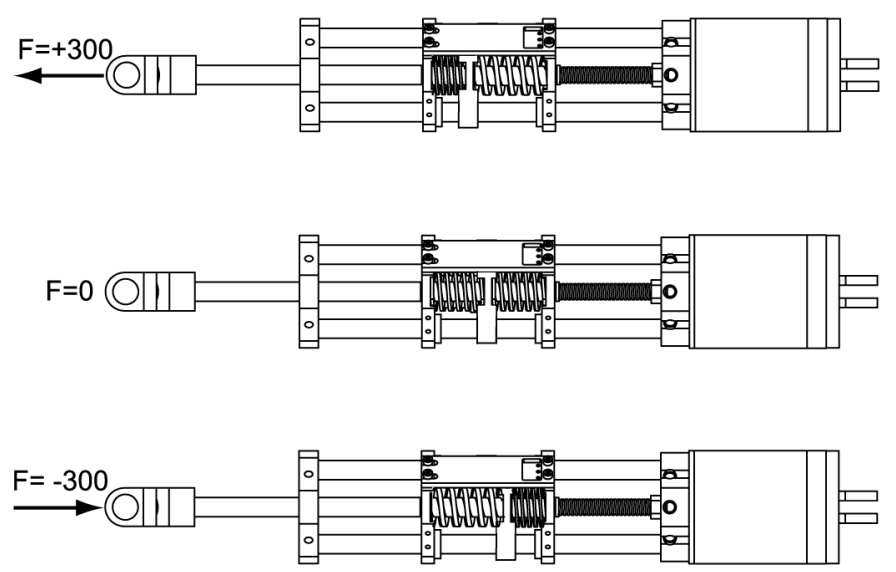

Figura 2.5: Funcionamento do Atuador Elástico em Série - MIT Leg Laboratory

\subsection{Modelagem do atuador}

O modelo usado para o AES consiste em um sistema massa - mola - amortecedor, com amortecimento $b_{m}$, constante elástica $k$ e força $F_{l}$ de saída, descrito por:

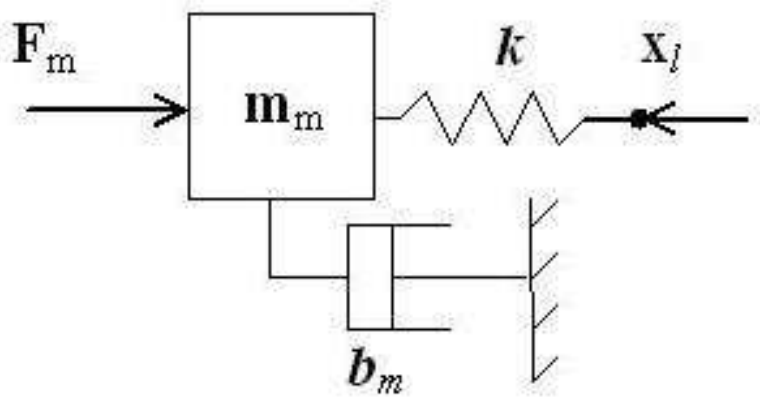

Figura 2.6: Modelo do Atuador Elástico em Série

$$
m_{m} \ddot{x}_{m}+b_{m} \dot{x}_{m}=F_{m}-F_{l},
$$

sendo a força de saída representada por:

$$
F_{l}=k\left(x_{m}-x_{l}\right),
$$


$x_{m}$ a posição linear do suporte da castanha, $x_{l}$ a posição relativa da carga, $m_{m}$ a massa do sistema de transmissão e $F_{m}$ a força gerada pelo motor. Aplicando-se a transformada de Laplace, amplamente utilizada para a análise de sistemas dinâmicos lineares, tem-se:

$$
m_{m} s^{2} X_{m}+b_{m} s X_{m}=F_{m}-F_{l}
$$

Portanto, a força $F_{l}$, que atua na carga, é função de duas variáveis: $F_{m}$ e $x_{l}$ :

$$
F_{l}(s)=\frac{F_{m}(s)-\left(m_{m} s^{2}+b_{m} s\right) x_{l}(s)}{\frac{m_{m}}{k} s^{2}+\frac{b_{m}}{k} s+1}
$$

\section{Análise de parâmetros}

Nesta Seção serão estudados os fatores que influenciam na largura de banda para o controle de força, o amortecimento do sistema e a determinação da série elástica. Para isso são tomadas como base as equações, em malha aberta, do sistema e colocadas em forma adimensional:

Sabendo que a frequência natural do sistema é:

$$
w_{n}=\sqrt{\frac{k_{s}}{m_{m}}}
$$

tem-se que:

$$
\begin{gathered}
S=\frac{s}{w_{n}} \\
B=\frac{b_{m}}{k_{s}} w_{n}
\end{gathered}
$$

A relação entre a força no motor e a força na carga pode ser descrita substituindo as Equações 2.7 e 2.6 na 2.4 , considerando o termo $x_{l}$ sendo zero (carga fixa):

$$
\frac{F_{l}(S)}{F_{m}(S)}=\frac{1}{S^{2}+B S+1}
$$

O coeficiente $b_{m}$, Equação 2.7, é estimado em função da força e velocidade máximas, reali- 
zadas pelo efetuador (PALUSKA E HERR , 2006), ou seja,

$$
b_{m}=\frac{F_{\max }}{V_{\max }} .
$$

Este coeficiente aparece nos casos em que é usado motor DC e pode ser interpretado como uma força contra-eletromotriz, que surge quando o motor está em rotação, é proporcional à velocidade do mesmo, como mostra a Equação 2.9. De acordo com WALSH et al. (2006), esta estimativa é considerada uma primeira aproximação para as limitações do motor elétrico DC ou de um músculo biológico.

Levando em consideração a força contra-eletromotriz, deve-se modificar o fator de amortecimento $B$, descrito na Equação 2.7, que passará a ser:

$$
B=\frac{b_{m}}{k_{s}}
$$

Sabendo que:

$$
W=\frac{w}{w_{n}}
$$

Pode-se escrever, a partir das Equações 2.10 e 2.11, a magnitude $F_{l} / F_{m}$ :

$$
M a g=\frac{F_{l}}{F_{m}}=\frac{1}{\sqrt{\left(1-W^{2}\right)^{2}+(B W)^{2}}}
$$

A Figura 2.7 mostra, para diferentes valores de $B$ a máxima força de saída que pode ser fornecida pelo atuador. Duas regiões importantes devem ser observadas: frequências em torno de $w_{n}$ e altas frequências. O amortecimento está diretamente relacionado com a forma como o atuador libera força à carga. No caso criticamente amortecido e sobre-amortecido, há um decréscimo acentuado na amplitude da força de saída em torno da frequência natural, em contrapartida, quando está trabalhando em condição sub-amortecida, o dispositivo pode operar em sobrecarga, visto que há aumento na amplitude da força de saída. Independentemente do amortecimento do sistema, elevadas amplitudes para a força em altas frequências não são possíveis por causa dos efeitos da mola sobre o motor. Este estudo mostra que, adicionando a série elástica ao atuador, há uma redução da largura de banda de operação para o controle de força e um aumento do esforço do controlador para altas frequências. 


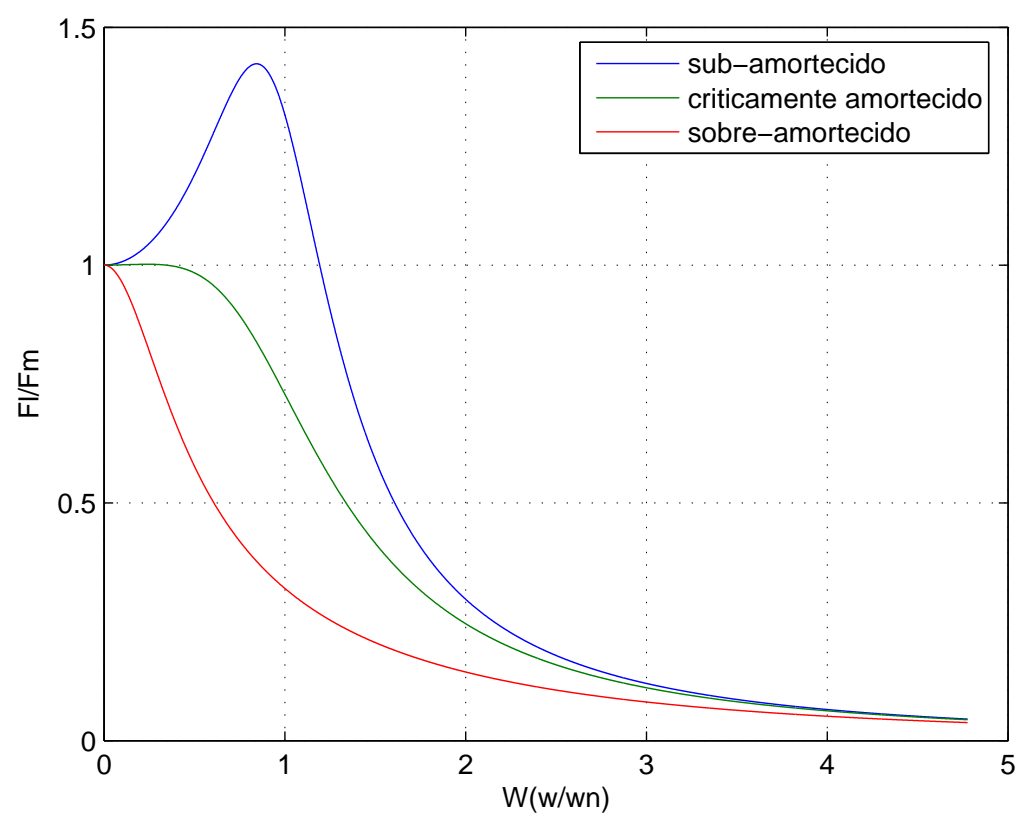

Figura 2.7: Comportamento em malha aberta para diferentes valores de B

\section{Serie elástica}

A escolha da constante elástica das molas, deve ser feita considerando-se o equilíbrio entre obter altos valores para a largura de banda de operação, necessitando de altos valores para o $k$, e manter baixos o atrito e a impedância, valores baixos de $k$, (ROBINSON et al. , 1999).

A constante elástica do conjunto série elástica é determinada considerando a associação de duas molas em paralelo, ou seja, $k_{e q}=k_{1}+k_{2}$. A partir do conhecimento da força, velocidade, e potência que o dispositivo irá operar, pode-se determinar o motor e a transmissão a serem utilizados. Esta escolha define a massa do motor, fatores de redução e amortecimento. A partir da largura de banda operacional do atuador, $\omega_{0}$, tem-se uma relação direta com a freqüência natural do sistema, de maneira que se pode estimar valores para $k$.

\subsection{Montagem}

O atuador elástico em série foi reproduzido tomando como base o dispositivo desenvolvido por PRATT E WILLIAMSON (1995). As peças que o compõem, Figuras 2.9 e 2.10, foram usinadas em alumínio, e a montagem foi feita no Laboratório de Mecatrônica - Departamento de Engenharia Mecânica. 


\subsubsection{Componentes}

O dispositivo, Figura 2.8, é composto por 6 peças de suporte, 1 efetuador, 1 motor DC de 150W, acoplamento elástico, fuso de esferas recirculantes com castanha, mancais e rolamentos para suporte do fuso. Dois parafusos foram adicionados ao projeto, parafusos de ajuste da série elástica, para dar suporte às molas quanto ao posicionamento de referência zero, discutido na Seção 5.2, os dois parafusos são posicionados paralelamente ao fuso e proporcionam uma compressão inicial às molas. Rolamentos lineares são usados para diminuir o atrito entre as guias e a Plataforma de Movimento. O potenciômetro é fixado através de um suporte feito em acrílico, que por sua vez é fixado nas peças de suporte. A massa total do AES é $2.110 \mathrm{~kg}$, o dispositivo montado é mostrado na Figura 2.11. Os componentes são listados na Tabela A.1.

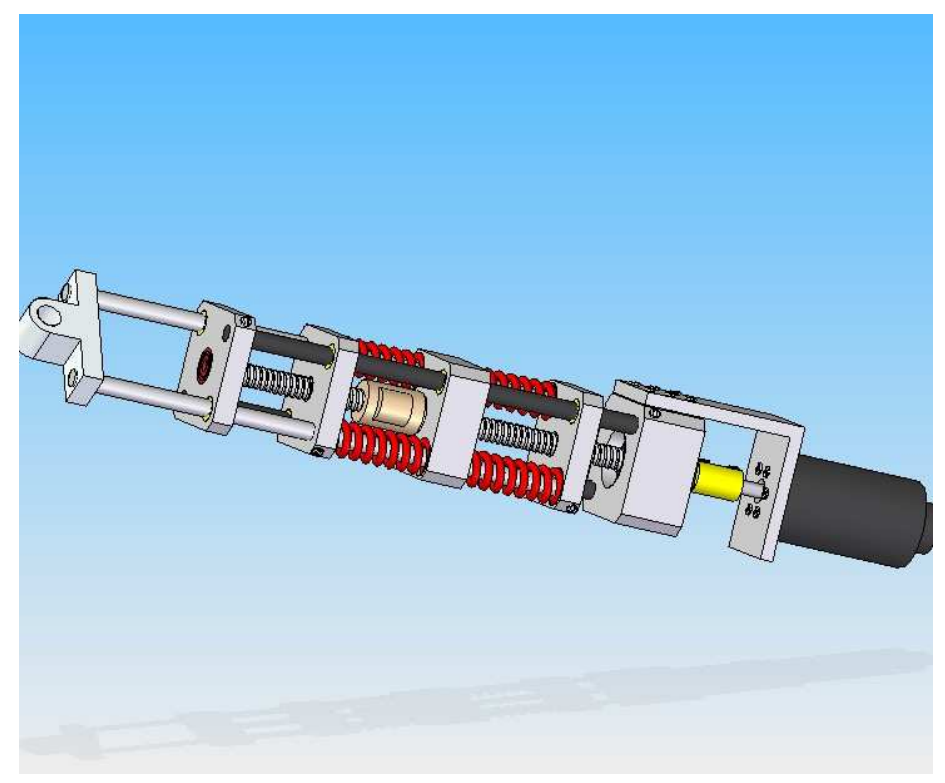

Figura 2.8: Atuador Elástico em Série

\subsubsection{Cálculo da constante elástica}

A constante elástica das molas foi verificada através de ensaios em uma prensa hidráulica, na qual as molas foram colocadas uma por vez. Uma força linear foi aplicada e para cada diferencial de força adicionado a medida da amplitude e deformação era realizada: $F$ e $\Delta x$. Os dados experimentais foram interpretados no software Matlab e a curva obtida é mostrada na Figura 2.12.

A curva experimental é representada por uma reta cuja equação é descrita por: 


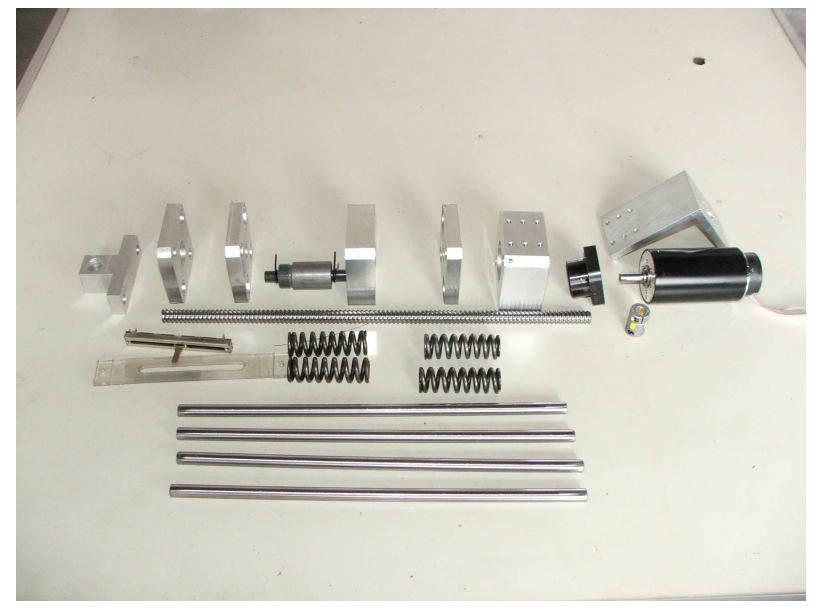

Figura 2.9: Peças - AES

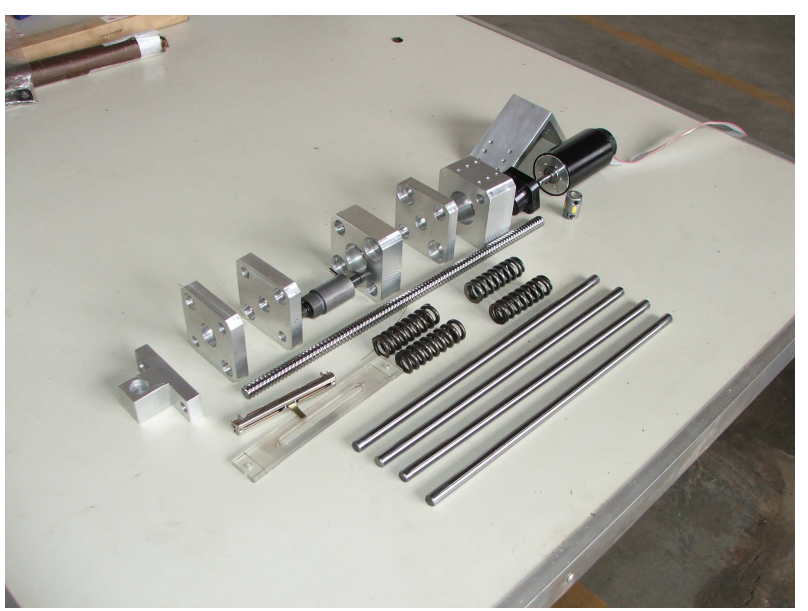

Figura 2.10: Peças - AES

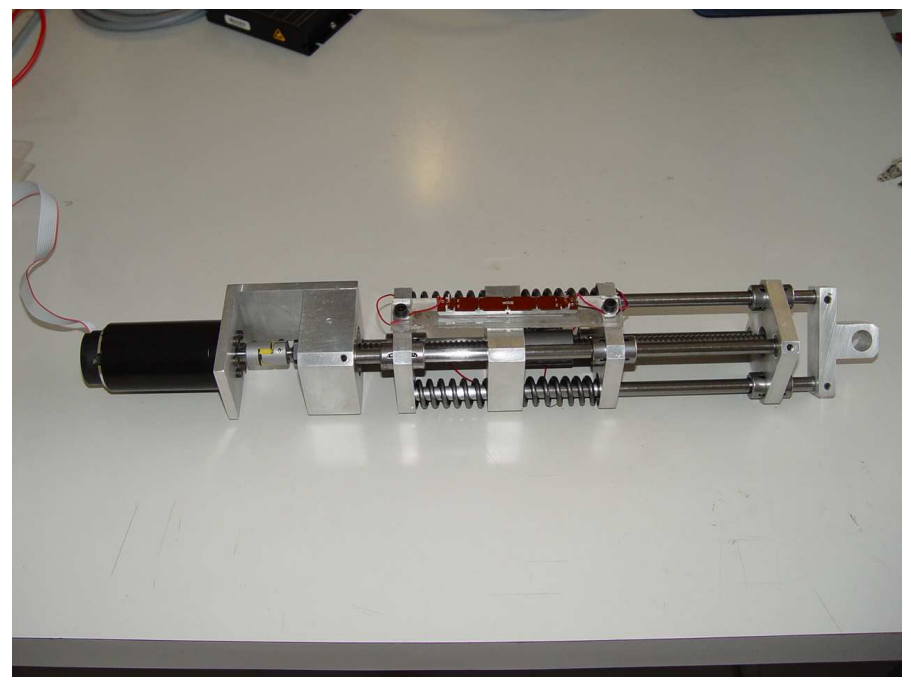

Figura 2.11: Atuador Elástico em Série - Configuração Final 


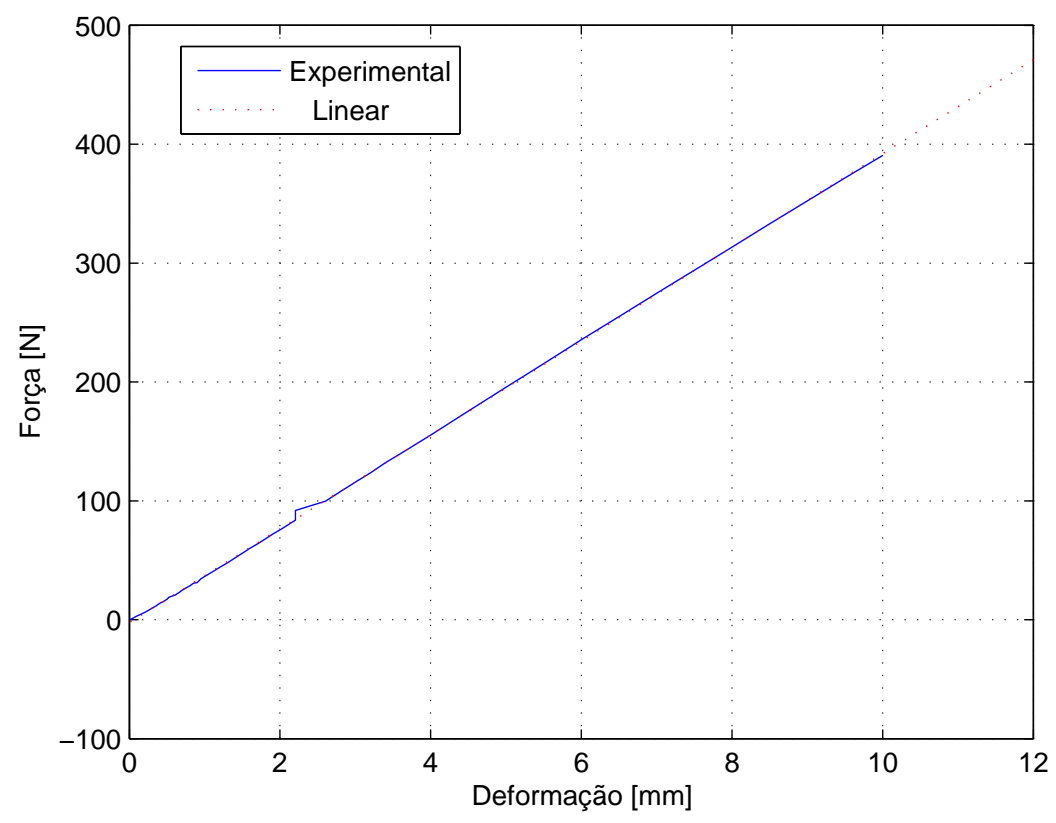

Figura 2.12: Curva Para Obter o Coeficiente Elástico das Molas

$$
F(x)=39.45 x-2.38
$$

Através dela, pode-se determinar a constante elástica das molas, utilizando a Lei de Hooke: $F=-k x$. Admitindo que a reta passa pela origem, ou seja, desprezando o segundo termo da equação, determina-se que a constante elástica das molas é $39.45 \mathrm{~N} / \mathrm{mm}$. Esta aproximação é admitida sabendo que o segundo termo da equação surge devido ao posicionamento das molas na prensa, de forma que mesmo sem estarem deformadas o aparelho media uma pequena força elástica, logo pode-se considerar como constante equivalente da série elástica a soma das constantes: $78.9 \mathrm{~N} / \mathrm{mm}$.

\subsubsection{Potenciômetro linear deslizante}

Neste projeto é utilizado um potenciômetro linear deslizante para realizar a medida da deformação da série elástica. Este dispositivo é alimentado com uma tensão $15 \mathrm{VDC}$ e, a medida que seu cursor se movimenta, é enviado um sinal analógico, proporcional à deformação das molas, para um circuito subtrator-amplificador que ajusta o mesmo para uma escala de tensão adequada para ser lida por uma das entradas analógicas do driver de potência, EPOS, detalhado na Seção 3.1. 
Este sinal é uma tensão DC de 0 a $5 \mathrm{~V}$ que informa a deformação das molas, uma vez que o potenciômetro está fixo às duas peças de suporte que compõem a Plataforma de Movimento e estas peças são fixas nas duas guias, a distância entre as mesmas não varia. O cursor do potenciômetro está fixo na peça de suporte da castanha, portanto, quando esta se movimenta, comprimindo as molas, o cursor movimenta-se junto, gerando uma tensão diretamente proporcional à deformação das molas. Através da lei de Hooke, $F=-k X$, a força aplicada à carga é calculada. Para obter a relação entre a tensão de saída do potenciômetro e a deformação das molas, foi feito um experimento para determinar a constante elástica das molas e da série elástica (molas em paralelo) e qual é o valor de tensão correspondente ao zero do potenciômetro, ou seja, molas sem deformação. Sabendo esses valores a deformação das molas é obtida de acordo com a Equação 2.14

$$
\Delta x=\frac{\Delta V}{m}
$$

sendo $\Delta V$ a diferença entre o valor zero do potenciômetro e a tensão correspondente à posição do cursor e $m$ é o coeficiente angular de uma reta cujos pontos foram obtidos experimentalmente do potenciômetro. Esta reta mostra a relação entre a tensão de saída do potenciômetro e a posição do cursor, ou seja, o cursor foi movimentado da posição zero(resistência zero) até a posição final (resistência máxima) e para cada milímetro movimentado foi medido a tensão de saída e a resistência correspondente. Após varrer todo comprimento do dispositivo e obter as tensões e resistências correspondentes, foi calculada a equação que relaciona essas variáveis e chegou-se a equação de uma reta, mostrando que o potenciômetro pode ser considerado como linear na região na qual ele opera, possibilitando o cálculo do coeficiente angular da reta obtida, Figura 2.13 .

Sabendo qual é a deformação das molas e a sua constante elástica, obtida na Seção 2.3.2, a força no efetuador é calculada.

A Figura 2.11 ressalta o funcionamento do potenciômetro, mostra de forma clara que suas extremidades estão fixas à duas plataformas pertencentes à Plataforma de Movimento, enquanto seu cursor está fixo à Plataforma de Suporte da castanha.

\subsection{Teste de potência e energia}

Estudos em biomecânica mostram que a elasticidade dos tendões permite aos músculos trabalharem dentro de uma escala ótima para as curvas de comprimento-força e velocidade-força 


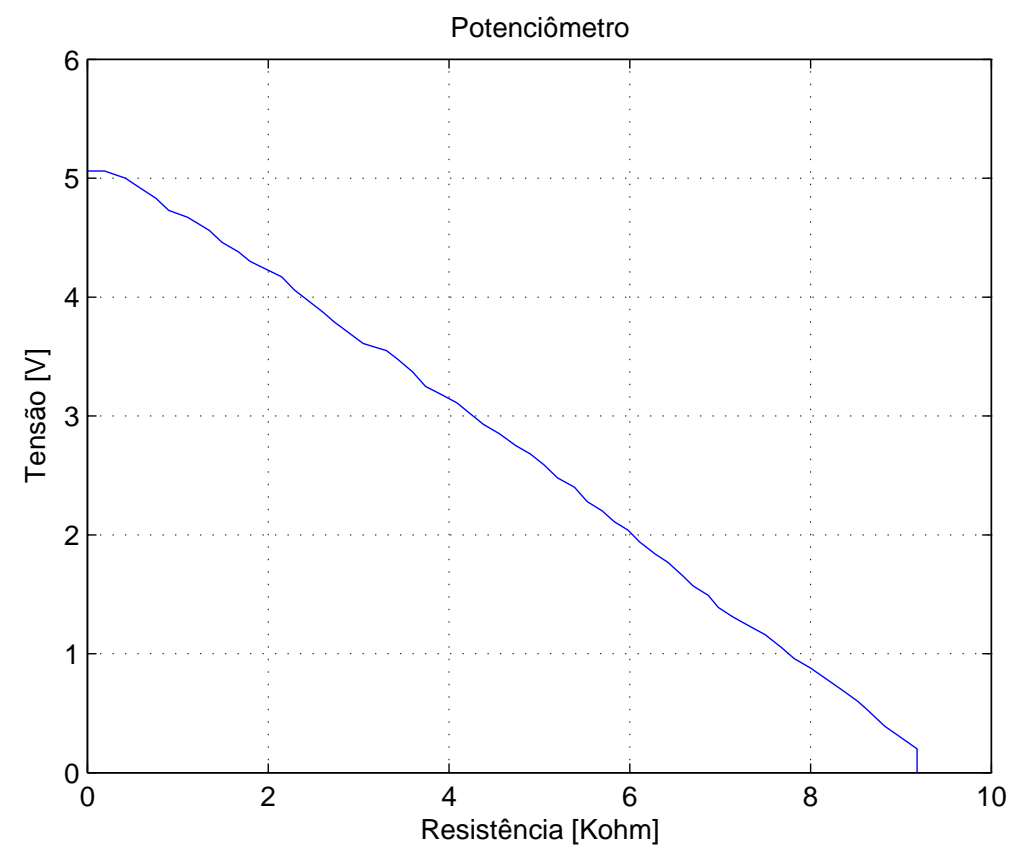

Figura 2.13: Curva experimental para obter a relação de linearidade do potenciômetro

com o objetivo de amplificar o trabalho e a potência de saída. Por meio deles pode-se transferir, atavés do princípio de alavanca, a força gerada nos músculos para as articulações.

Nesta seção são apresentados a capacidade da série elástica de amplificar o trabalho e a potência de saída do atuador. O experimento foi feito fixando-se o atuador em uma plataforma, sendo que o efetuador estava livre para movimentar uma outra plataforma, na qual pesos podiam ser adicionados, Figura 2.14. O experimento foi realizado com o driver habilitado no modo Position Mode, no qual é enviado a posição desejada para o efetuador, denominada $X_{\text {stroke }}$. Neste modo de operação, é enviado ao driver um degrau na posição, de forma que o motor vai efetuar esta tarefa com velocidae, aceleração e desaceleração máximas. Pode-se assim calcular a energia cinética, que foi transferida à plataforma, através da medida da velocidade do motor e da velocidade de compressão/descompressão das molas.

A energia liberada à carga é limitada pela potência, concluindo que a limitação na velocidade do atuador e a massa da carga definem o limite de potência de trabalho do atuador:

$$
\begin{gathered}
P=F v \\
E(t)=\int P d t
\end{gathered}
$$


Adicionando a série elástica no sistema, nota-se que quando o atuador move a carga (degrau na posição) a energia liberada é aparentemente maior. Não está ocorrendo o fenômeno de geração de energia durante o movimento. O que ocorre, é que durante a movimentação, as molas sofrem deformação, e dada sua elevada rigidez elas se descomprimem rapidamente fazendo com que ocorra um pico de velocidade e consequentemente um aumento da potência de saída. A integral sobre esta curva mostra o valor da energia, que por sua vez irá se mostrar com amplitude maior do que na medida feita sem a adição da série elástica. Vale ressaltar, que a área total sobre a curva referente à potencia transferida à plataforma nos dois casos tem o mesmo valor, mostrando a conservação da energia. Ou seja, a energia que está sendo consumida pelo motor é a mesma que comprime as molas e faz com que a carga adquira movimentação, o que muda é a sua forma da distribuição. Este comportamento é mostrado na Figura 2.15, na qual a energia está normalizada a unidade, ou seja o valor de referência unitário é o da energia sem a influência da série elástica.

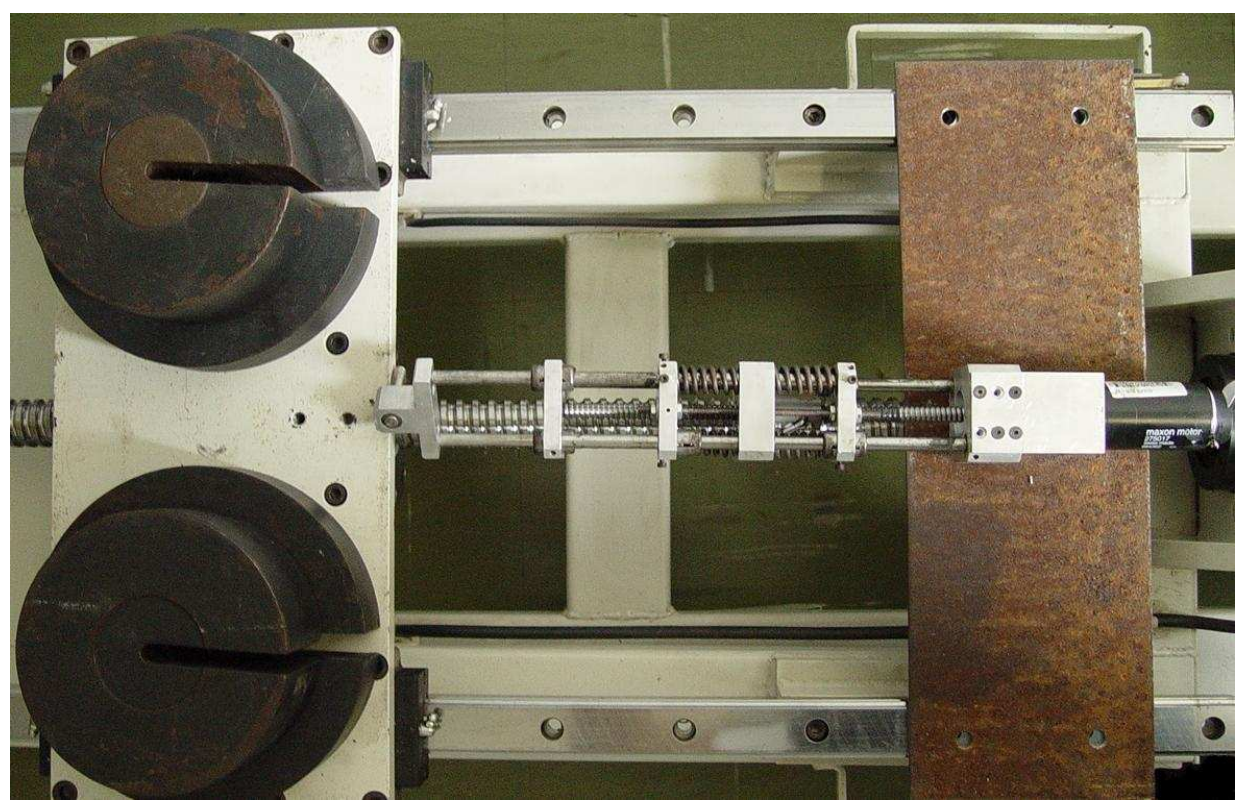

Figura 2.14: Aparato Experimental

Este é o comportamento denominado catapulta, no qual uma fonte limitada de potência libera toda sua energia para uma mola e esta por sua vez acumula esta energia e a libera para a carga de forma diferente, de maneira mais rápida, o que aparenta ser um ganho de energia. Este fenômeno é observado na ligação dos tendões com os músculos, ocorre principalmente com atletas, que precisam desenvolver elevadas potências para arremessar pesos, chutar bola ou correr. 


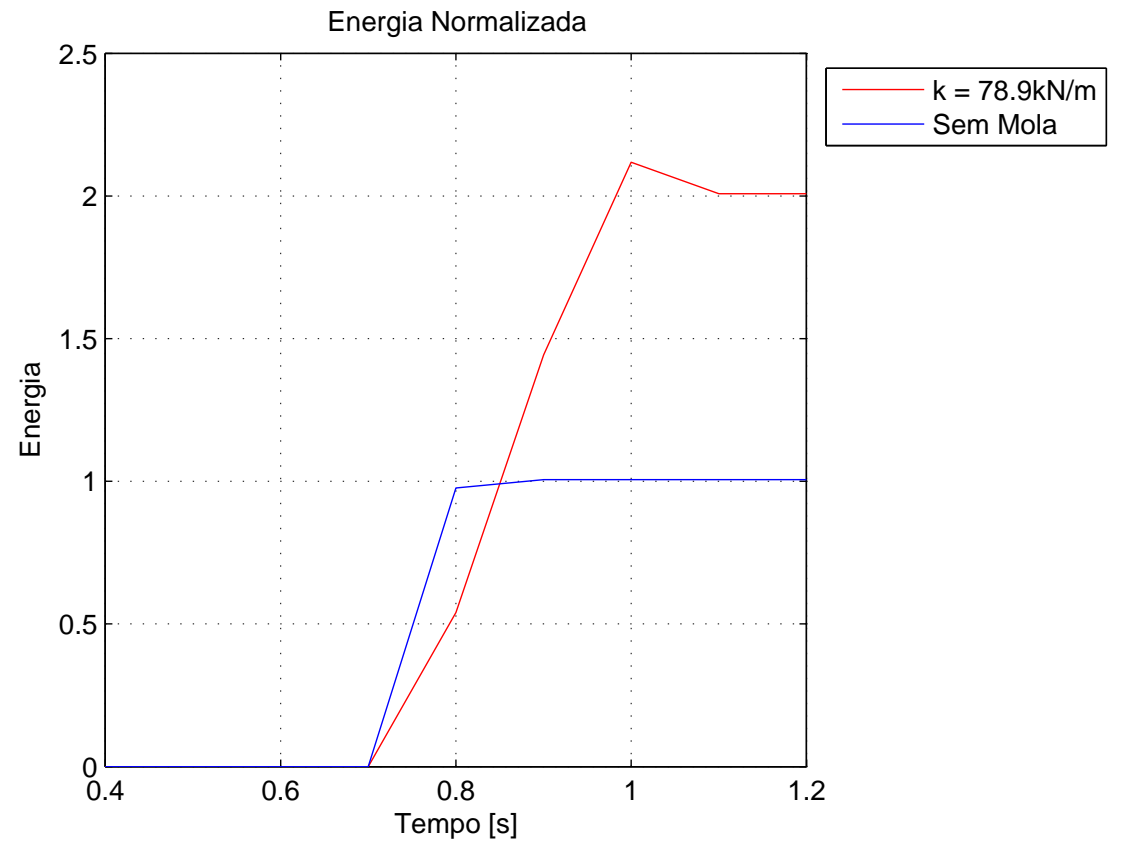

Figura 2.15: Energia liberada à carga - AES 


\section{Capítulo 3}

\section{Controle de Atuadores Elásticos em}

\section{Série}

Para estudar o comportamento dos atuadores elásticos em série e implementá-los na órtese foram desenvolvidos 3 tipos de controle:

1. Controle de Posição

2. Controle de Força

3. Controle de Impedância

O controle dos atuadores é feito através de um driver de potência denominado EPOS 70/10 Positioning Controller, fabricado pela Maxon Motor. Este dispositivo é responsável por fornecer potência aos motores, ler os encoders, as entradas digitais e analógicas e fazer a comunicação com o computador.

\subsection{Driver de potência}

O driver de Potência utilizado, EPOS 70/10 Positioning Controller, Figura 3.1, pode operar em 8 modos diferentes no controle de motores: Step/Direction Mode, Master Encoder Mode, Current Mode, Velocity Mode, Position Mode, Profile Position Mode, Profile Velocity Mode e Homing Mode. Ao conectar o dispositivo pela primeira vez, é necessário fazer a configuração do mesmo. Através de uma interface disponibilizada pelo fabricante, pode-se configurar o tipo de 
motor que será conectado à EPOS, o tipo de encoder ligado ao motor, a taxa de transferência de dados com o computador, selecionar o modo de comunicação, que pode ser via CANopen ou $R S-232$, e por fim salvar todos estes dados na memória do dispositivo.

Uma vez que as especificações técnicas estão salvas na EPOS, deve-se ajustar os parâmetros dos controladores de posição, velocidade e corrente. Esta etapa pode ser feita manualmente ou automaticamente, Figura 3.2, na qual serão determinados os ganhos proporcional, derivativo e integrativo dos controladores PID, de posição e PI, de corrente, internos da EPOS. A regulagem automática é recomendada por ser uma boa aproximação dos ganhos, para posteriormente fazer o ajuste manual até obter os valores desejados. O dispositivo vem com um software, escrito em linguagem $C++$, através do qual pode-se controlar três variáveis do motor: posição, especificando a posição desejada, velocidade ou corrente. Para o desenvolvimento deste projeto, foi feito um software, também em linguagem $C++$, no qual é possível realizar controle de posição, de modo que o motor siga uma trajetória desejada, controle de impedância, fazendo o atuador ter o comportamento de uma mola virtual e ainda fazer controle de força, através do controle de corrente. Todos estes controladores serão detalhados posteriormente.

Este driver funciona com tensão $D C$ de 11 a $70 \mathrm{~V}$, corrente elétrica máxima de $10 \mathrm{~A}$, eficiência de 0,93 podendo fornecer potência de saída de $150 \mathrm{~W}$. Possui 8 entradas digitais, 6 delas com isolamento óptico e nível alto para tensões de 9 a 24VDC. Duas entradas analógicas com resolução de 10Bit e tensão de entrada de até $5 \mathrm{~V}$ e 4 saídas digitais opto isoladas. A comunicação através da porta serial $R S-232$ pode ser feita com taxa de $115200 \mathrm{Bit} / \mathrm{s}$ e via $C A N$ por $1 \mathrm{MBit} / \mathrm{s}$. O peso do dispositivo é aproximadamente $330 \mathrm{~g}$.

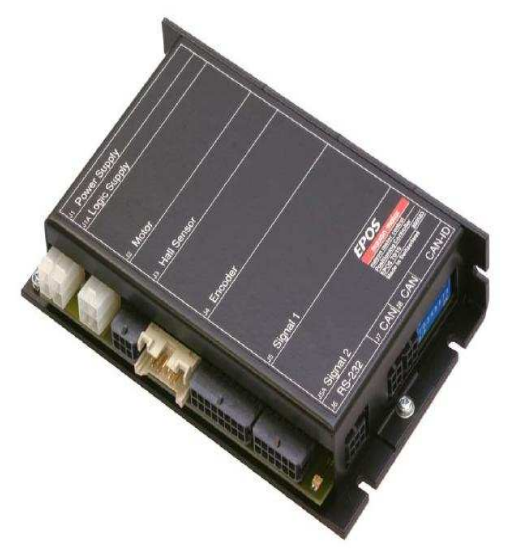

Figura 3.1: EPOS 70/10 Position Controller 


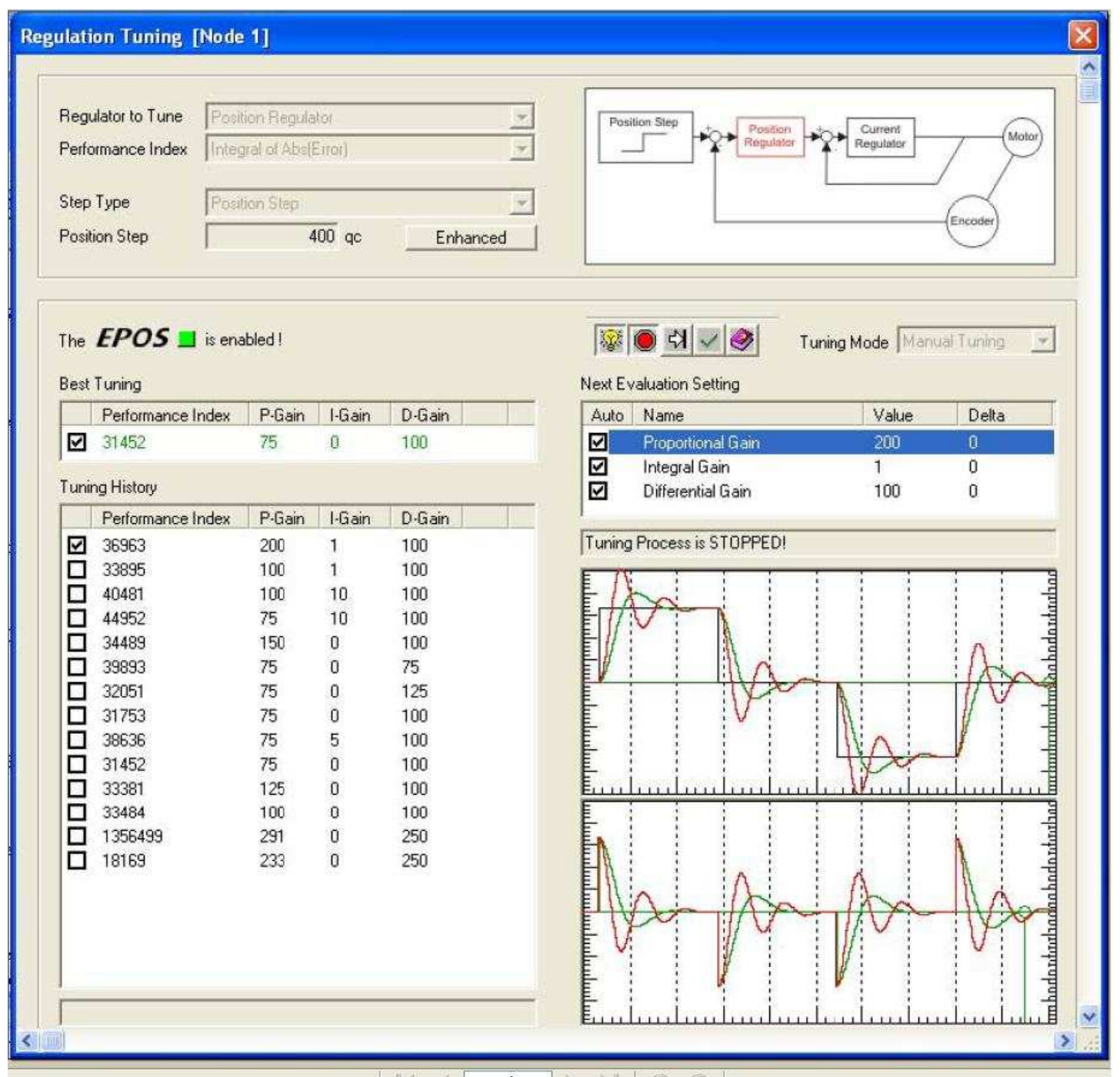

Figura 3.2: Parâmetros de Controle EPOS - Interface de ajuste do controlador interno do driver - Modo automático para a sintonia do PID 


\subsection{Controle de posição}

Com o objetivo de melhorar as condições de vida de pacientes com doenças degenerativas e lesões medulares que causam problemas e dificuldades no caminhar, foi desenvolvida uma órtese tornozelo-pé ativa que reproduz as características do caminhar humano tomando como base a trajetória angular do tornozelo de uma pessoa hígida. A idéia básica é fazer com que a órtese siga uma trajetória determinada e o paciente que utiliza o mecanismo volta a ter os movimentos do tornozelo ativos novamente. Para testar o atuador e o conjunto Órtese Tornozelo-Pé Ativa, OTPA, foram estabelecidas duas trajetórias: uma curva senoidal com amplitude e freqüência determinadas em software e um polinômio de ordem 20 que reproduz a trajetória angular de um tornozelo humano de uma pessoal hígida caminhando.

Para a obtenção do polinômio, foram utilizados dados experimentais de KIRTLEY (2007), levando em consideração somente a trajetória angular do tornozelo, no qual os ângulos da juntas que compõe o caminhar de uma pessoa hígida são medidos.

Os pontos obtidos foram interpolados no Matlab e um polinômio de ordem 20 foi gerado para simular esta trajetória. O software desenvolvido em $C++$ carrega este polinômio e gera a trajetória de referência para o atuador seguir. Enviando os pontos desejados da trajetória ao driver operando no modo Profile Position Mode. O software apresenta a interface mostrada na Figura 3.3, na qual é possível fazer todos ajustes referentes aos parâmetro de controle e do motor e visualizar as medidas dos sensores, entradas analógicas e digitais.

\subsection{Controle de força}

Controle de força é uma tecnologia desenvolvida para melhorar a interação entre robô e o ambiente ao qual ele se encontra. Esta tecnologia é muito utilizada nas indústrias, nos processos automatizados: acabamentos superficiais e usinagens. O robô deve ser capaz de conhecer melhor seu espaço de trabalho através do controle de força ROBINSON et al. (1999).

Para implementar o controle de força no atuador é necessário selecionar a EPOS para trabalhar no modo Current Mode, que proporciona ao motor o controle de corrente. Sabendo que para o motor DC utilizado tem-se uma relação diretamente proporcional entre a corrente enviada ao motor e o torque gerado pelo mesmo, Equação 3.1, pode-se fazer o controle de força via controle de corrente. 


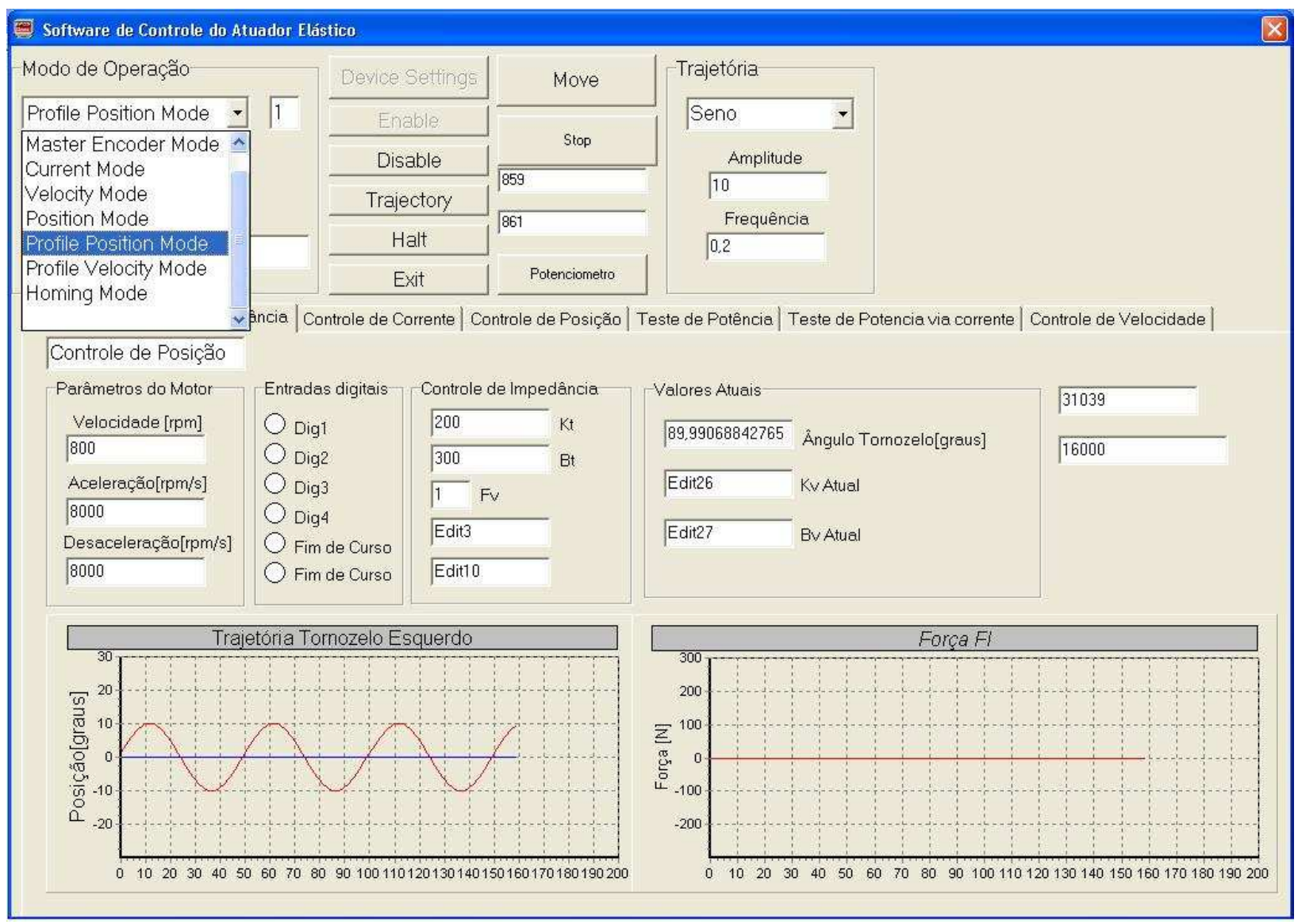

Figura 3.3: Interface de Controle - Borland Builder $\mathrm{C}++$ 


$$
\tau=K_{m} I
$$

Dois tipos de controlador foram implementados, um PID e um PD com realimentação direta. Nos dois casos a realimentação é feita através de um potenciômetro linear deslizante, descrito na Seção 2.3.3.

O primeiro controlador apresentado é o PID, dado por:

$$
F_{m}=K_{c}\left[e(t)+\frac{1}{T_{i}} \int_{-\infty}^{t} e(t) d t+T_{d} \frac{d e(t)}{d t}\right]
$$

sendo $e=F_{d}-F_{l}, \dot{e}, T_{i}$ e $T_{d}$, respectivamente, o erro entre a força desejada e a força medida, a derivada do erro, o tempo integral e o tempo derivativo. Aplicando a transformada de Laplace chega-se na seguinte equação:

$$
F_{m}(s)=K_{c}\left(F_{d}-F_{l}\right)\left[1+\frac{1}{s T_{i}}+s T_{d}\right]
$$

A malha fechada do sistema é obtida através das equações 2.4 e 3.2 :

$$
F_{l}(s)=\frac{\left(K_{d} s^{2}+K_{c} s+K_{i}\right) F_{d}(s)-\left(m_{m} s^{3}+b_{m} s^{2}\right) x_{l}(s)}{\frac{m_{m}}{k_{s}} s^{3}+\left(\frac{b_{m}}{k_{s}}+K_{d}\right) s^{2}+\left(1+K_{c}\right) s+K_{i}}
$$

Para estudar o caso no qual o atuador está travado (carga fixa), foi determinado $x_{l}$ igual a zero, obtendo a seguinte função transferência em malha fechada:

$$
\frac{F_{l}(s)}{F_{d}(s)}=\frac{K_{d} s^{2}+K_{c} s+K_{i}}{\frac{m_{m}}{k_{s}} s^{3}+\left(\frac{b_{m}}{k_{s}}+K_{d}\right) s^{2}+\left(1+K_{c}\right) s+K_{i}}
$$

Quando pretende-se trabalhar com o atuador livre e impedância zero é feito $F_{d}$ igual a zero e chega-se a seguinte função transferência em malha fechada:

$$
\frac{F_{l}(s)}{x_{l}(s)}=\frac{-\left(m_{m} s^{3}+b_{m} s^{2}\right)}{\frac{m_{m}}{k_{s}} s^{3}+\left(\frac{b_{m}}{k_{s}}+K_{d}\right) s^{2}+\left(1+K_{c}\right) s+K_{i}}
$$

O segundo tipo de controlador implementado foi um PD com um termo de realimentação direta adicionado: 


$$
F_{m}(s)=\left(F_{d}(s)-F_{l}(s)\right)\left(K_{p}+K_{d} s\right)+F_{d}
$$

$$
F_{m}(s)=\left(K_{p}+K_{d} s\right) E(s)+F_{d}(s)
$$

Combinando as equações (2.4) e (3.7) determina-se a força na carga resultante do controle em malha fechada:

$$
F_{l}(s)=\frac{\left(K_{d} s+K_{p}+1\right) F_{d}(s)-\left(m_{m} s^{2}+b_{m} s\right) x_{l}(s)}{\frac{m_{m}}{k} s^{2}+\frac{b_{m}+k K_{d}}{k} s+\left(K_{p}+1\right)},
$$

para os casos de carga fixa e impedância zero temos, respectivamente, as seguintes funções transferência:

$$
\begin{aligned}
& \frac{F_{l}(s)}{F_{d}(s)}=\frac{K_{d} s+\left(K_{p}+1\right)}{\frac{m_{m}}{k} s^{2}+\frac{b_{m}+k K_{d}}{k} s+\left(K_{p}+1\right)} \\
& \frac{F_{l}(s)}{x_{l}(s)}=\frac{-\left(m_{m} s^{2}+b_{m} s\right)}{\frac{m_{m}}{k} s^{2}+\frac{b_{m}+k K_{d}}{k} s+\left(K_{p}+1\right)}
\end{aligned}
$$

A Figura 3.4 apresenta o diagrama de blocos do controle de força proposto para o caso em que é implementado o controle PD com o termo de realimentação direta.

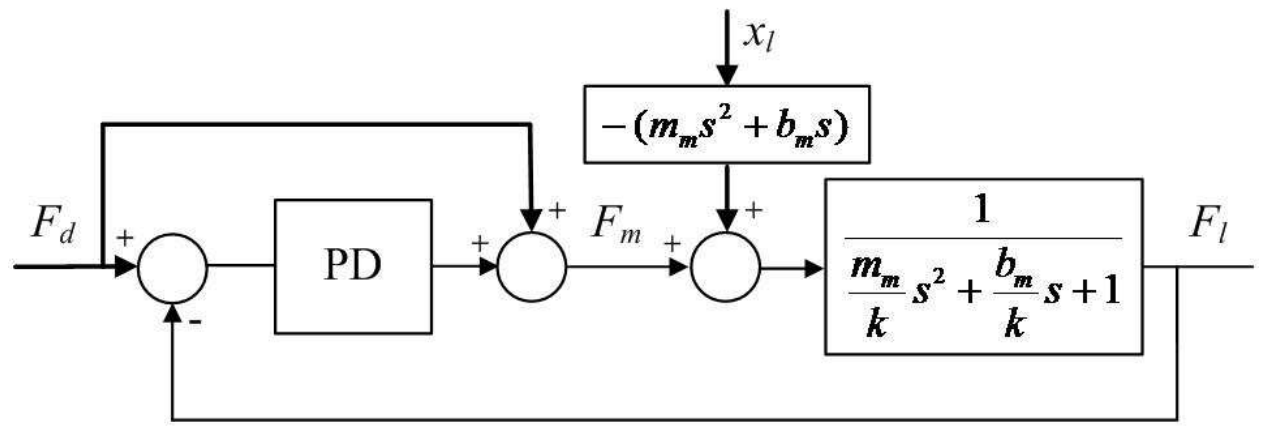

Figura 3.4: Controle em malha fechada.

Para relacionar a força que o motor deve aplicar à carga com o torque de saída do motor foi usada a seguinte relação: 


$$
F_{m}=\frac{2 \pi \eta}{p} \tau
$$

sendo $\eta$ a eficiência do fuso trapezoidal e $p$ o passo. Considerando os valores do AES, $\eta=0,9$ e $p=3 m m$, e utilizando a Equação 3.1, estabelecemos uma relação para enviar a corrente desejada para a EPOS para posteriormente ser enviada ao motor.

$$
I=\frac{F_{m}}{0,114}
$$

Sendo todas unidades pertencentes ao sistema internacional (SI), a corrente calculada é dada em Ampéres, para ser enviada à EPOS é necessário convertê-la para $m A$.

\subsection{Controle de impedância}

O objetivo deste método de controle é fazer com que a interface mecânica entre o atuador e a carga não seja fixa, ou seja, permitir que a impedância seja variável. Esta característica é importante para atuadores que serão implementados em órteses porque é uma característica presente nos músculos e tendões. A fórmula geral que define a impedância mecânica de um contato é dada por:

$$
Z(s)=\frac{X(s)}{F(s)}
$$

sendo $Z(s)$ a impedância, $F(s)$ a força e $X(s)$ a posição.

Para implementar o controle de impedância no AES, foram determinadas as seguintes variáveis de controle: $K_{v}, B_{v}$ e $F_{v}$, respectivamente, a constante elástica, o amortecimento e a força desejadas, todas virtuais, ou seja, são características que o atuador vai assumir após o controle ser implementado.

Neste modo de controle, é necessário determinar a posição desejada para o motor, denominada por $X_{m d}$, como uma função da força $F_{l}$, medida pelo potenciômetro. A força $F_{l}$, no efetuador, é dada por:

$$
F_{l}=F_{v}-K_{v} X_{l}-B_{v} \dot{X}_{l}
$$

Através da compressão das molas, tem-se: 


$$
X_{s}=\frac{F_{l}}{K_{s}}
$$

Sabendo que

$$
X_{m d}=X_{l}+X_{s},
$$

pode-se então determinar a seguinte relação:

$$
X_{l}=X_{m d}-\frac{F_{l}}{K_{s}}
$$

Substituindo $X_{l}$ e $\dot{X}_{l}$ na Equação 3.15 obtêm-se a equação:

$$
F_{l}=F_{v}-K_{v} X_{m d}+\frac{K_{v}}{K_{s}} F_{l}-B_{v} \dot{X}_{m d}+\frac{B_{v}}{K_{s}} \dot{F}_{l}
$$

Uma vez que a constante da série elástica utilizada neste trabalho é de $78,9 \mathrm{kN} / \mathrm{m}$ e o coeficiente de amortecimento é da ordem de $10 \mathrm{Ns} / \mathrm{m}$, pode-se desprezar o último termo da Equação 3.19 obtendo-se:

$$
F_{l}=F_{v}-K_{v} X_{m d}+\frac{K_{v}}{K_{s}} F_{l}-B_{v} \dot{X}_{m d}
$$

Pode-se agora implementar o controle de impedância de duas formas distintas, de acordo com o controle utilizado:

1. Controle de velocidade

2. Controle de posição

Resolvendo a Equação 3.19 para $\dot{X}_{m d}$ temos a relação de controle para o modo de velocidade:

$$
\dot{X}_{m d}=\frac{F_{v}-K_{v} X_{m}+\frac{\left(K_{v}-K_{s}\right)}{K_{s}} F_{l}}{B_{v}}
$$

Neste caso o coeficiente de amortecimento não deve ser muito pequeno, de acordo com PRATT E PRATT (1999), $B_{v}$ deve ser no mínimo igual a $10 \frac{\mathrm{Ns}}{\mathrm{m}}$.

Para controlar a impedância do atuador pelo segundo método, controle de posição, é necessário resolver a equação 3.19 em termos de $X_{m d}$ : 


$$
X_{m d}=\frac{F_{v}+\frac{\left(K_{v}-K_{s}\right)}{K_{s}} F_{l}-B_{v} \dot{X}_{m d}}{K_{v}}
$$

Para obter o valor da velocidade pode-se derivar a posição em relação ao tempo, através do método de Euler para aproximação de derivadas, chegando-se na seguinte equação de controle:

$$
X_{m d[t]}=\frac{F_{v}+\frac{\left(K_{v}-K_{s}\right)}{K_{s}} F_{l[t]}+\frac{B_{v}}{\Delta t} X_{m d[t-1]}}{K_{v}+\frac{B_{v}}{\Delta t}}
$$

É importante notar neste caso, que $K_{v}$ e $B_{v}$ não podem assumir valores muito pequenos, já que isso pode causar um aumento significativo na amplitude 


\section{Capítulo 4}

\section{Órtese Tornozelo-Pé Ativa}

Neste capítulo serão apresentados o desenho, feito em CAD, no software Solid Edge, que mostra o posicionamento dos AES em relação à órtese e os mecanismos de acionamento de cada articulação do exoesqueleto, o projeto mecânico da órtese construída, a modelagem cinemática da mesma, descrição do sensor de força utilizado e uma análise da articulação do tornozelo humano.

\subsection{Desenho de conjunto do exoesqueleto}

O projeto de construção do exoesqueleto para membros inferiores está, atualmente, na fase de construção da articulação do tornozelo, porém os desenhos em Solid Edge, para determinar o primeiro protótipo do dispostivo completo está feito. O desenho do exoesqueleto foi feito tendo como base a órtese de marcha recíproca adquirida.

A órtese adquirida, Figura 4.1(a), corresponde a uma órtese de marcha recíproca LSU (Lousiana State University), desenvolvida no Ontario Crippled Children's Centre, em Toronto, no início da década de 1970. Indicada para pacientes paraplégicos portadores de lesões medulares, a órtese é composta de duas KAFOs (Knee-Ankle-Foot-Orthosis), conhecidas como goteiras, confeccionadas em termoplástico unidas a uma banda pélvica metálica por barras também metálicas. Dois cabos de reciprocação conectam as articulações pélvicas, permitindo movimentos alternados de flexão e extensão do quadril. Também foram adquiridas duas goteiras articuladas, Figura 4.1(b), que permitirão o estudo do exoesqueleto considerando seis graus de liberdade. O mecanismo de reciprocação não será utilizado no projeto, tendo em vista o objetivo de desenvolver 


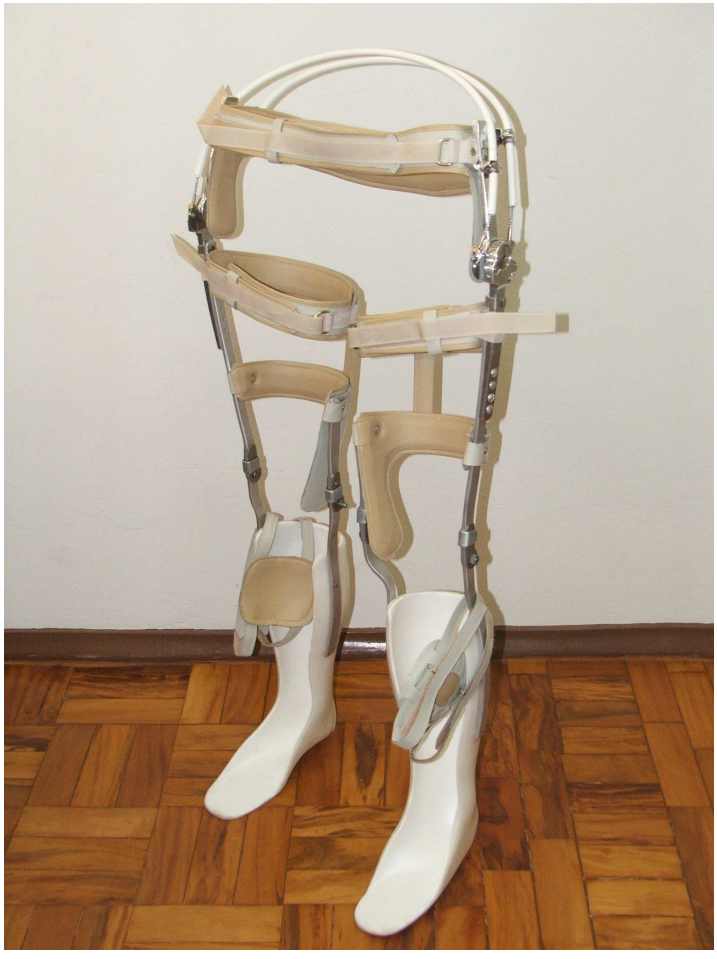

(a)

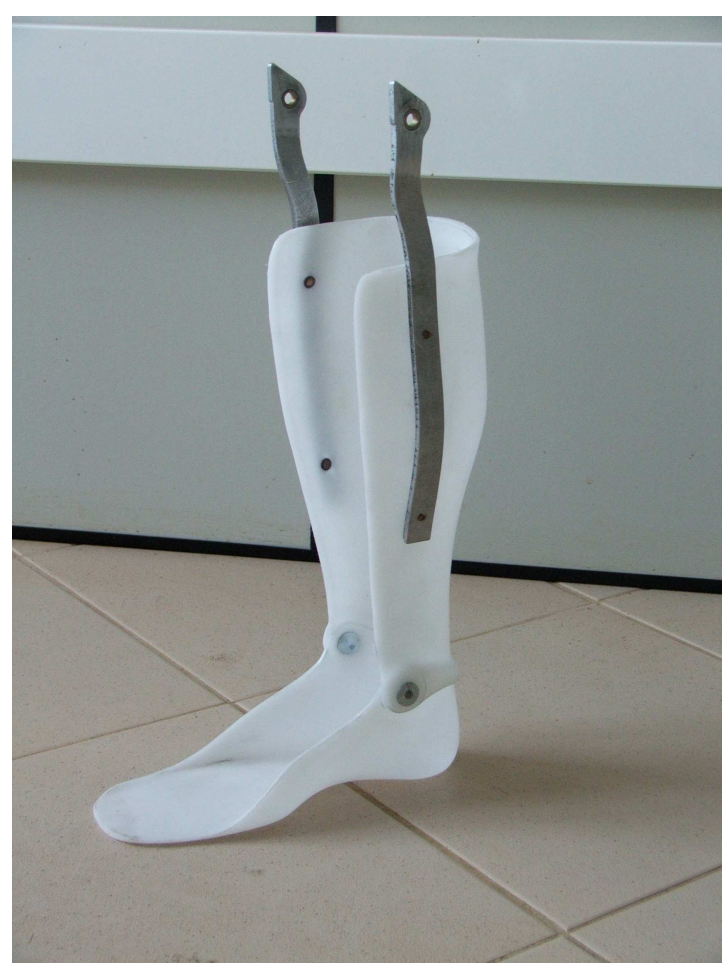

(b)

Figura 4.1: Órtese adquirida para o projeto de pesquisa. 
um exoesqueleto que tivesse um padrão de caminhar próximo ao padrão natural do ser humano hígido. Com o mecanismo de reciprocação, a flexão de um quadril - formando determinado grau com a vertical - faz com que o quadril contralateral se estenda no mesmo ângulo. No caminhar natural do ser humano, no entanto, o ângulo de flexão do quadril é maior que o ângulo de extensão. Assim, se o mecanismo fosse utilizado, o ângulo máximo de extensão do quadril do usuário seria o limitante para o ângulo de flexão do quadril contralateral, o que claramente cria um padrão de caminhar artificial. Além disso, o efeito que o mecanismo de reciprocação proporciona à órtese poderá ser obtido pelo sistema de controle através dos acionamentos (AES) a serem inseridos nas articulações do quadril.

Com os desenhos da órtese e do atuador elástico em série, feitos em Solid Edge, foi possível posicionar os atuadores, AES, com relação à órtese e projetar os mecanismos de acionamento de cada articulação, Figuras 4.2 e 4.3. Os atuadores das articulações do quadril e dos joelhos foram posicionados no elo referente à coxa, na parte externo da órtese. Com este posicionamento, o paciente poderá se sentar utilizando o exoesqueleto. Os atuadores da articulações dos tornozelos foram posicionados na parte posterior da perna (panturrilha), com acionamento no calcanhar. Os detalhes dos mecanismos de acionamento são mostrados nas Figuras 4.4, 4.5, e 4.6. Como os atuadores são lineares, é necessário criar uma articulação na parte posterior do dispositivo, na flange que prende o motor, permitindo o movimento de rotação dos mecanismos de acionamento das juntas. 

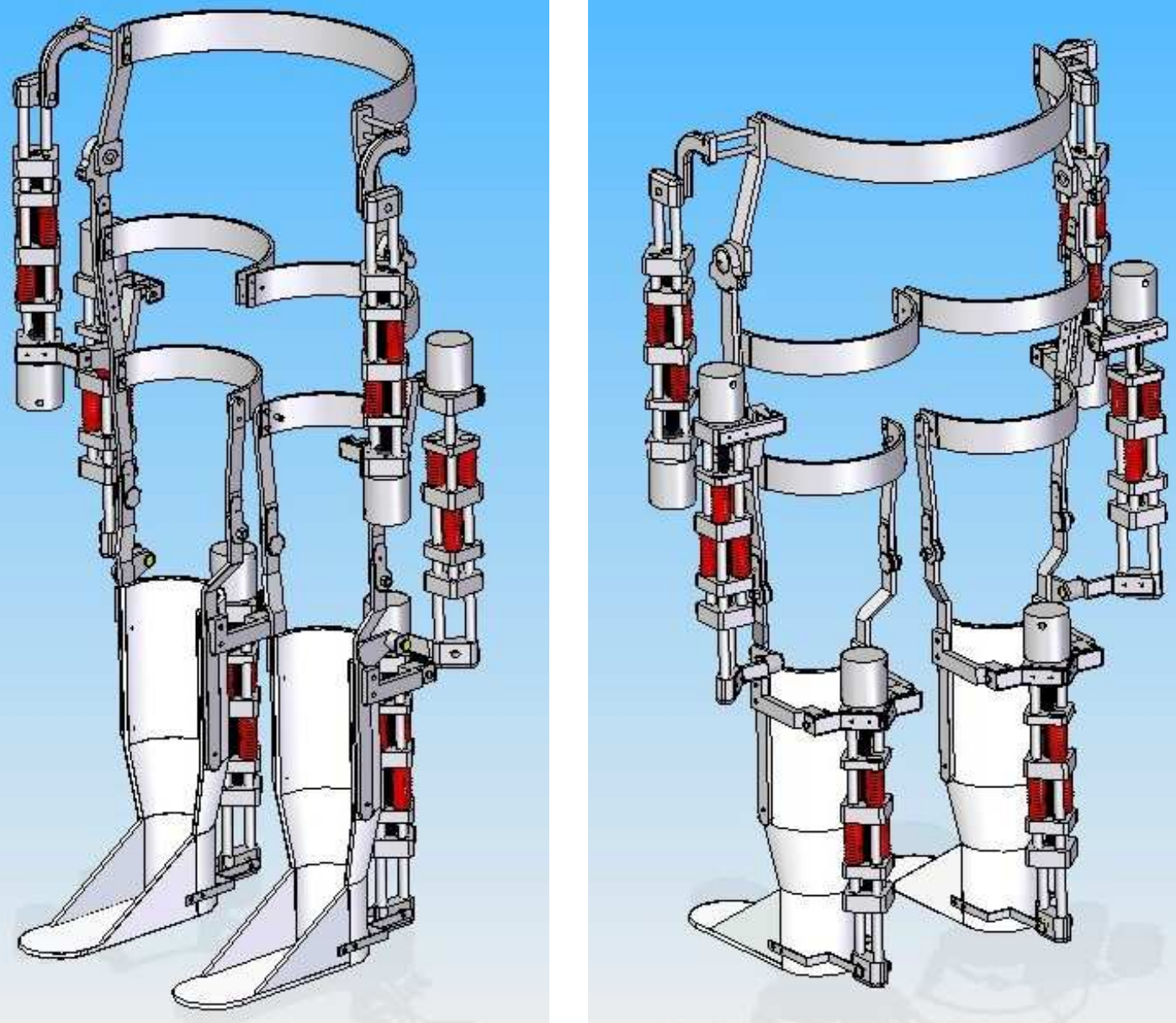

Figura 4.2: Desenho de conjunto do exoesqueleto. 

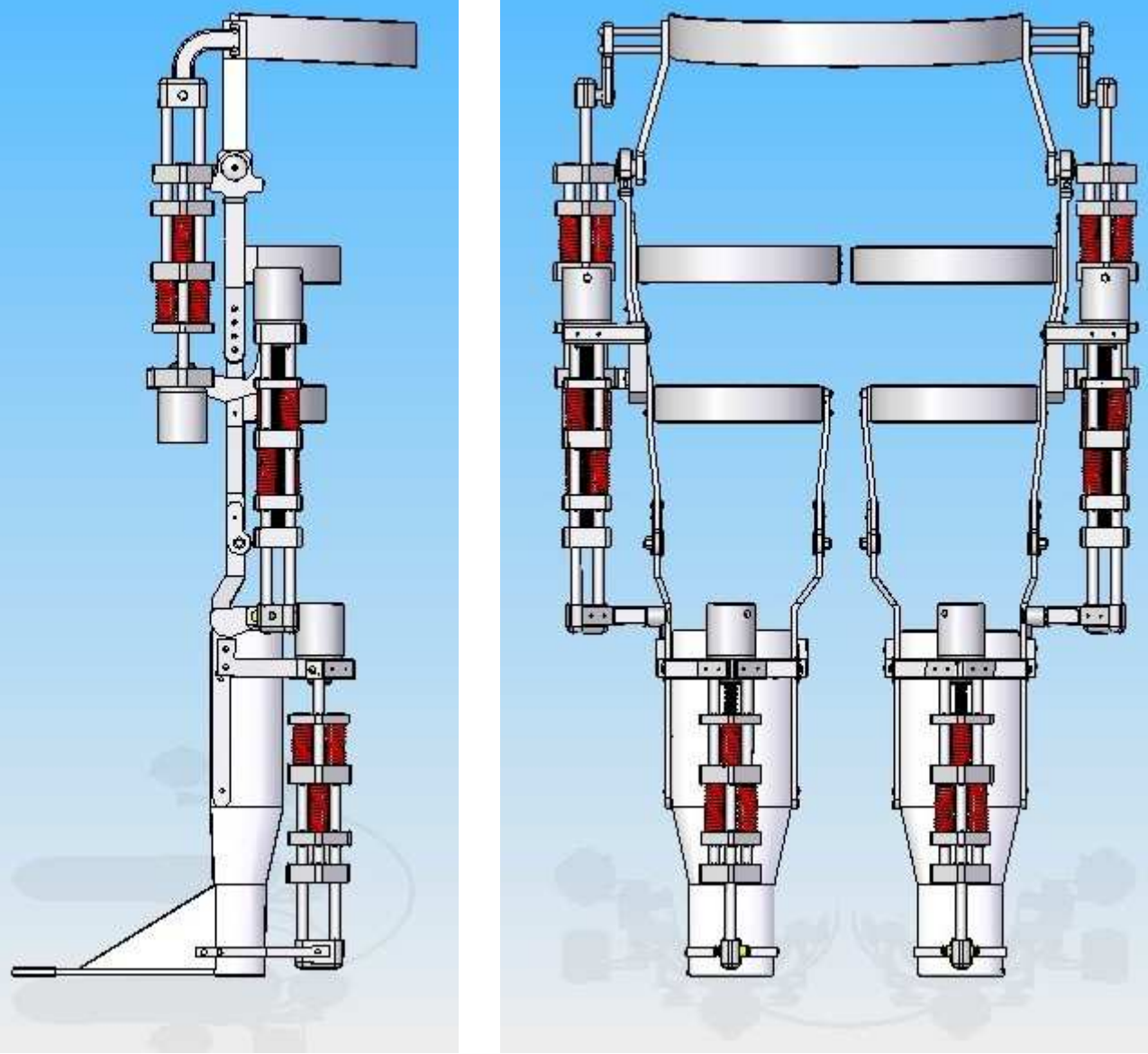

Figura 4.3: Desenho de conjunto do exoesqueleto: vista lateral e posterior.
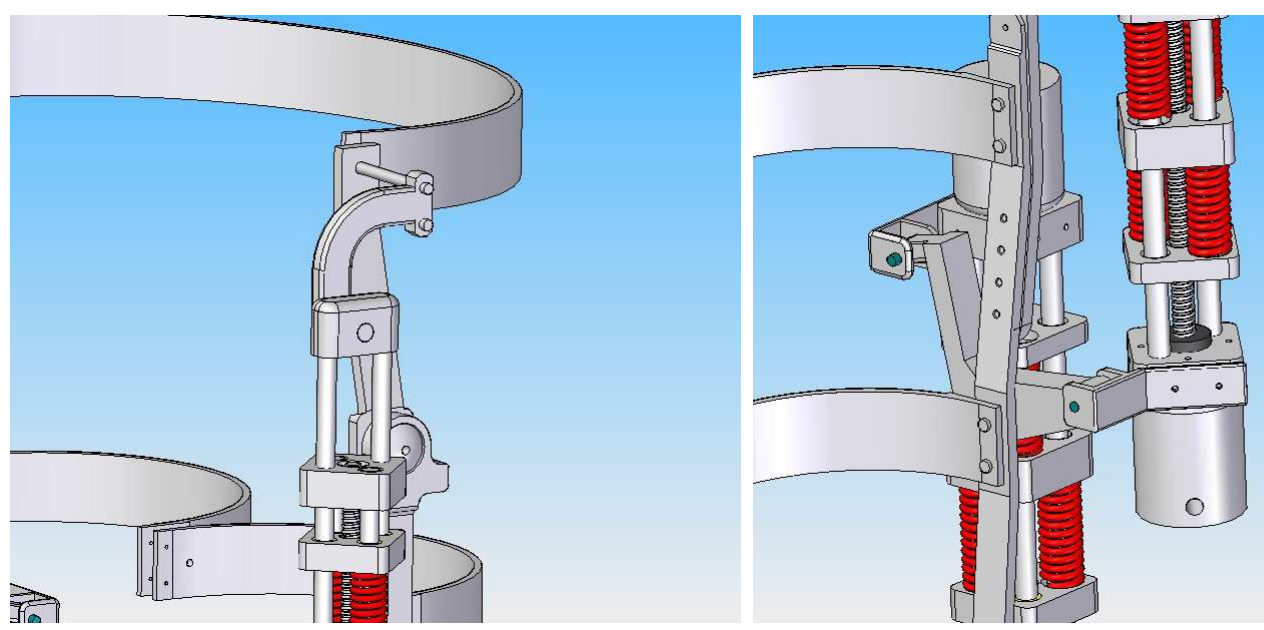

Figura 4.4: Mecanismos de acionamento da articulação do quadril. 

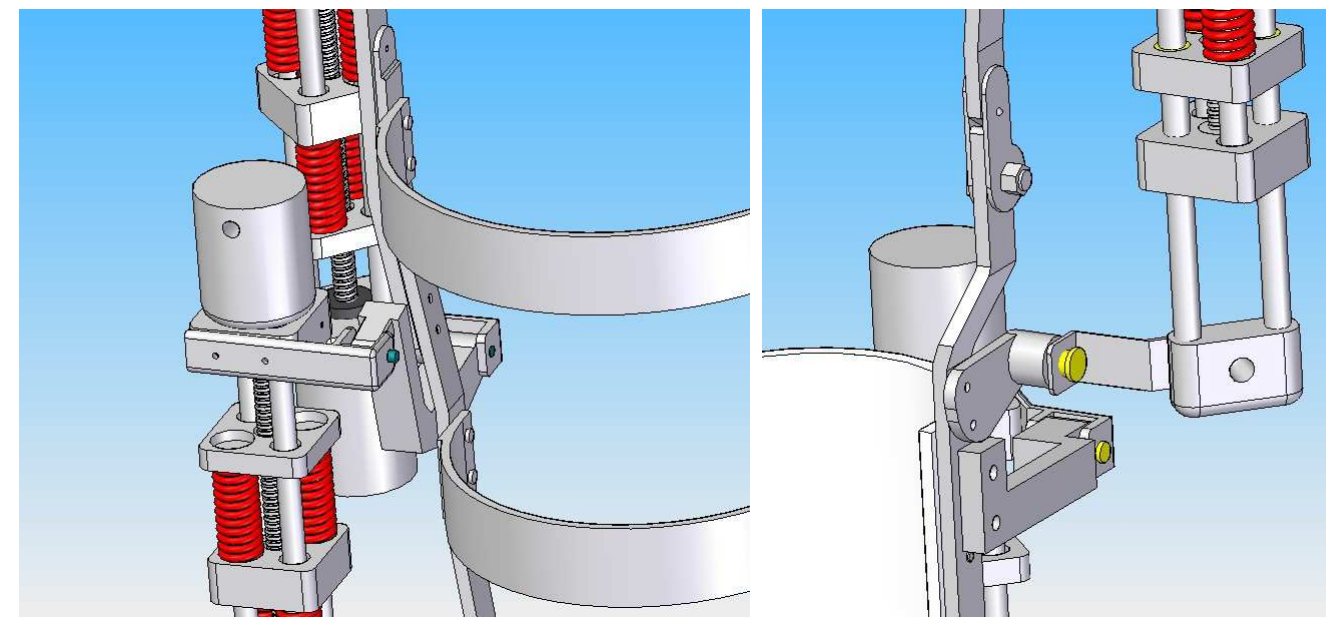

Figura 4.5: Mecanismos de acionamento da articulação do joelho.
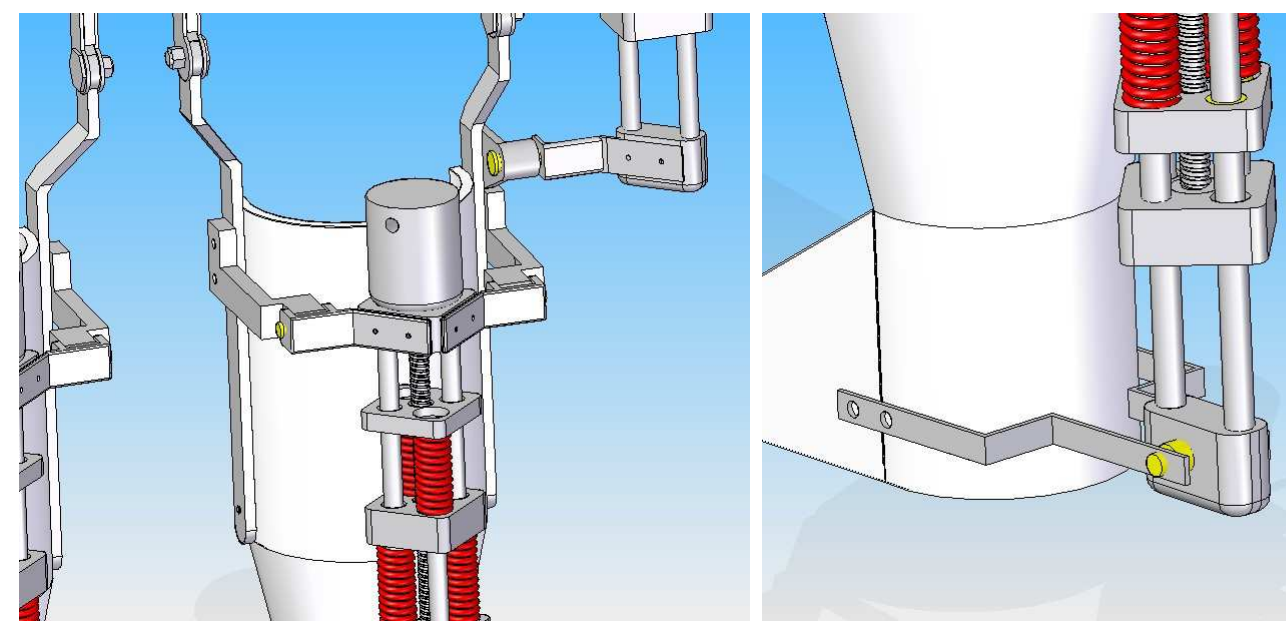

Figura 4.6: Mecanismos de acionamento da articulação do tornozelo. 


\subsection{Projeto e construção de uma Órtese Tornozelo-Pé Ativa}

\subsubsection{Requisitos}

Alguns dos requisitos mais importantes para o projeto são: custo, tamanho, peso, segurança, funcionalidade, demanda energética e estética (YAKIMOVICH et al. , 2006). Segundo PRATT et al. (2004), para ser útil e aceito, os exoesqueletos devem possuir certas capacidades e características, como: melhoria da performance humana, baixa impedância, longa vida útil, conforto e interface natural com o usuário. Dessa forma, o exoesqueleto deve: determinar a intenção de movimento do usuário, aplicar forças quando necessário e apresentar baixa impedância.

\subsubsection{Características}

O projeto da órtese possui uma arquitetura pseudo-antropomórfica, ou seja, as propriedades do exoesqueleto tentam se aproximar às humanas, mas não são idênticas a elas. Portanto, medidas antropométricas como dimensões e massa do pé e da perna e os ângulos observados normalmente no caminhar de um indivíduo saudável são considerados. A Tabela 4.1 abaixo contém algumas dessas informações referentes ao movimento do tornozelo.

Tabela 4.1: Amplitudes dos movimentos do tornozelo humano - BLEEX

\begin{tabular}{|c|c|c|}
\hline Movimento do Tornozelo & Máximo durante a marcha & Máximo Médio para um Militar \\
\hline Flexão & $14,1^{\circ}$ & $35,0^{\circ}$ \\
\hline Extensão & $20,6^{\circ}$ & $38,0^{\circ}$ \\
\hline Abdução & não disponível & $23,0^{\circ}$ \\
\hline Adução & não disponível & $24,0^{\circ}$ \\
\hline
\end{tabular}

\subsubsection{Projeto}

Para atender às necessidades biomecânicas e estruturais do projeto, e proporcionar um ponto de fixação do atuador elástico em série e dos sensores para a realização de testes, o projeto mecânico, mostrado na Figura 4.7, foi concebido.

Os desenhos foram feitos utilizando o software de CAD Solid Edge e as dimensões levaram em conta necessidades antropométricas e estruturais.

Após a montagem das peças usinadas, parte de uma goteira em polipropileno foi adaptada 


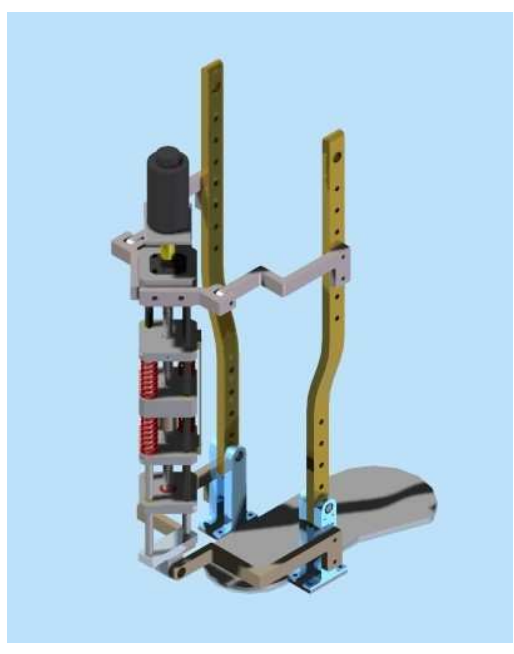

(a) Vista Isométrica

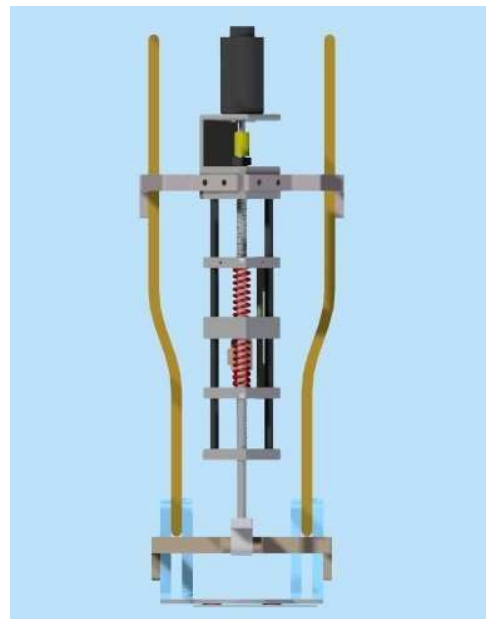

(b) Vista Frontal

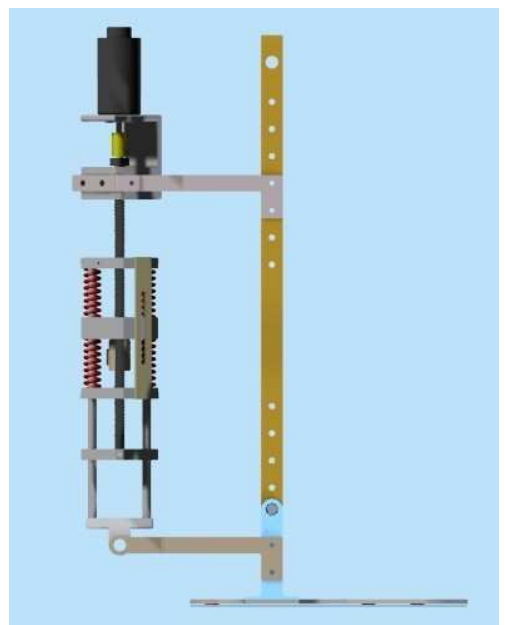

(c) Vista Lateral

Figura 4.7: Órtese tornozelo-pé projetada em CAD. 
e fixada às hastes. A montagem final da OTPA pode ser vista na Figura 4.8.
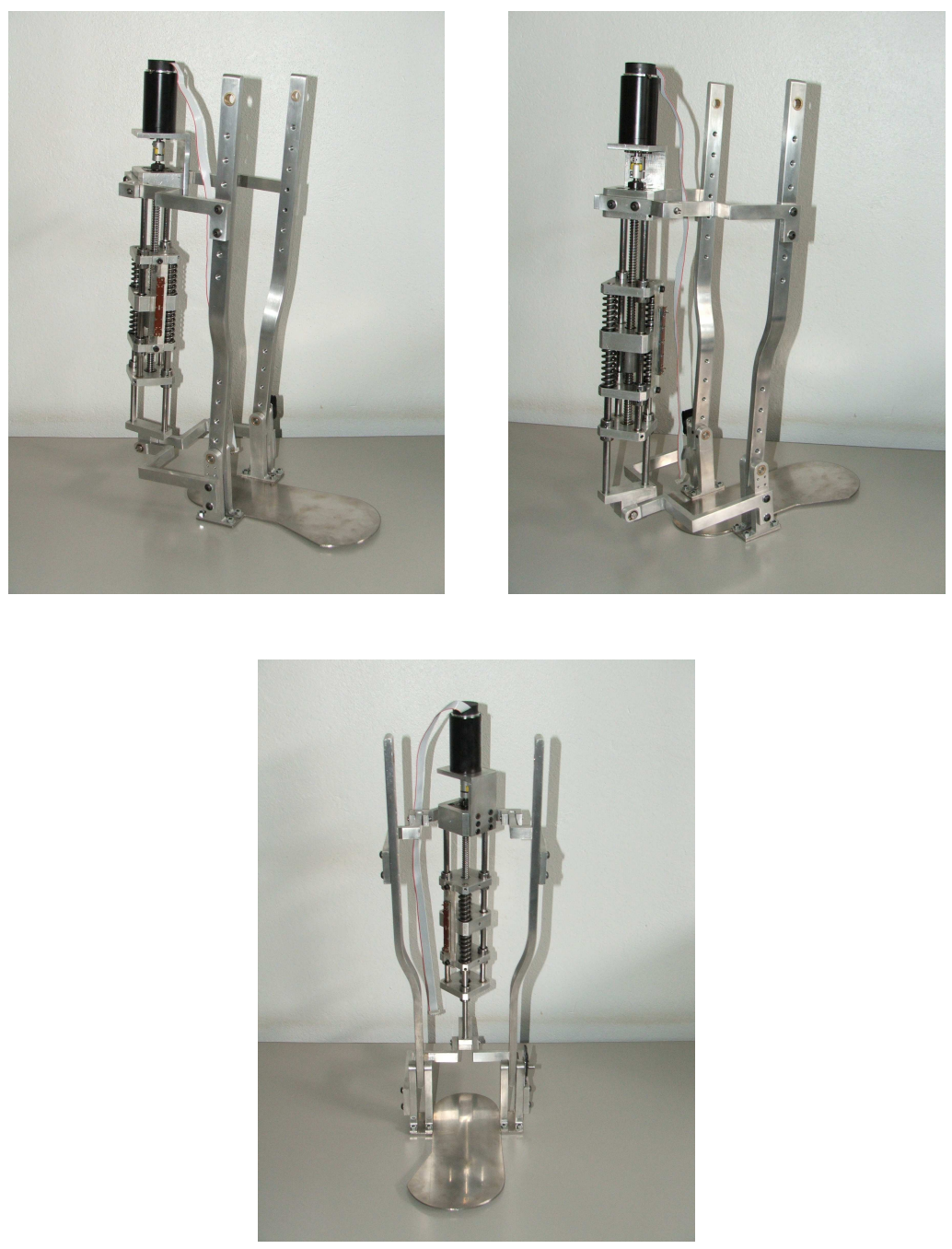

Figura 4.8: Órtese Tornozelo-Pé Ativa

Para reduzir o peso, grande parte das peças foram usinadas em duralumínio, material que possui boa resistência mecânica e baixa densidade quando comparado a outros metais. Devido às grandes solicitações mecânicas a que estava exposto, o único componente que foi usinado em outro material foi a palmilha do pé. O material escolhido foi o aço devido a sua maior resistência mecânica em relação ao duralumínio. Contudo, tal material possui densidade elevada, o que aumentou o peso do protótipo. Para efeitos de comparação, a palmilha é responsável por $0,500 \mathrm{~kg} \operatorname{dos} 2,490 \mathrm{~kg}$ correspondentes à OTPA. Porém, mesmo com sua maior resistência mecânica, o pé fletiu durante um teste no qual o usuário ergueu-se na ponta do pé. Dessa forma, este componente tornou-se foco de possíveis melhorias no projeto. 


\section{Interação exoesqueleto-usuário}

Diversos meios de se fixar o exoesqueleto ao usuário foram considerados, entre eles:

- Uso de tiras com velcro adaptadas a própria órtese;

- Adaptação de um calçado comercial sobre a sola do exoesqueleto, utilizando a palmilha em aço como base;

- Confecção e adaptação de uma bota ortopédica ao protótipo.

A forma de fixação escolhida foi a confecção e adaptação de uma bota ortopédica à órtese. A órtese completa e pronta para os testes pode ser vista na Figura 4.9.

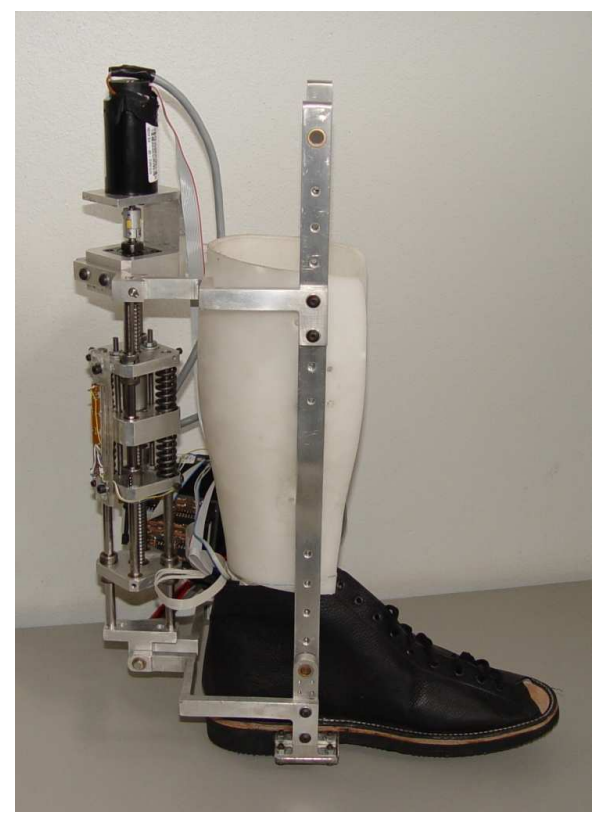

Figura 4.9: Exoesqueleto montado.

Para atender às especificações de manufatura da bota e de resistência mecânica para que o pé não fletisse durante os testes, a base do protótipo teve que ser redesenhada como mostra a Figura 4.10, o material utilizado continuou sendo o aço.

A função dos furos é proporcionar um local para rebitar a palmilha da bota na base e as laterais alongadas servem como suporte para a estrutura do exoesqueleto. Como pode-se perceber a palmilha teve suas dimensões reduzidas, porém sua espessura foi aumentada para evitar novas falhas mecânicas durante os testes. Por isso seu peso manteve-se praticamente inalterado, caindo para $0,490 \mathrm{~kg}$. O peso do conjunto final, com a bota e o atuador é $4,600 \mathrm{~kg}$. A 


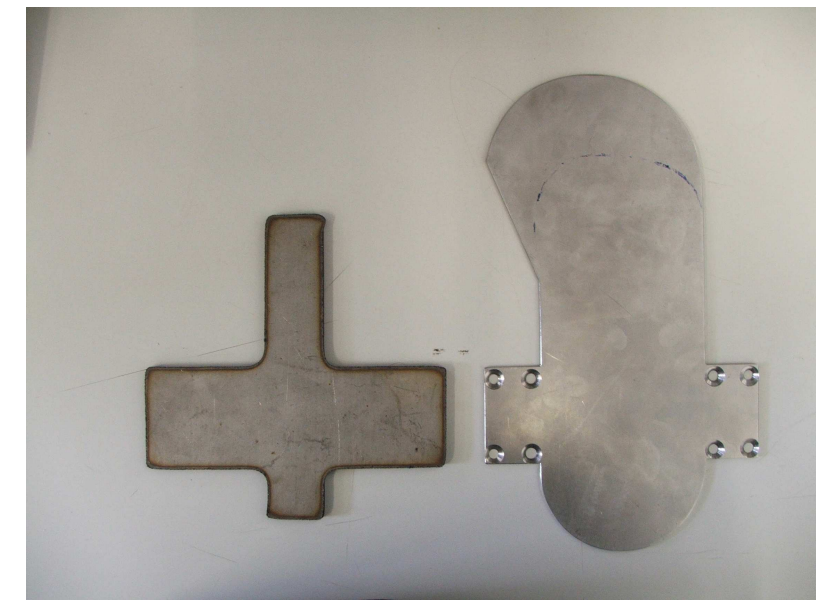

Figura 4.10: Comparação entre as duas bases utilizadas.

vantagem da bota é que ela forneceu um meio de fixação fácil e confortável ao usuário e melhorou a estética do protótipo.

\section{Sensor de Instante de Contato}

Para identificar os eventos da marcha com maior precisão, são utilizados sensores PTF (do inglês, Polymer Thick Films), denominados neste trabalho por Sensor de Instante de Contato (SIC). Estes dispositivos apresentam uma queda de resistência elétrica com o respectivo aumento da força aplicada em sua superfície ativa, e alta sensibilidade (comportamento de switch) a pequenas forças. Em BLAYA (2002), por exemplo, um sensor semelhante é utilizado para detectar o apoio do calcanhar com menor atraso do que os outros sensores de pressão.

Os testes realizados com este sensor mostram que estes captam muito bem o instante de contato entre o pé e o solo. Portanto, foi desenvolvida uma palmilha flexível, moldada em borracha, na qual 4 sensores SIC são acoplados, Figura 4.11.

Para a aquisição dos dados proveniente dos sensores, foi desenvolvido um circuito seguidor de tensão. Um seguidor de tensão é um amplificador de ganho unitário usado para isolar e conectar um estágio de alta impedância de saída a uma carga de baixa impedância de entrada. Ele é também conhecido como acoplador/casador de impedâncias. Como é um amplificador de ganho unitário, não fornece ganho de tensão, porém o amplificador operacional pode fornecer alto valor de corrente (dentro de suas limitações), já que possui impedância de saída nula. 


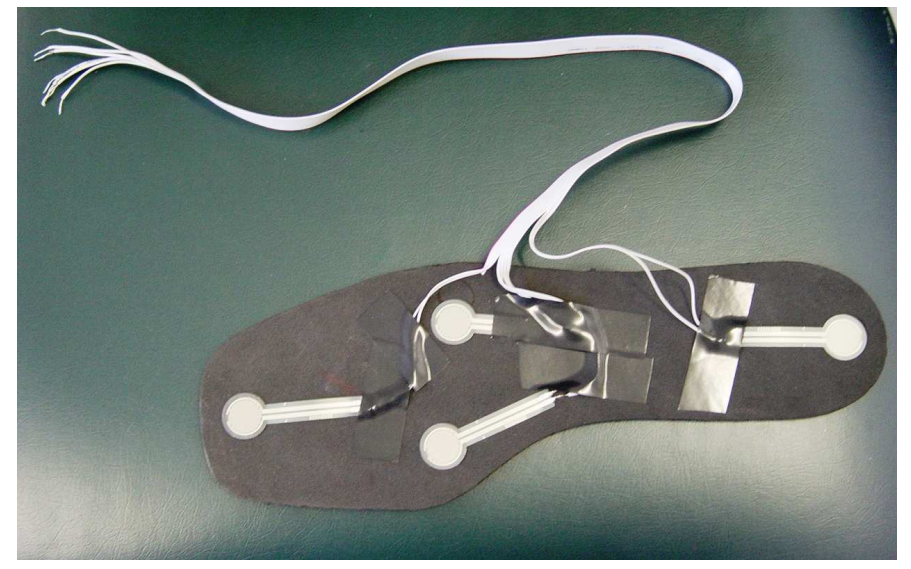

Figura 4.11: Palmilha flexível com sensores SIC

\subsection{Modelagem cinemática da órtese}

Nesta seção serão desenvolvidas as relaçoes entre a posição do efetuador do AES, o ângulo da junto do tornozelo, a impedância e o amortecimento na articulação e o torque resultante das forças aplicadas à articulação.

Considerando as variáveis definidas na Figura 4.12 e através da lei dos cossenos, a seguinte relaçào é obtida:

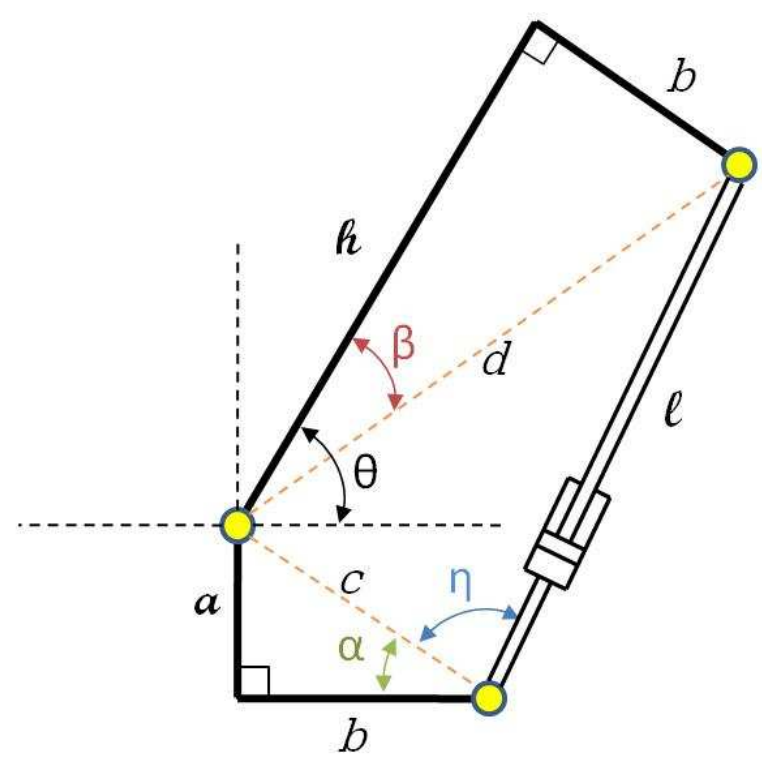

Figura 4.12: Modelagem Cinemática - OTPA

$$
\theta=\beta-\alpha+\cos ^{-1}\left(\frac{d^{2}+c^{2}-l^{2}}{2 c d}\right),
$$


que determina a relação entre a posição da articulação, $\theta$, e o deslocamento do efetuador do SEA, $l$.

$$
\eta=\cos ^{-1}\left(\frac{l^{2}+c^{2}-d^{2}}{2 l c}\right)
$$

Após obter a Equação 4.2 pode-se determinar o momento gerado pela força aplicada pelo atuador à órtese:

$$
M=c F \sin (\eta),
$$

A força, $F$, é determinada através da compressão da série elástica pela leitura do potenciômetro ou no controle de impedância é o produto entre $K_{v}$, rigidez da articulação, e $\Delta l$, deslocamento do efetuador.

$$
F=K v \Delta l
$$

Para definir valores para a rigidez e o amortecimento da articulação do tornozelo são utilizadas as equações 4.5 e 4.6, que possibilitam fazer o controle da articulação através dos parâmetros de controle do atuador, ou seja, determina-se valores desejados para a impedância da articulação e, através dessas equações, é possível saber a impedância que o atuador deve prover.

$$
\begin{gathered}
K_{v}=K_{t} \frac{\left[d^{2}+c^{2}-2 d \cos (\alpha-\beta+\theta)\right]^{\frac{1}{2}}}{d c^{2} \operatorname{sen}(\eta) \operatorname{sen}(\alpha-\beta+\theta)} \\
B_{v}=B_{t} \frac{h+a+\Delta l}{d c^{2} \operatorname{sen}(\eta) \operatorname{sen}(\alpha-\beta+\theta)}
\end{gathered}
$$

\subsection{Análise da articulação do tornozelo}

Os movimentos do pé são realizados por músculos extrínsecos e intrínsecos a este. Os músculos extrínsecos possuem origem abaixo do joelho e inserção no pé, e realizam os movimentos do tornozelo como dorsiflexão, a plantiflexão, a inversão e eversão, além de atuarem na movimentação dos artelhos (dedos). Os músculos intrínsecos são representados pelos que se originam abaixo da articulação do tornozelo, podendo situar-se no dorso ou na planta do pé, estes mús- 
culos realizam a movimentação dos artelhos. A Figura 4.13 mostra os possíveis movimentos realizados pelo pé de uma pessoa normal.

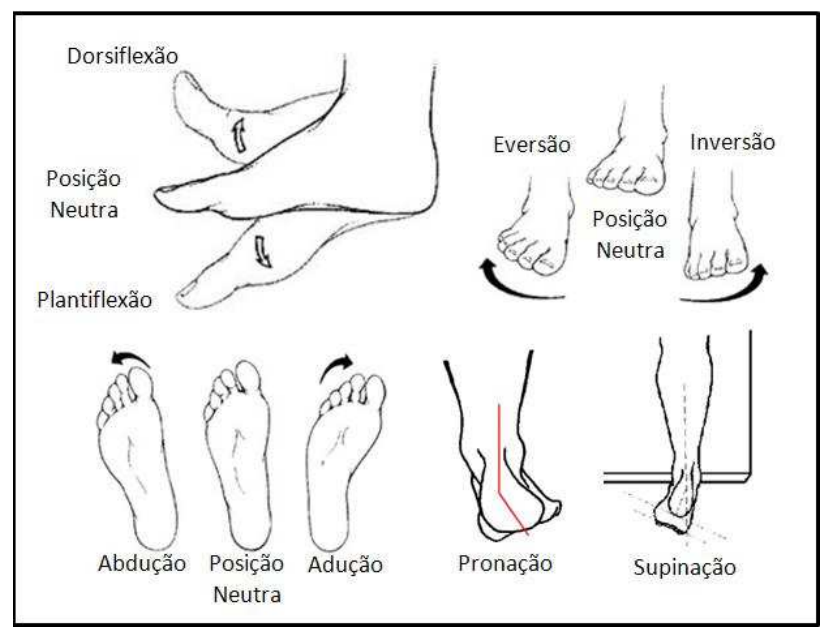

Figura 4.13: Posições do tornozelo - MIT

Dorsiflexão é o movimento de aproximação do dorso do pé à parte anterior da perna. Os músculos que atuam neste movimento são o tibial anterior, o extensor longo dos dedos e o fibular terceiro.

Plantiflexão consiste em abaixar o pé procurando alinhá-lo em maior eixo com a perna, elevando o calcanhar do chão. Esse movimento é realizado principalmente pelos músculos sóleo e gastrocnêmios.

Inversão ocorre quando a borda medial do pé dirige-se em direção a parte medial da perna. A amplitude máxima deste movimento é de $20^{\circ}$. Realizado principalmente pelo músculo tibial posterior, e auxiliado pelos músculos gastrocnêmios, sóleo e flexor longo dos dedos.

Eversão ocorre quando a borda lateral do pé dirige-se em direção a parte lateral da perna. A amplitude máxima é de $5^{\circ}$. Realizado principalmente pelos músculos fibular curto e longo, auxiliado pelos músculos extensor longo dos dedos e fibular terceiro.

Abdução é o movimento que ocorre no plano transverso, com os artelhos apontando para fora. A adução consiste no movimento oposto, de apontar os artelhos para dentro.

Pronação, este movimento é triplanar, ocorre com uma combinação de movimentos sendo formado por uma eversão do calcâneo, abdução e dorsiflexão, onde o calcâneo move-se em relação ao tálus. Supinação é o oposto da pronação, ocorrendo uma inversão do calcâneo, adução e flexão plantar. 
O ciclo do caminhar humano inicia-se quando o calcanhar toca o solo e termina quando este mesmo calcanhar toca o solo novamente. O ciclo é dividido em duas partes: Fase de Suporte e Fase de Balanço. A fase de balanço é a etapa na qual o pé não toca no solo, corresponde cerca de $40 \%$ do ciclo. A fase de suporte, que abrange $60 \%$ do ciclo, pode ser dividida em três subfases: Plantiflexão Controlada, Dorsiflexão Controlada e Plantiflexão com torque, Figura 4.14.

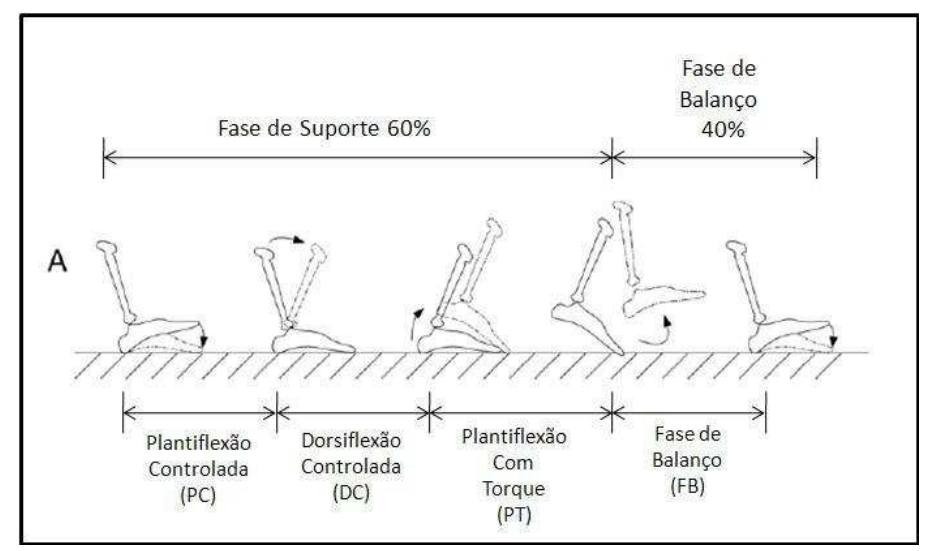

Figura 4.14: Etapas do caminhar - tornozelo - MIT

\section{- Plantiflexão Controlada}

Esta etapa começa com o calcanhar tocando o solo e termina quando o pé está completamente em contato com o solo. Durante esta fase do passo o torque na articulação do tornozelo é proporcional à posição do mesmo e a impedância (rigidez) é constante, comportando-se como uma mola linear com constante bem definida.

- Dorsiflexão Controlada

Quando o pé está completamente em contato com o solo inicia-se a etapa de dorsiflexão controlada que se estende até o ângulo máximo de dorsiflexão. Esta etapa é importante para o armazenamento de energia elástica, utilizada para propulsionar o corpo na próxima fase do caminhar.

- Plantiflexão com torque

Inicia-se depois da DC e termina quando o pé sai do solo. Esta etapa é modelada como uma mola linear em paralelo com uma fonte de torque.

No trabalho de BLAYA E HERR (2004) os valores da impedância para as etapas da marcha são obtidos e implementados em uma órtese tornozelo-pé ativa, Tabela 4.2 
Tabela 4.2: Rigidez e amortecimento do tornozelo - MIT Leg Laboratory

\begin{tabular}{|c|c|c|}
\hline Velocidade da Marcha & $\mathrm{K}[\mathrm{Nm} / \mathrm{rad}]$ & $\mathrm{B}[\mathrm{Nms} / \mathrm{rad}]$ \\
\hline Devagar & 28.65 & 0.57 \\
\hline Normal & 37.24 & 1.03 \\
\hline Rápida & 45.84 & 1.15 \\
\hline
\end{tabular}

Os valores implementados no trabalho são definidos para evitar que o paciente arraste o pé na fase de balanço.

A Figura 4.15 mostra a posição da articulação do tornozelo no plano sagital, plano que divide o ser humano em lado direito e esquerdo. Este valor corresponde ao ângulo relativo entre o pé e a perna. Embora a figura apresente uma pequena variação do ângulo do tornozelo, uma pessoa normal pode realizar a flexão plantar e a dorsi-flexão de $-38^{\circ}$ até $35^{\circ}$, respectivamente, Tabela 4.1. O torque na articulação do tornozelo é quase inteiramente negativo durante o ciclo (um atuador unidirecional é indicado neste caso), controlando o movimento para frente do centro de massa na fase de suporte (Figura 4.16(a)). Enquanto o torque é elevado na fase de suporte, ele pode ser desprezado na fase de balanço. Isto sugere que um mecanismo de desengate do atuador do exoesqueleto seja utilizado nesta fase, conservando energia.

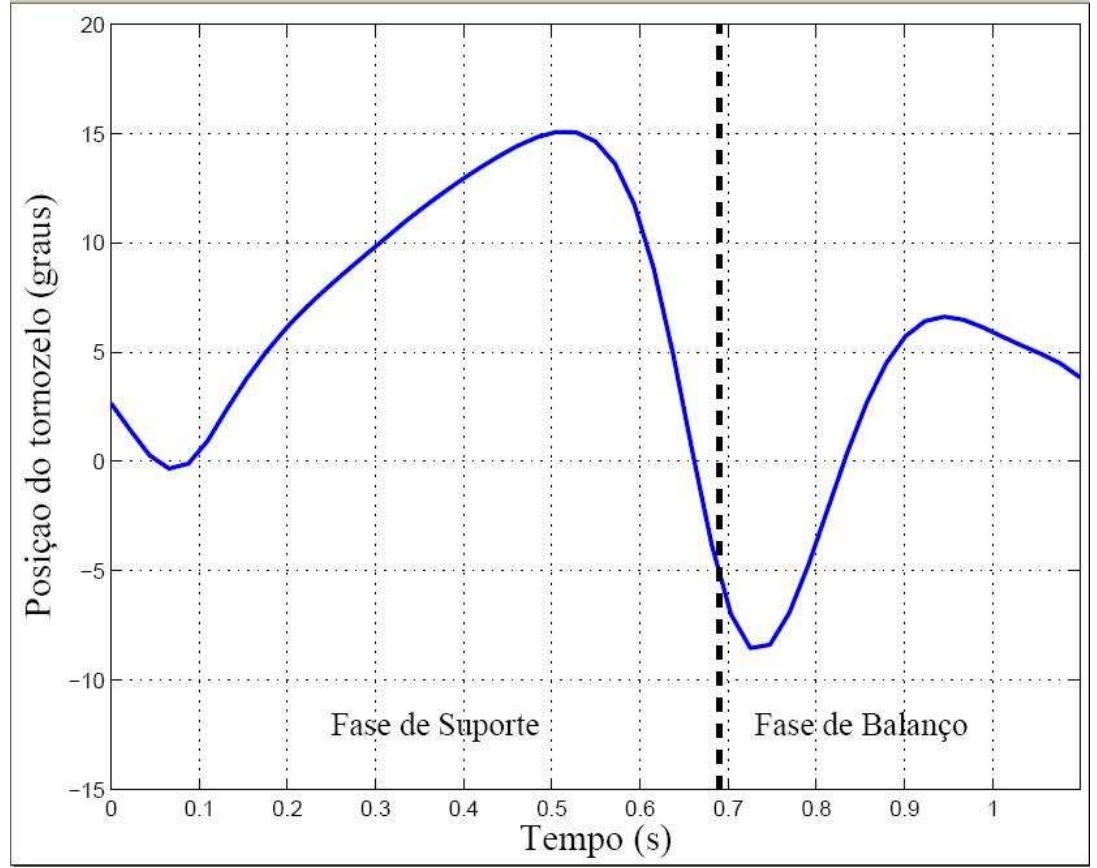

Figura 4.15: Posição do tornozelo.

A Figura 4.16(b) mostra a potência mecânica no tornozelo. Note que o tornozelo absorve energia durante a primeira metade da fase de suporte e libera energia instantes antes da retirada 
do pé do chão (máxima potência positiva do caminhar humano). A potência média é positiva, indicando que a produção de energia é necessária no tornozelo. Para baixas velocidades, uma mola pode ser utilizada para atuar no tornozelo, absorvendo energia durante a fase de suporte e liberando-a antes da retirada do pé do chão.

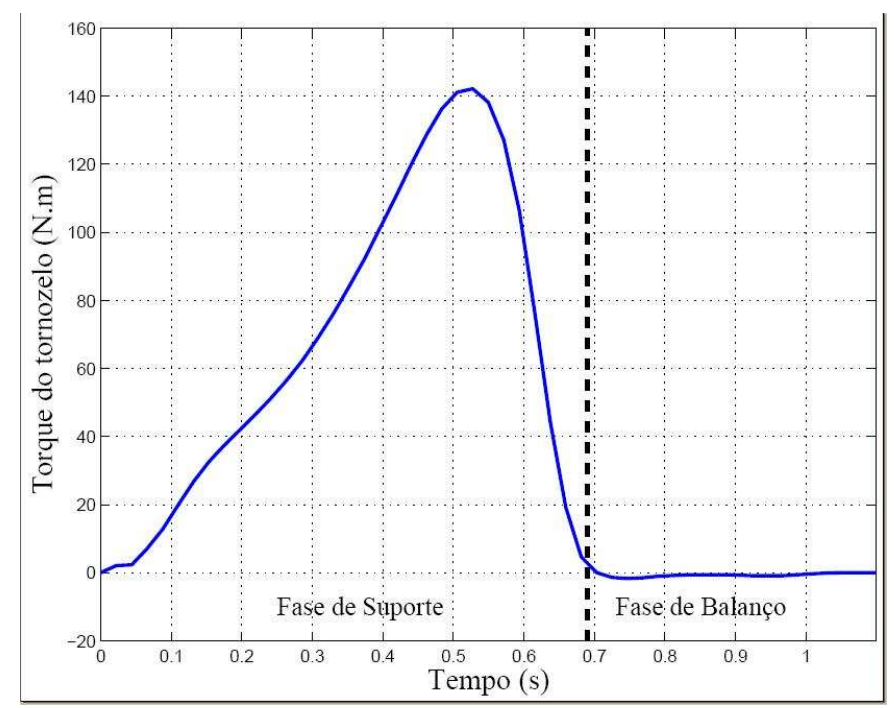

(a) Torque

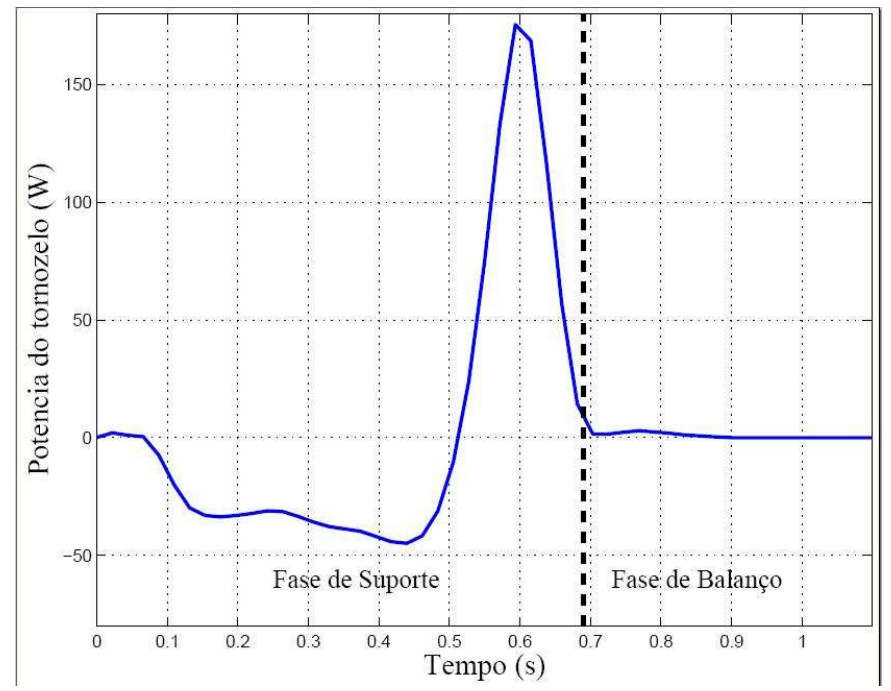

(b) Potência

Figura 4.16: Dados do tornozelo. 


\section{Capítulo 5}

\section{Resultados}

Com o objetivo de verificar o comportamento do AES foram realizados três tipos de controle. Os controles implementados foram: controle de posição, controle de força e controle de impedância.

\subsection{Controle de posição}

O controle de posição foi feito com o driver EPOS habilitado no modo Profile Position Mode, no qual é possível enviar uma trajetória desejada ao driver e ajustar os parâmetros do motor: velocidade, aceleração e desaceleração. Neste modo o controle é feito internamente na EPOS com o controlador do tipo PID e ganhos determinados automaticamente pelo dispositivo no momento de ajustar os parâmetros do driver. Foram feitos testes com duas trajetórias de referência diferentes, um seno e um polinômio de ordem 20, que replica a trajetória de uma pessoa saudável caminhando.

A transmissão dos dados OTPA/PC permitida é de 100ms, o que implicou em alterar a velocidade do caminhar, reduzida por um fator de 4 para que o atuador pudesse acompanhar a trajetória desejada, já para os testes com a função senoidal a freqüência limite é de $0.6 \mathrm{~Hz}$. Para valores acima deste a OTPA não consegue seguir a trajetória de referência. A causa da redução da velocidade do caminhar é relativa à taxa de transmissão dos dados entre o driver EPOS e o computador.

Para a implementação, foi considerada a posição $90^{\circ}$ para a junta do tornozelo, $\theta$, como a condição inicial de movimento. A Figura 5.1 mostra uma trajetória desejada senoidal de freqüên- 
cia $0.2 \mathrm{~Hz}$ e amplitude $10^{\circ}$ nesta situação a $O T P A$ segue a trajetória desejada sem defasagem ou diminuição da amplitude de movimento. A Figura 5.2 mostra a OTPA trabalhando em freqüência de $0.6 \mathrm{~Hz}$, que é a freqüência limite, observa-se que há uma defasagem (atraso) entre o desejado e o real e variações na amplitude do movimento. Na Figura 5.3 nota-se além da defasagem, alterações significativas na amplitude do sinal referente a trajetória real, neste caso a freqüência é $0.8 \mathrm{~Hz}$, acima da largura de banda do dispositivo.

A trajetória referente à Figura 5.4 mostra a $O T P A$ acompanhando os valores angulares desejados para a junta do tornozelo com certa dificuldade, causada pela limitação na taxa de amostragem.

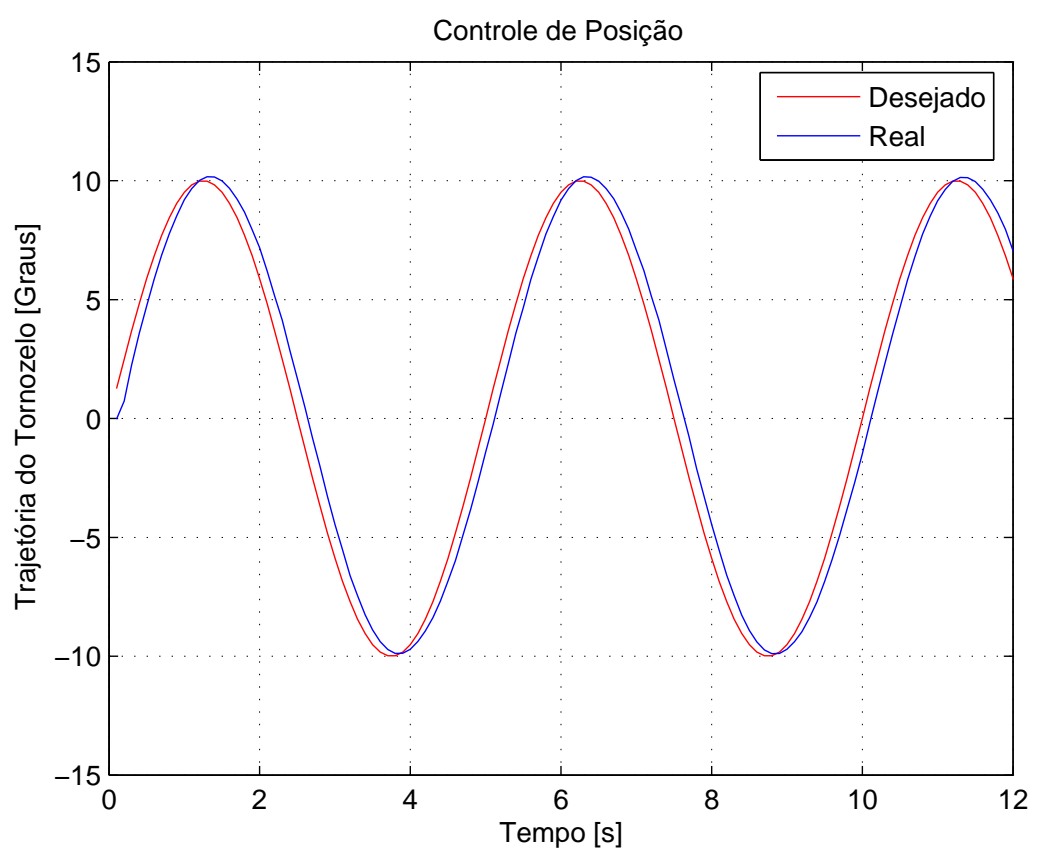

Figura 5.1: Controle de Posição com trajetória senoidal e frequência de $0.2 \mathrm{~Hz}$ 


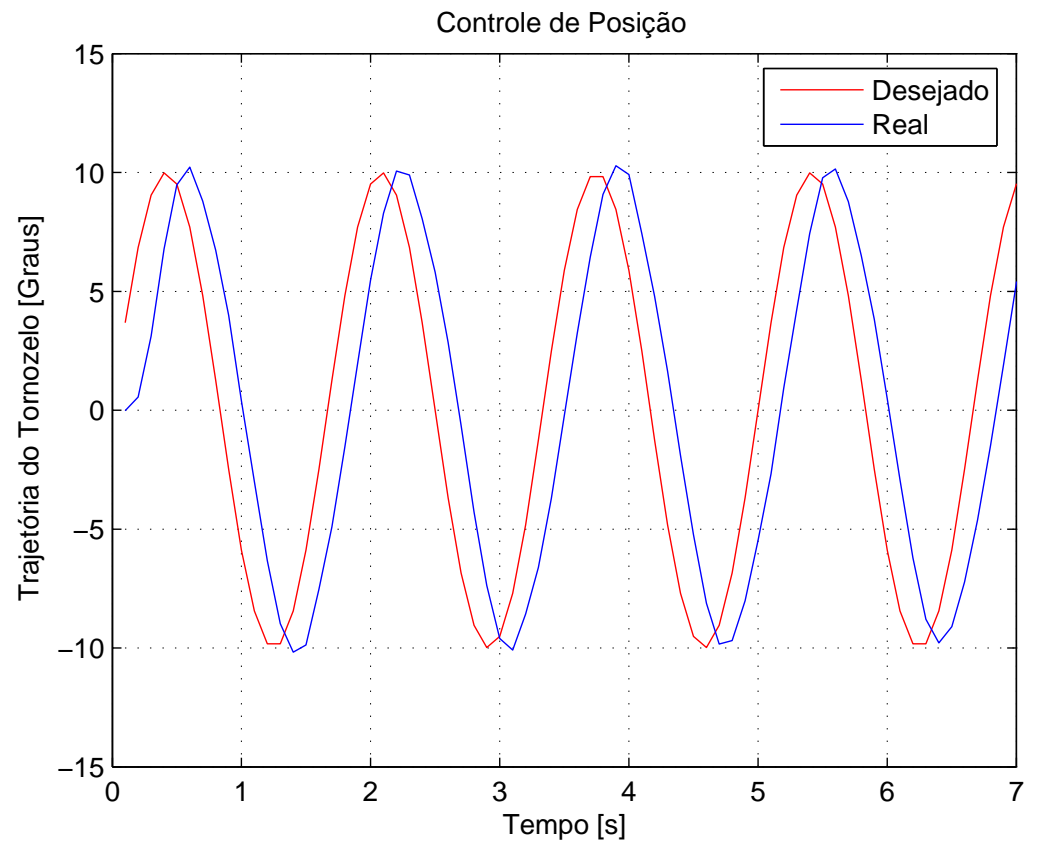

Figura 5.2: Controle de Posição com frequência de $0.6 \mathrm{~Hz}$

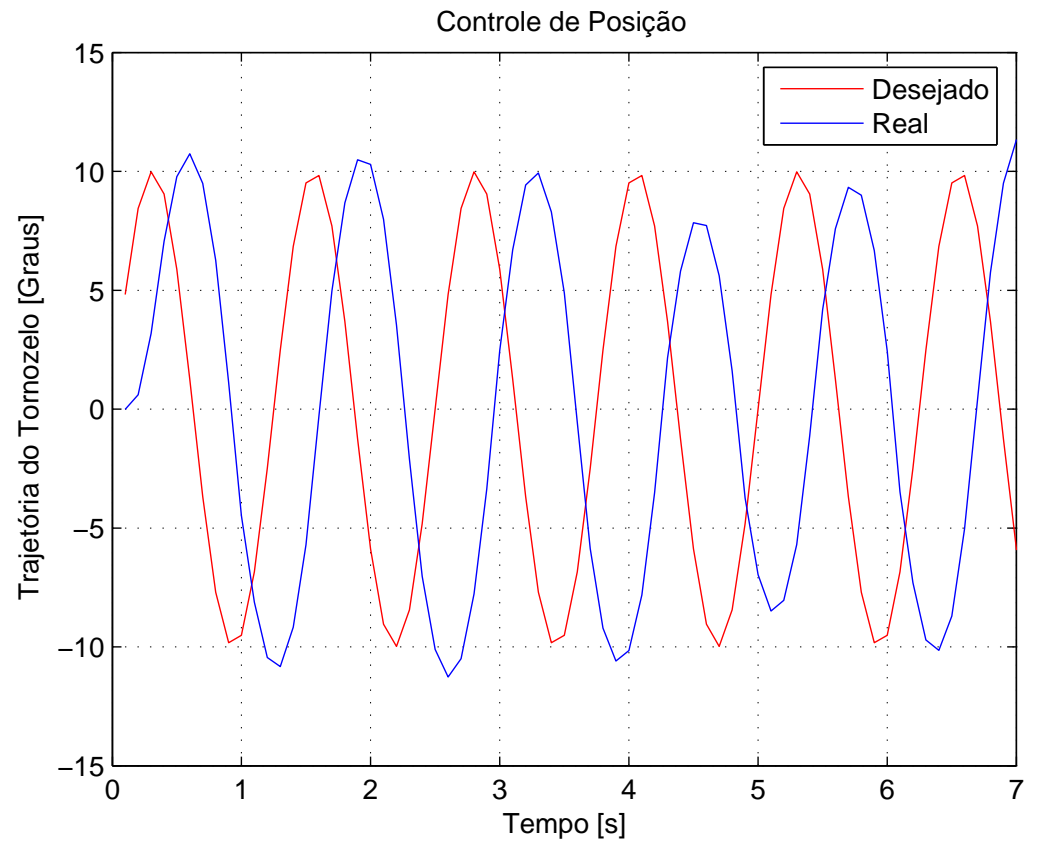

Figura 5.3: Controle de Posição com freqência de $0.7 \mathrm{~Hz}$ 


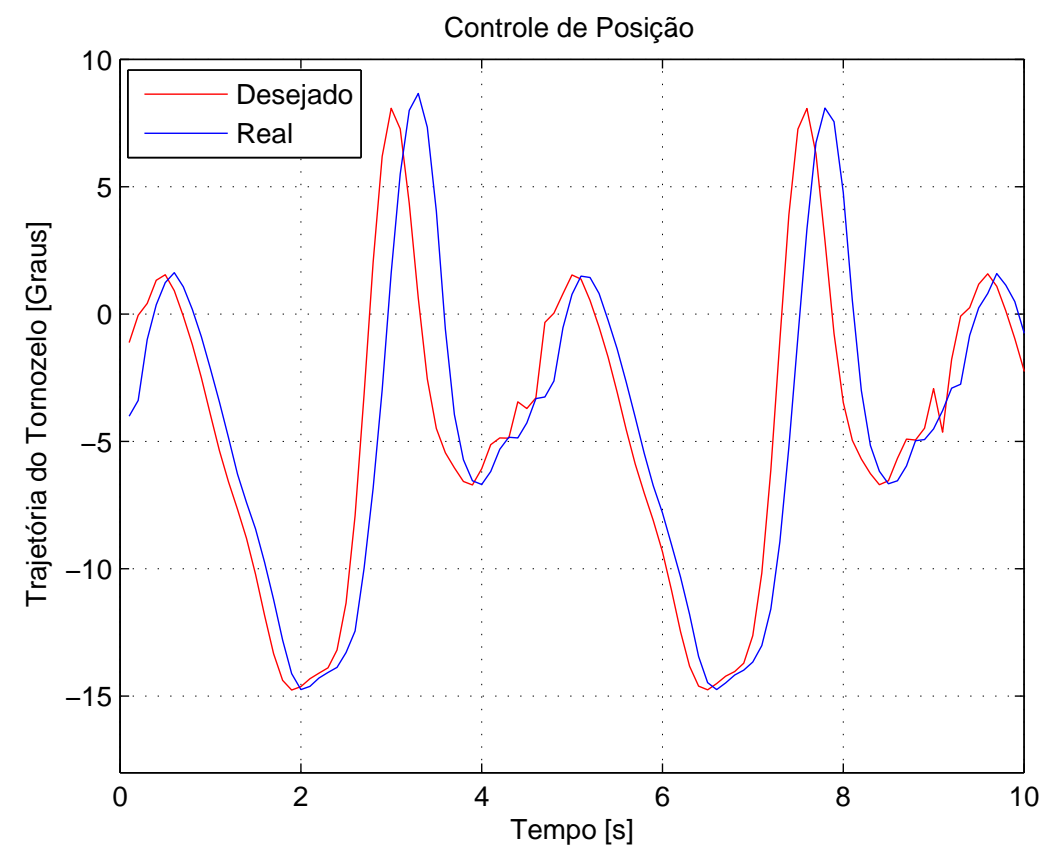

Figura 5.4: Controle de Posição, trajetória de uma pessoa saudável caminhando

\subsection{Controle de força}

Para implementar o controle de força ao atuador elástico em série, foi desenvolvido um software em Borland Builder $C++$, para que os parâmetros de controle pudessem ser ajustados. A interface de controle está representada na Figura 5.5, na qual pode-se observar que o modo de operação é o de corrente, Current Mode. Pode-se optar por fazer o controle PD com realimentação direta e PID. A realimentação é feita por um potenciômetro linear deslizante de $10 k \Omega$ e o sinal analógico obtido é filtrado por um fitro digital, de segunda ordem, do tipo FIR.

Neste caso o controlador implementado é o PID. Ainda nesta interface há a monitoração da corrente elétrica enviada ao motor, a corrente calculada via software pelo controlador, a deformação da série elástica, a força aplicada à carga, $F_{l}$, que por sua vez está travada, e por fim a força na peça de suporte da castanha denominada por $F_{m}$, calculada no sistema em malha fechada.

Os ganhos do controlador foram ajustados tomando como referência valores obtidos pelo método de Ziegler-Nichols, (OGATA , 1993). Este método em malha aberta só pode ser aplicado a plantas que não envolvam nem integradores, nem pólos complexos conjugados. Caso estas condições se confirmem, então a curva da resposta a degrau assemelhar-se-á a uma curva em forma de S, tal como é apresentada na Figura 5.6. Caso a curva não tenha esta forma, então 


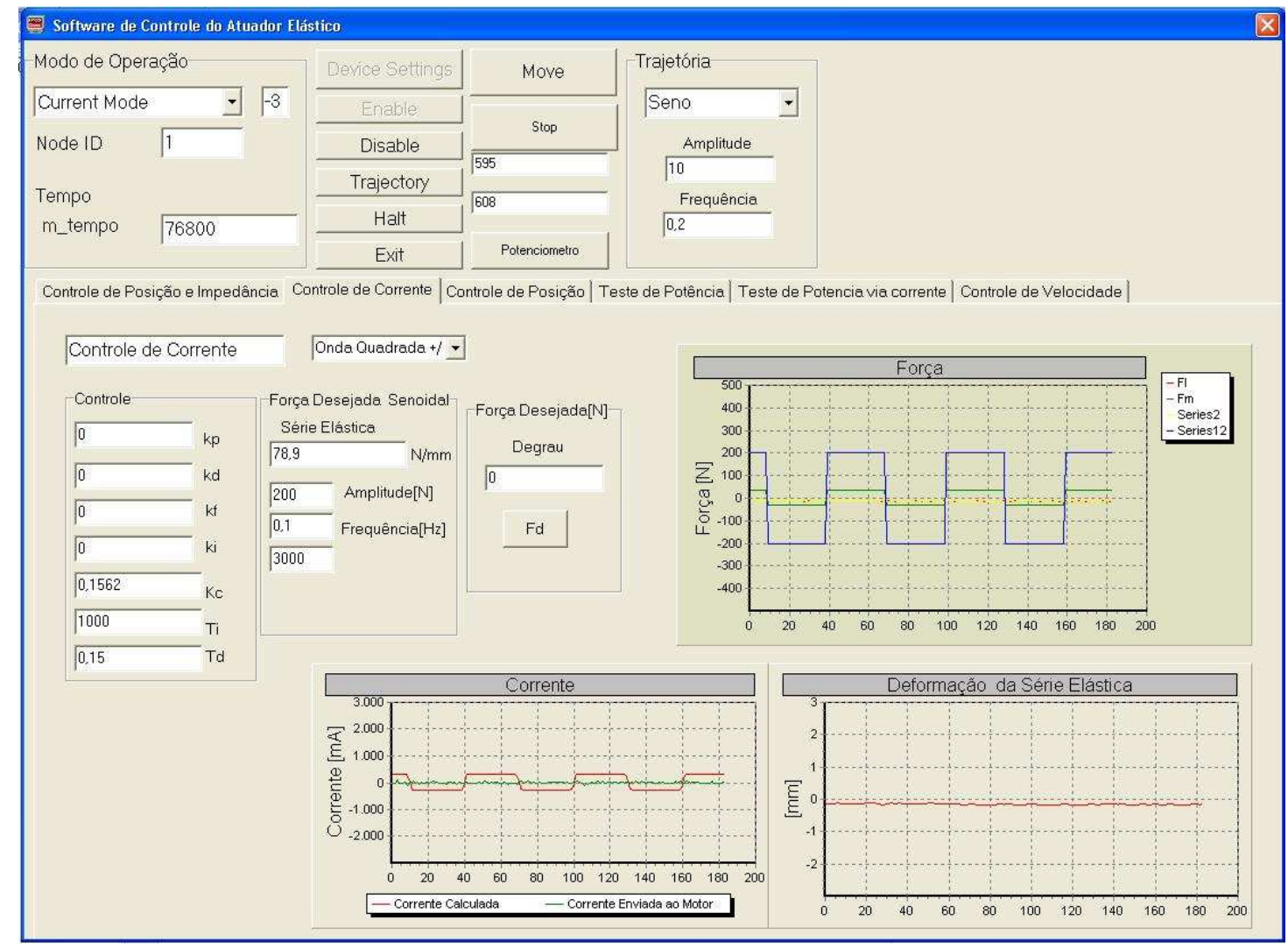

Figura 5.5: Interface de Controle

este método de sintonização não pode ser aplicado. É importante obter um compromisso entre a estabilidade/robustez e a velocidade de resposta/desempenho da malha de controle.

O cálculo dos ganhos foi feito através da abertura da malha do sistema, definindo como sendo zero os ganhos $K_{i}$ e $K_{d}$ ou $T_{d}$ zero e $T_{i} \rightarrow \infty$ mantendo $K_{p}$ unitário, obtendo-se assim a curva desejada de resposta a uma entrada degrau de amplitude $A$.

Na Figura 5.6, $L$ é o tempo de retardo e $T$ é a constante de tempo. Estas constantes são obtidas através de uma reta tangente no ponto de inflexão da curva em forma de $S$ e determinando-se as intersecções da tangente com o eixo dos tempos e com a reta que passa pelo ponto que determina a amplitude do movimento (resposta da planta) K. Após obter as constantes mencionadas pode-se recorrer à Tabela 5.1 para obter as relações propostas por Ziegler-Nichols. 


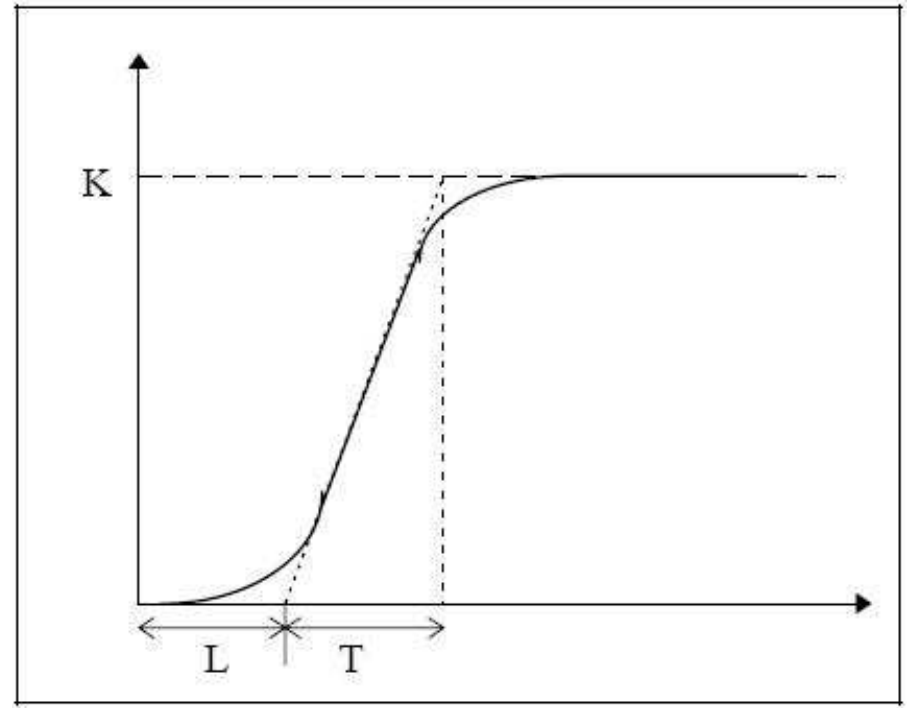

Figura 5.6: Sintonia de PID

Os valores obtidos por tal método permitem uma aproximação para os ganhos do controlador, sendo necessário fazer um ajuste experimental até que a resposta seja satisfatória. Para melhorar a resposta do sistema é necessário conhecer o comportamento dos parâmetros do controlador:

1. Ação Proporcional $\left(K_{p}\right)$ :

Ação imediata e proporcional ao valor do erro corrente, acelera a resposta de um processo controlado, reduz o tempo de subida e o erro máximo, aumenta o sobressinal e o tempo de estabilização.

2. Ação Integral $\left(K_{i}\right)$ :

Ação de controle gradual, proporcional a integral do erro. Responde ao passado do erro enquanto este for diferente de zero, reduz o tempo de subida, aumenta o sobressinal, o período de oscilação e tempo de estabilização, produzindo respostas lentas e oscilatórias. Tende a instabilizar a malha.

3. Ação Derivativa $\left(K_{d}\right)$ :

Ação antecipatória, resposta proporcional à derivada do erro. Usada para acelerar e estabilizar a malha, reduz o sobressinal, o erro máximo e o período de oscilação. Não é indicada para processos com ruído.

A Figura 5.7, mostra a resposta do SEA a uma entrada degrau de amplitude $200 N$. Neste caso o ganho $K_{p}$ ainda estava alto portanto observa-se o sobressinal $(M P)$ da ordem de 0.37 , tempo de pico $\left(t_{p}\right)$ aproximadamente $0.5 s$ e tempo de acomodação $\left(t_{a}\right)$ de $1.5 s$. A Figura 5.8, 
Tabela 5.1: Regra de determinação de parâmetros de Ziegler-Nichols baseada na resposta ao degrau da planta

\begin{tabular}{|c|c|c|c|}
\hline Tipo de Controlador & $K_{p}$ & $T_{i}$ & $T_{d}$ \\
\hline $\mathrm{P}$ & $\frac{T}{L}$ & $\infty$ & 0 \\
\hline $\mathrm{PI}$ & $0.9 \frac{T}{L}$ & $\frac{L}{0.3}$ & 0 \\
\hline $\mathrm{PID}$ & $1.2 \frac{T}{L}$ & $2 \mathrm{~L}$ & $0.5 \mathrm{~L}$ \\
\hline
\end{tabular}

representa a resposta a um degrau de amplitude negativa, neste caso o atuador deve aplicar uma força à carga no sentido de puxar a carga, pode-se observar que o sobressinal diminuiu, uma vez que o ganho referente à ação derivativa foi aumentado, Tabela 5.2

Tabela 5.2: Valores obtidos pelo método de Ziegler-Nichols para os ganhos do controlador PID implementado.

\begin{tabular}{|c|c|}
\hline Ganhos & Valor \\
\hline$K_{p}$ & 0.25 \\
\hline$T_{i}$ & 1000 \\
\hline$T_{d}$ & 0.15 \\
\hline
\end{tabular}

A Figura 5.9 mostra a resposta ao degrau de amplitude $-300 N$, neste caso o sobressinal diminuiu (0.20) e não apresenta erro de regime. Aumentando a amplitude do degrau para $-400 N$ e retornando ao valor desejado zero, Figuras 5.10 e 5.11, o dispositivo responde com pouco sobressinal e de forma mais rápida. Isso ocorre porque ao aumentar o valor desejado para a força as molas terão maior tração de forma que irão impelir uma força de amplitude maior à peça de suporte da castanha, fazendo com que esta volte á posição zero mais rápido porém, ainda apresenta imprecisão quanto à origem de movimentação.

É necessário determinar um valor de referência zero para o potenciômetro, denominado valor zero do potenciômetro. Este valor é a referência para o cálculo da força durante o controle, já que a medida é feita a partir da subtração do valor atual pelo valor de referência. A determinação do valor zero é feita manualmente, posicionando o cursor do dispositivo de modo que não haja deformação das molas. As imprecisões geradas neste procedimento fazem com que o valor medido da força no efetuador seja diferente de zero (quando não há deformação) ou então a força não consegue atingir o valor desejado pois o dispositivo perde a referência correta em relação ao zero do sistema.

A força de saída do efetuador apresenta imprecisões para retornar ao valor zero, também por problemas na resolução do conversor analógico digital interno da EPOS. A resolução de 


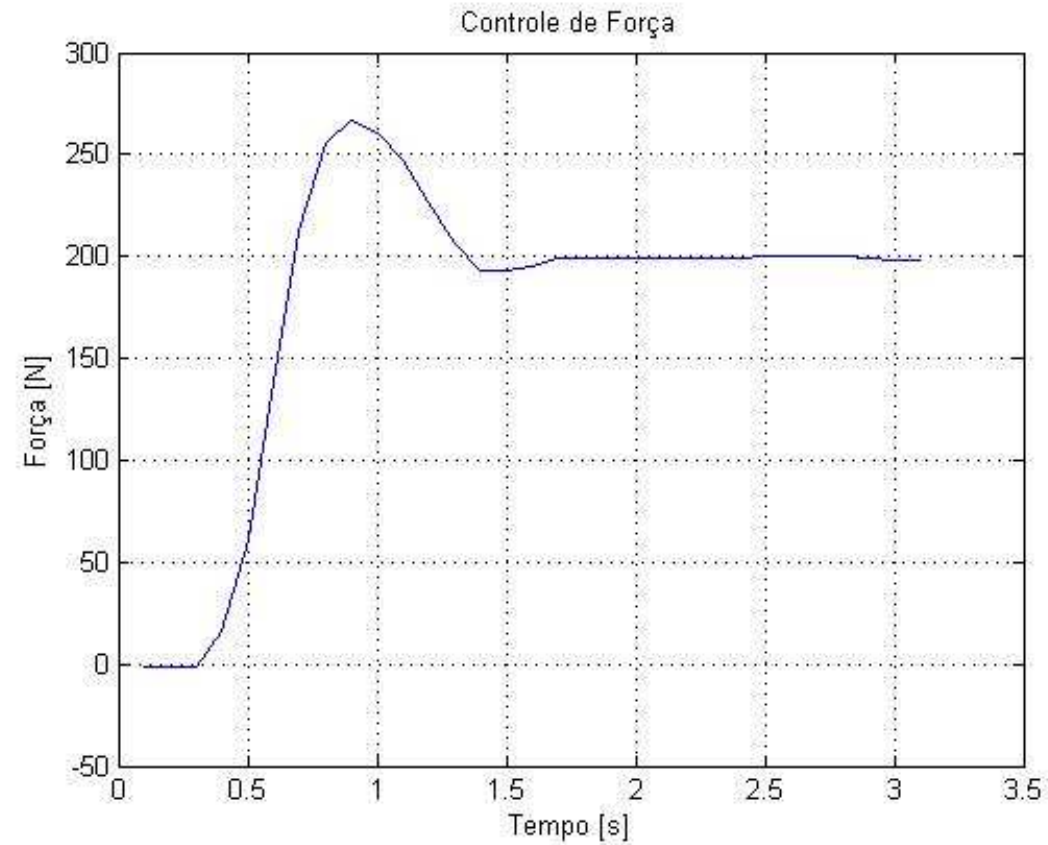

Figura 5.7: Resposta a um degrau de amplitude $200 N$

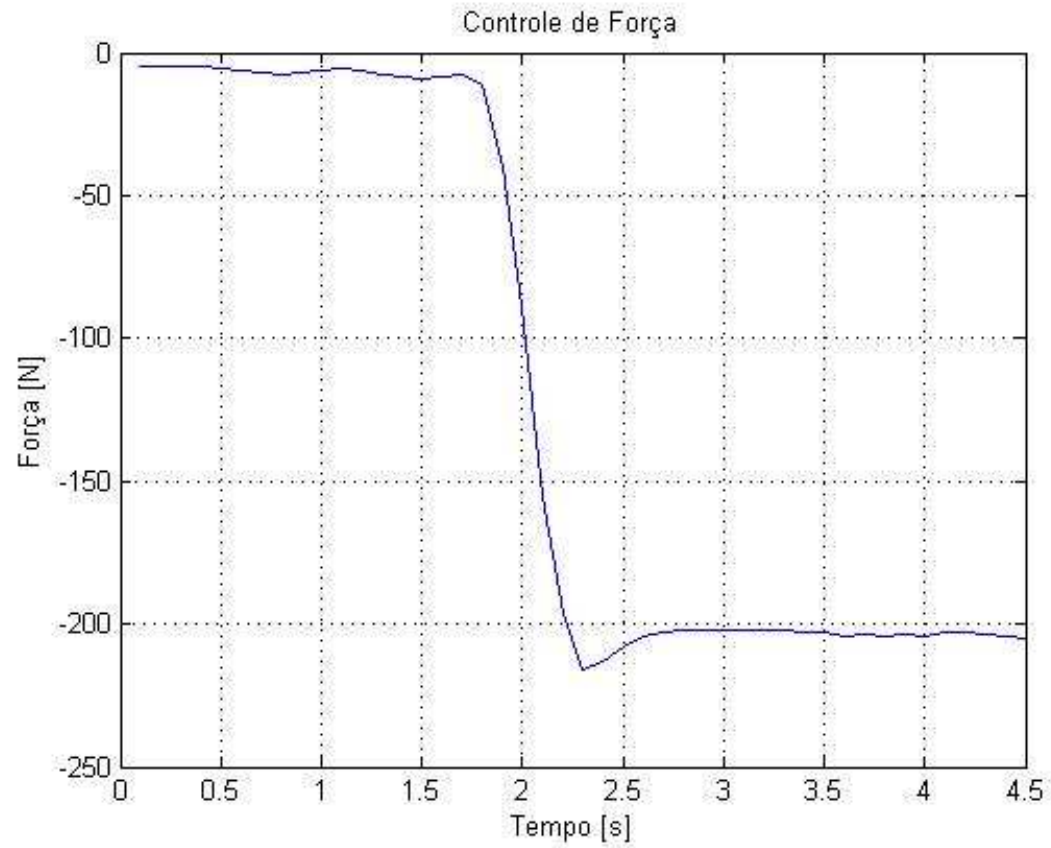

Figura 5.8: Resposta a um degrau de amplitude $-200 N$ 


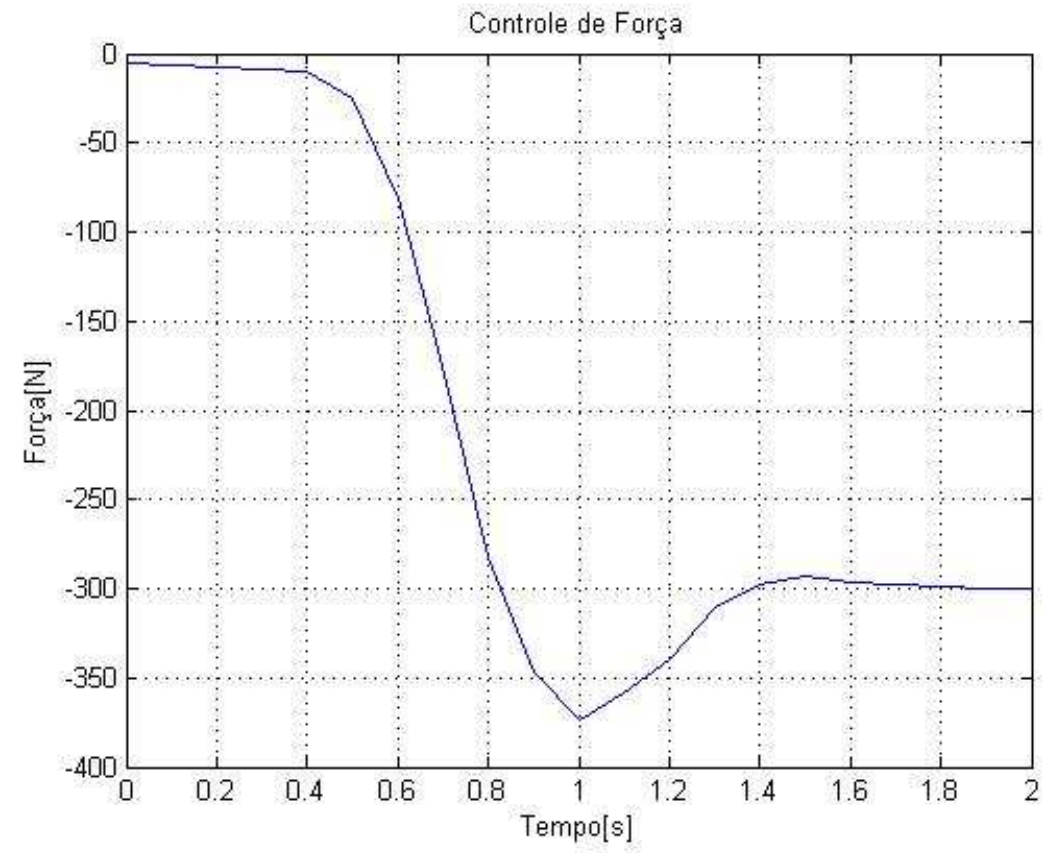

Figura 5.9: Resposta a um degrau de amplitude $-300 N$

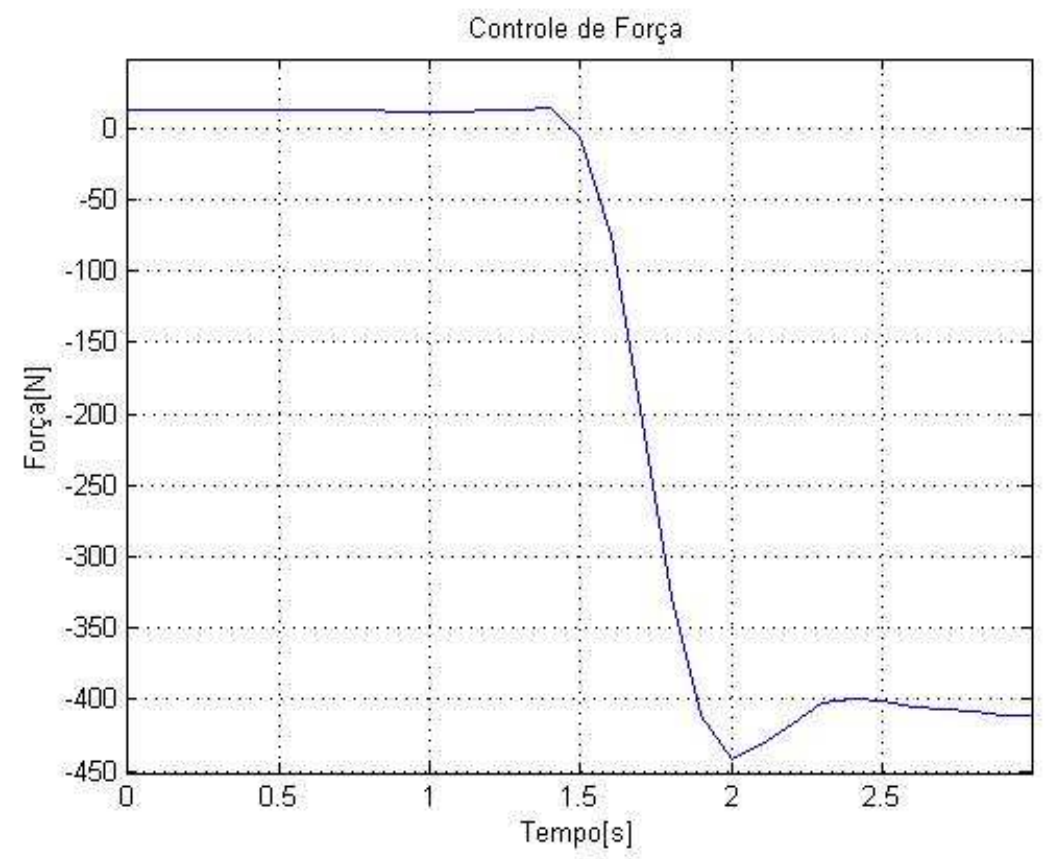

Figura 5.10: Resposta a um degrau de amplitude $-400 N$ 


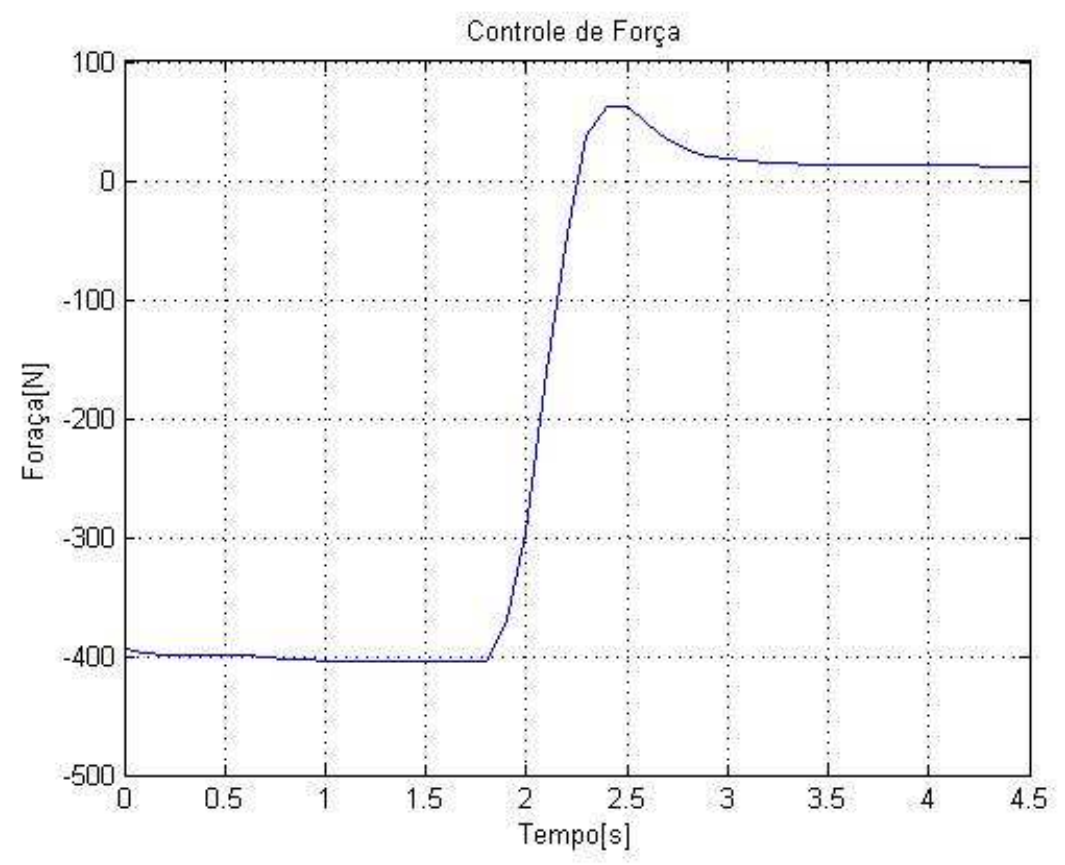

Figura 5.11: Retornar ao valor zero $(\Delta x=0)$

tal dispositivo é 10Bits, ou seja, $2^{10}=1024$ pontos, ao dividir a escala de tensão da entrada analógica da EPOS $(5000 \mathrm{mV})$ por esta resolução, obteremos o valor aproximado de $5 \mathrm{mV}$, isto mostra que a oscilação na medida da força, desta ordem de grandeza, é propriedade intrínseca do conversor, que pode ser eliminada aumentando-se a resolução do mesmo.

Como detalhado na Seção 3.3, duas situações para o controle de força foram estudadas: Carga Fixa e Impedância Zero. No segundo método, o efetuador é destravado e pode se movimentar no sentido positivo e negativo. É adotado valor zero para a força desejada na saída do dispositivo de modo que se um impacto ou força forem aplicados ao efetuador, este irá se mover até que a deformação das molas seja zero, ou seja, $F_{l}$ deve ser sempre zero. Nesta configuração é possível movimentar o efetuador com facilidade, característica denominada por impedância zero. Tal efeito é mostrado nas Figuras 5.12 e 5.13.

A Figura 5.12 mostra a resposta do AES quando é aplicado uma força no efetuador, pode-se interpretar esta força como sendo a tentativa de movimentar o mesmo, no sentido positivo. Notase que quando as molas sofrem compressão o motor começa a se mover para que a deformação das mesmas vá a zero, de modo que o efetuador se movimenta no mesmo sentido da força aplicada. Também mostra um pico de força negativo (força de reação à força aplicada ao efetuador) isso muitas vezes "mostra"que a força aplicada ao efetuador está no sentido positivo de movimentação, de acordo com o que é observado no comportamento em relação à posição do efetuador, que se 


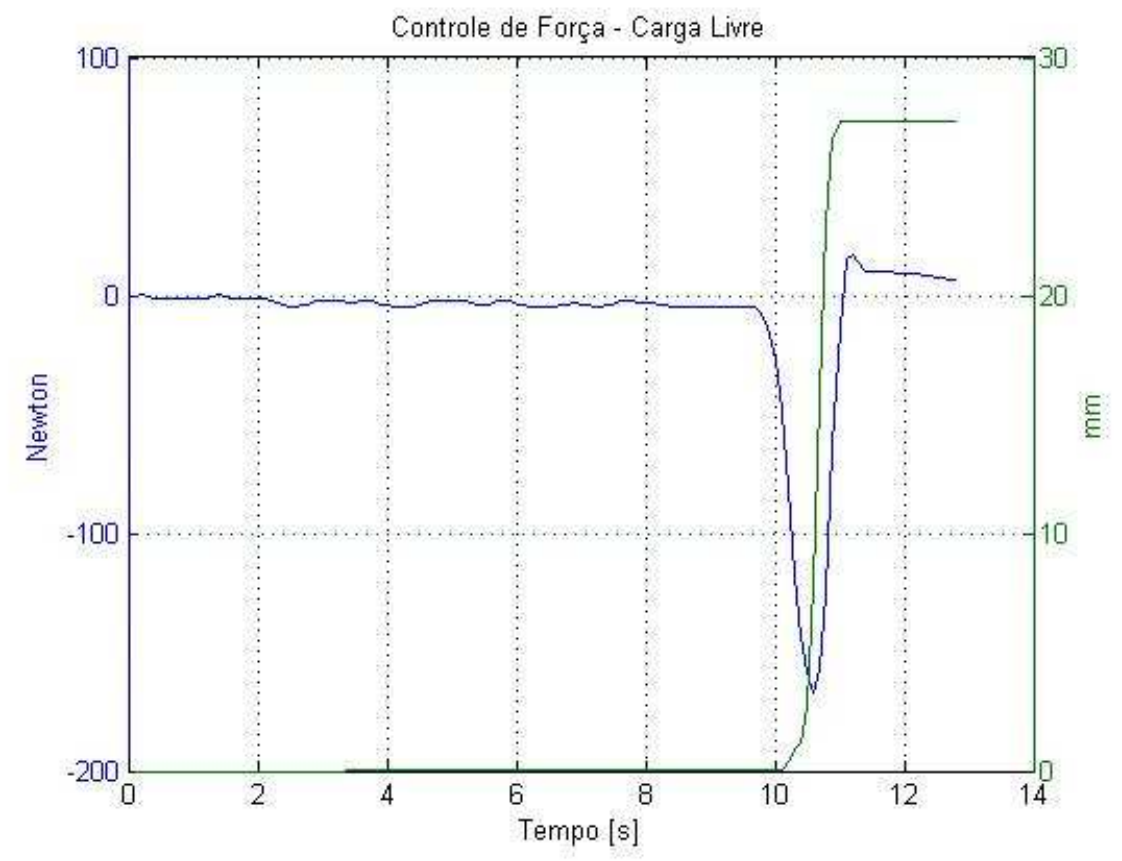

Figura 5.12: Controle de Força - Carga Livre

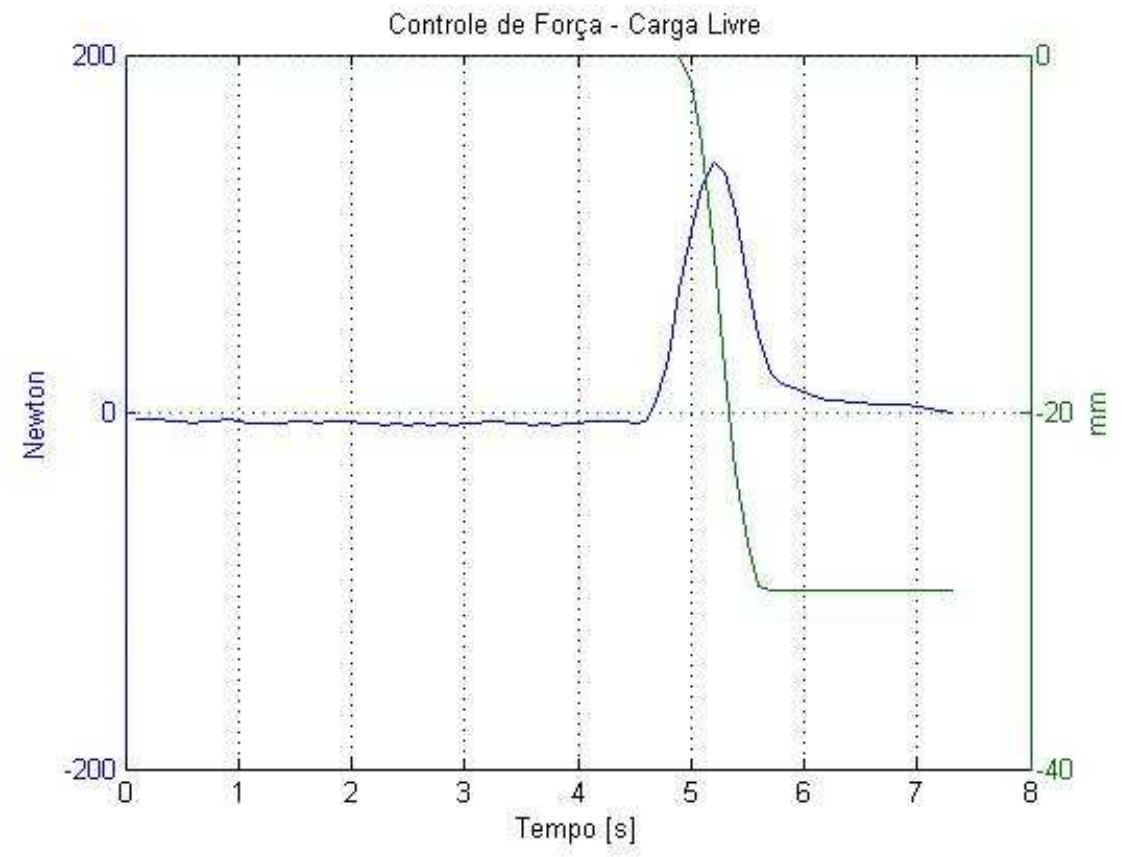

Figura 5.13: Controle de Força - Carga Livre 
desloca no mesmo sentido.

Se desejarmos movimentar o efetuador no sentido negativo é necessário aplicarmos uma força com o mesmo sentido, logo se observa na Figura 5.13 um pico positivo na força (força de reação) e movimentação negativa na posição do efetuador. Trata-se do efeito contrário ao mostrado na Figura 5.12. Nos dois casos apresentados observa-se o pico de força seguido da movimentação do efetuador e quando o potenciômetro mede zero para a deformação das molas, o efetuador pára de se movimentar, verificando-se o comportamento de impedância zero.

Utilizando o controle PD, com ganhos $K p=0.65$ e $K d=0.15$ e com termo de realimentação direta, foram obtidos os resultado mostrados nas Figuras 5.14 e 5.15.

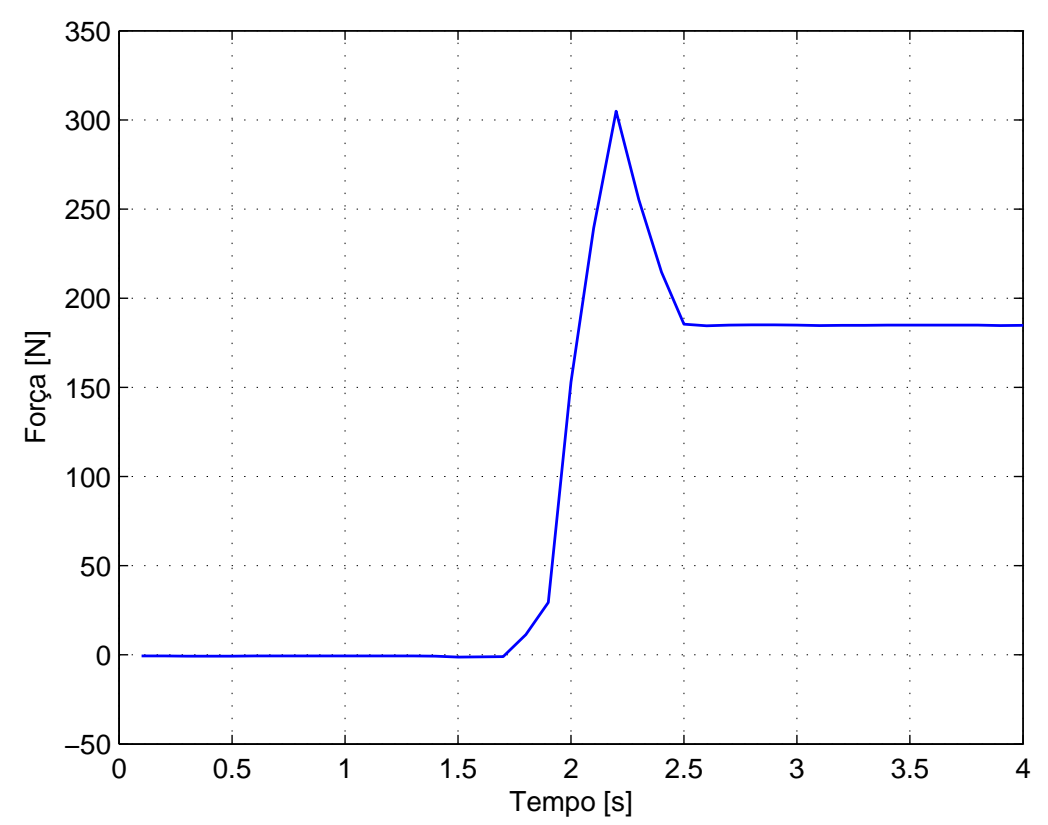

Figura 5.14: Controle de Força - Degrau 200N

A Figura 5.14 mostra a resposta do atuador à um degrau de amplitude $200 N$, nota-se que o controlador não está funcionando de forma satisfatória já que apresenta valor elevado para o sobressinal. O problema ocorre devido a taxa de amostragem do sistema em conjunto com o tipo de controlador utilizado. O primeiro fator faz com que o atuador não tenha atualização rápida para a leitura do potenciômetro, causando o sobressinal elevado. O segundo fator são os ganhos do controlador, difíceis de serem ajustados quando se considera o atraso na leitura do potenciômetro. Se ajustarmos valores altos para estes o atuador responde rápido, porém fica muito instável, de forma que ruídos captados pelos fios de alimentação do potenciômetro são amplificados, prejudicando o controle e danificando o equipamento. Adotando valores muito 


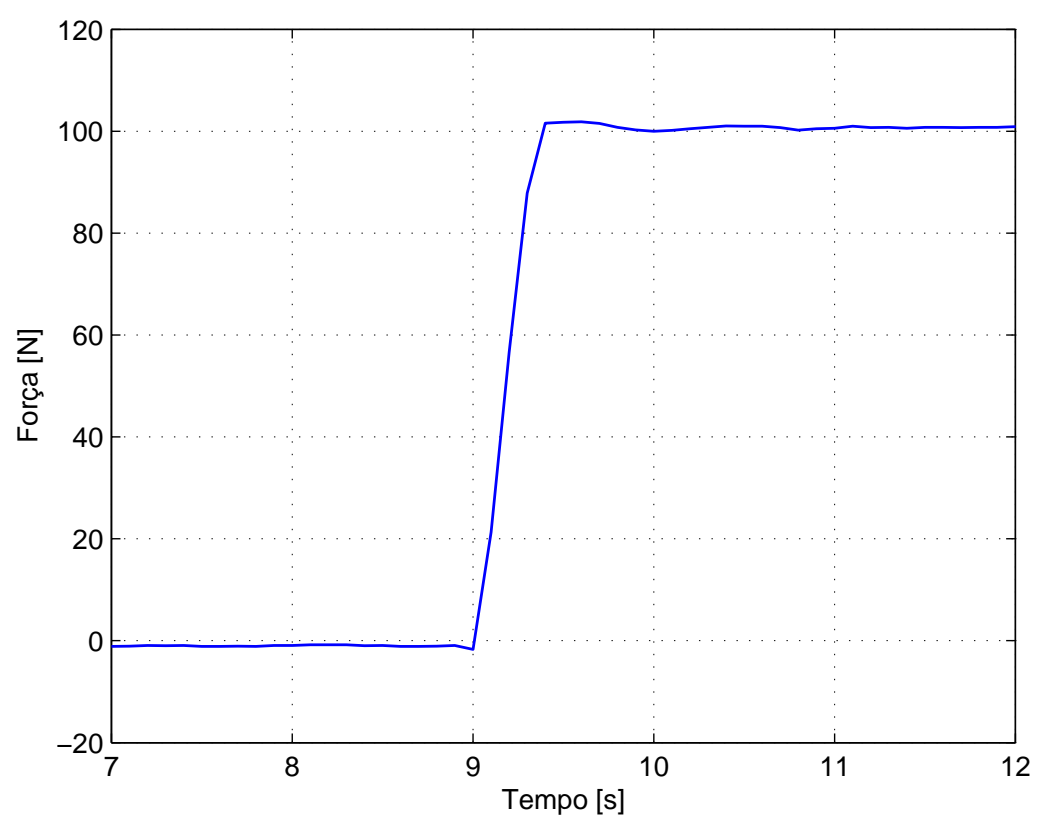

Figura 5.15: Controle de Força - Degrau -100N

baixos para o controlador o sistema fica muito lento. A Figura 5.15 mostra um comportamento melhor com relação a anterior porque nesse caso a amplitude da força desejada é menor, de forma que o atuador não oscila e também não fica instável.

\subsection{Controle de impedância - OTPA}

O controle de impedância, detalhado na Seção 3.4, relaciona a posição da carga com a força aplicada à mesma. Uma vez que se pode implementar o controle no SEA, ao fixarmos este à OTPA, procuramos uma maneira de fazer a atuação na junta com o mesmo controle, ou seja, escolhemos valores para a rigidez da junta e através de uma modelagem feita a partir do conjunto, Figura 4.12, podemos controlar a impedância da junta. Para isso, foram determinados os parâmetros $K_{t}$ e $B_{t}$, coeficientes de elasticidade e amortecimento para a junta. Logo, relacionando estes termos com os do atuador, $B_{v}$ e $K_{v}$, podemos transferir o controle de impedância do atuador para a junta. Este processo é necessário porque sabe-se que para cada etapa do caminhar a impedância da junta do tornozelo assume valores diferentes, em função do ângulo da junta, $\theta$.

Foram feitas duas interfaces em Borland Builder $C++$ para a visualização dos resultados, Figuras 5.16 e 5.17. A primeira interface é referente ao modo de posição, ou seja, o driver EPOS 
é selecionado para trabalhar no modo Profile Position Mode, sendo enviada ao driver a posição desejada para o motor, $X_{m d}$, Equação 3.23. Na segunda interface, o driver é configurado no modo Velocity Mode. Nesta configuração, a velocidade desejada, obtida pela Equação 3.21 é enviada ao mesmo.

As duas interfaces permitem a monitoração da posição do efetuador, ângulo da junta, força, entradas digitais e determinar valores para os parâmetros $K_{t}$ e $B_{t}$. Também é possível salvar os dados experimentais em uma pasta localizada no computador para que estes possam ser analisados com o auxílio do software Matlab.

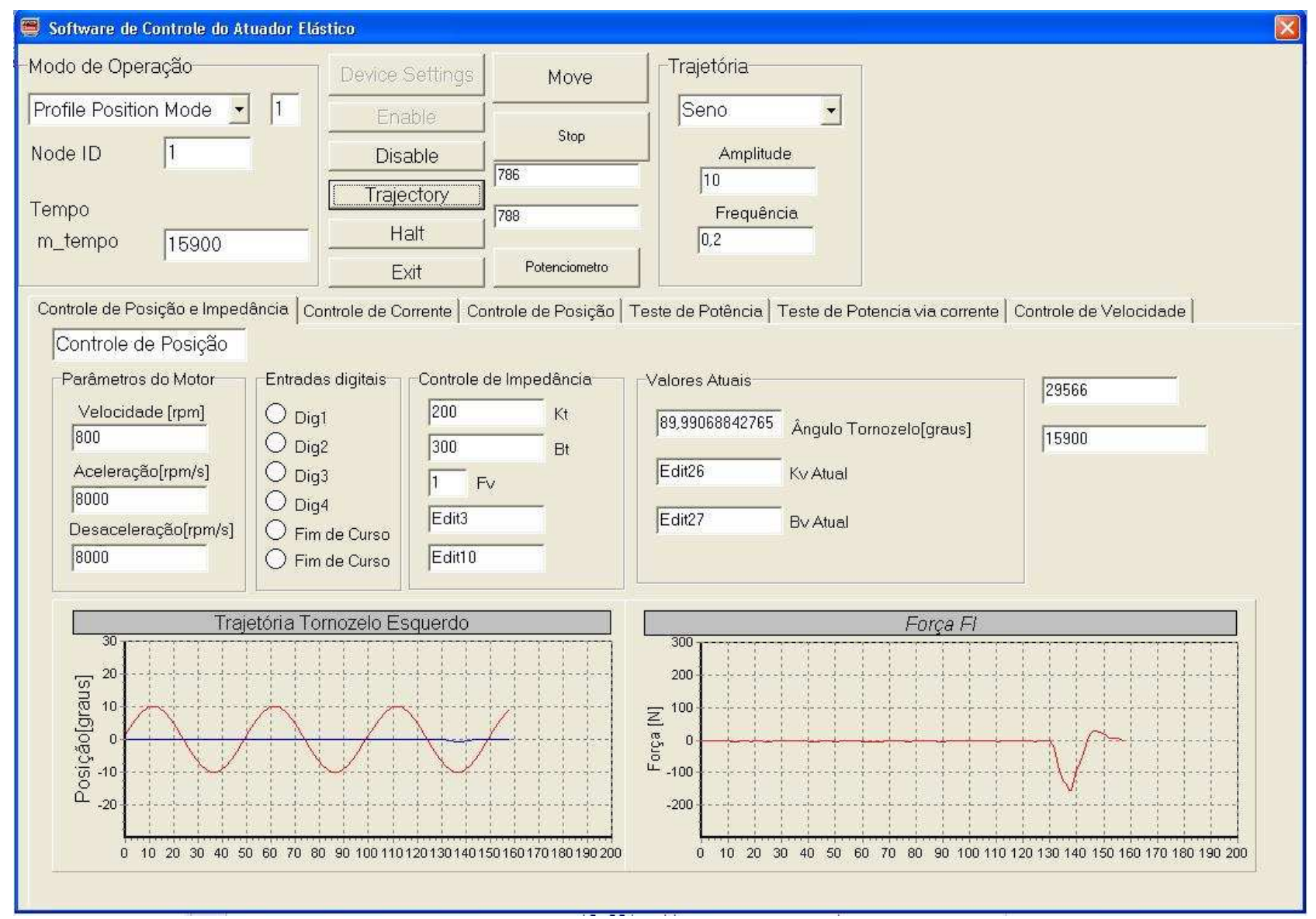

Figura 5.16: Interface para Controle de Impedância

A Figura 5.18, mostra o comportamento da OTPA quando os parâmetros $K_{t}$ e $B_{t}$ são $200 \mathrm{Nmm} / \mathrm{rad}$ e $0 \mathrm{Nmms} / \mathrm{rad}$, respectivamente, correspondendo a valores de $K_{v}$ e $B_{v}$ de $10 \mathrm{~N} / \mathrm{mm}$ e $0 \mathrm{Ns} / \mathrm{mm}$. Neste caso, o dispositivo se comporta como uma mola virtual, atuando na junta do tornozelo. Pode-se notar que a força e a posição estão em fase. Ao mudar os valores dos coeficientes $K_{t}$ e $B_{t}$ para $0 \mathrm{Nmm} / \mathrm{rad}$ e $800 \mathrm{Nmms} / \mathrm{rad}$ respectivamente, obtendo $K_{v}=0 \mathrm{~N} / \mathrm{mm}$ e $B_{v}=40 \mathrm{Ns} / \mathrm{mm}$. Neste caso a OTPA desempenha o papel de um amortecedor virtual, logo a 


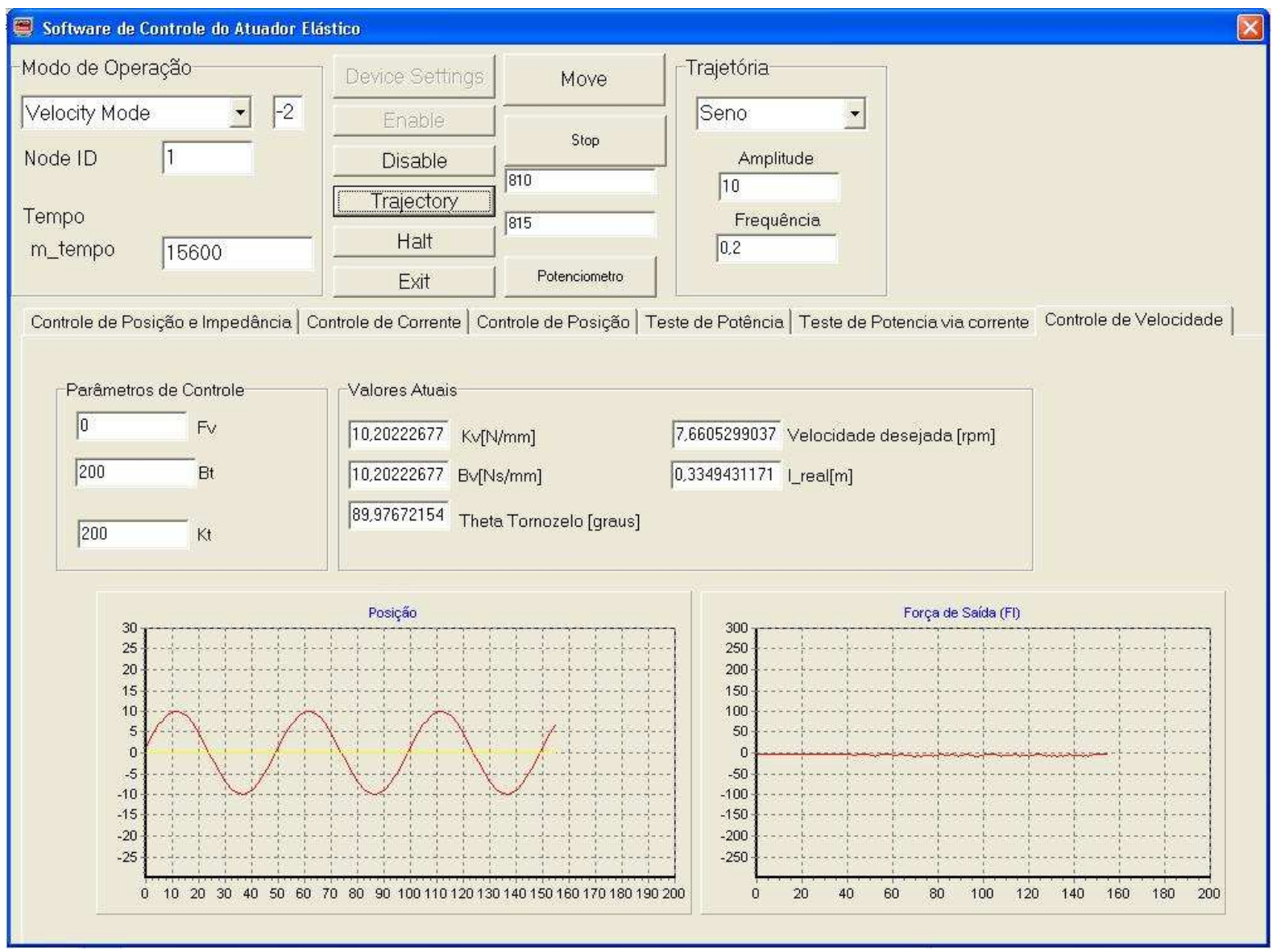

Figura 5.17: Interface para Controle de Impedância 
Figura 5.19 mostra que a posição segue a integral da força. Quando os valores dos coeficientes são respectivamente $200 \mathrm{Nmm} / \mathrm{rad}$ e $200 \mathrm{Nmms} / \mathrm{rad}$, ou seja, termos de mola e de amortecimento em conjunto, pode-se notar, Figura 5.20, que uma vez que a força retorna ao valor zero quase como sendo um degrau (instantâneo), a posição comporta-se como um decaimento exponencial, evidenciando o comportamento mola - amortecedor.

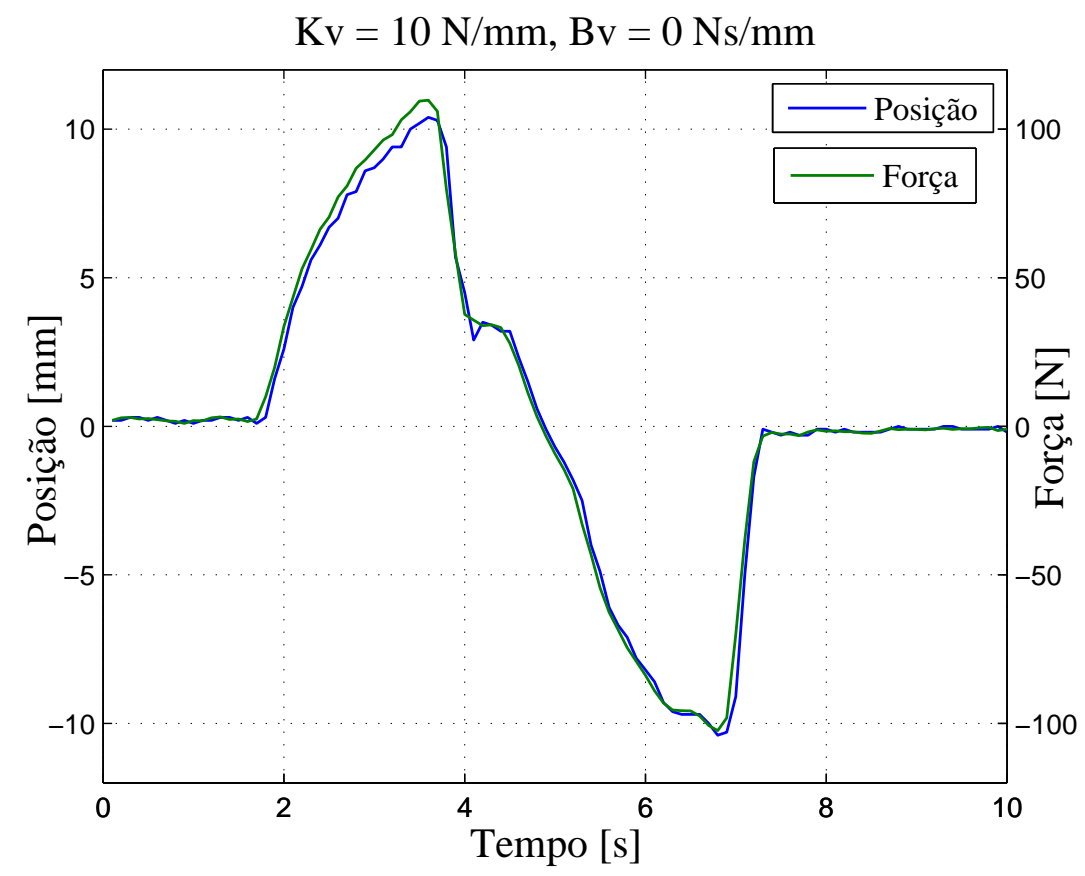

Figura 5.18: OTPA - Mola Virtual

Os resultados apresentados para o controle de impedância foram obtidos com o driver EPOS habilitado no modo de velocidade. No modo de controle de posição é necessário fazer integrações numéricas dentro da malha de controle, portanto, sua utilização torna o controle menos preciso com relação ao modo de velocidade. Os resultados para o modo de posição são satisfatórios se implementados com valores menores para a taxa de amostragem. 


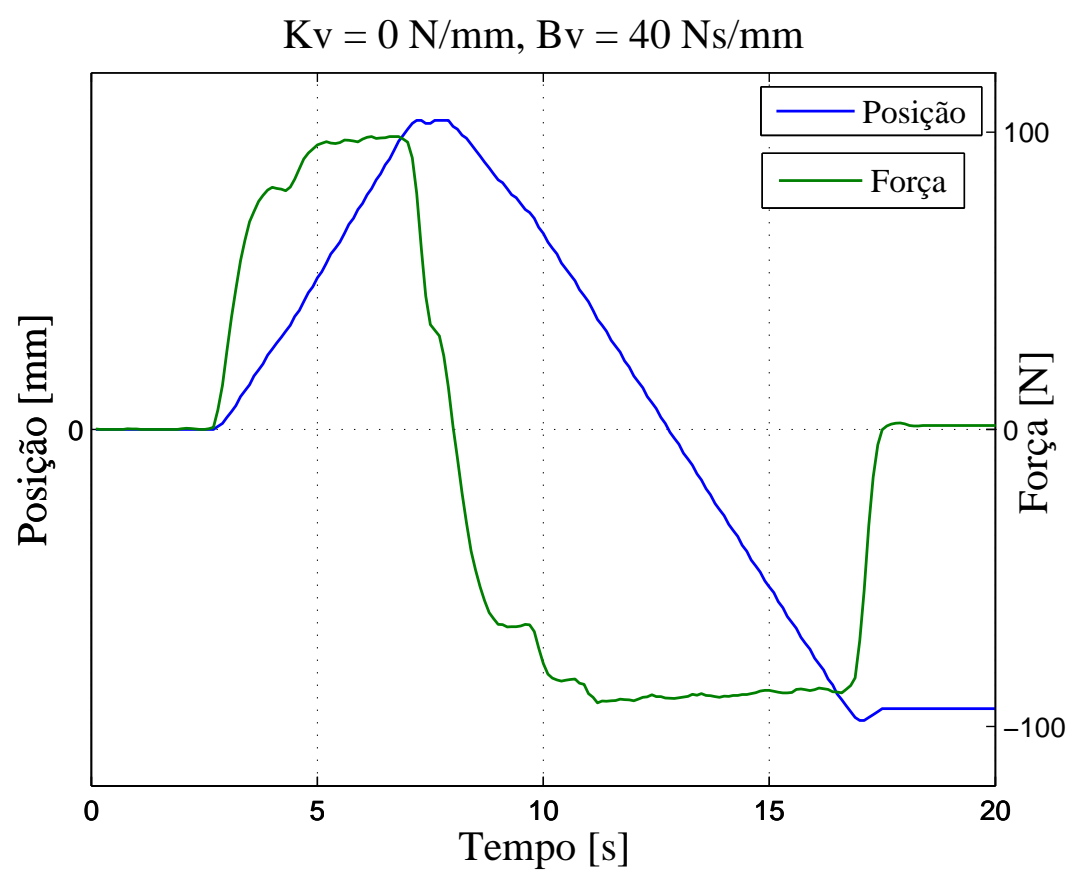

Figura 5.19: OTPA - Amortecedor Virtual

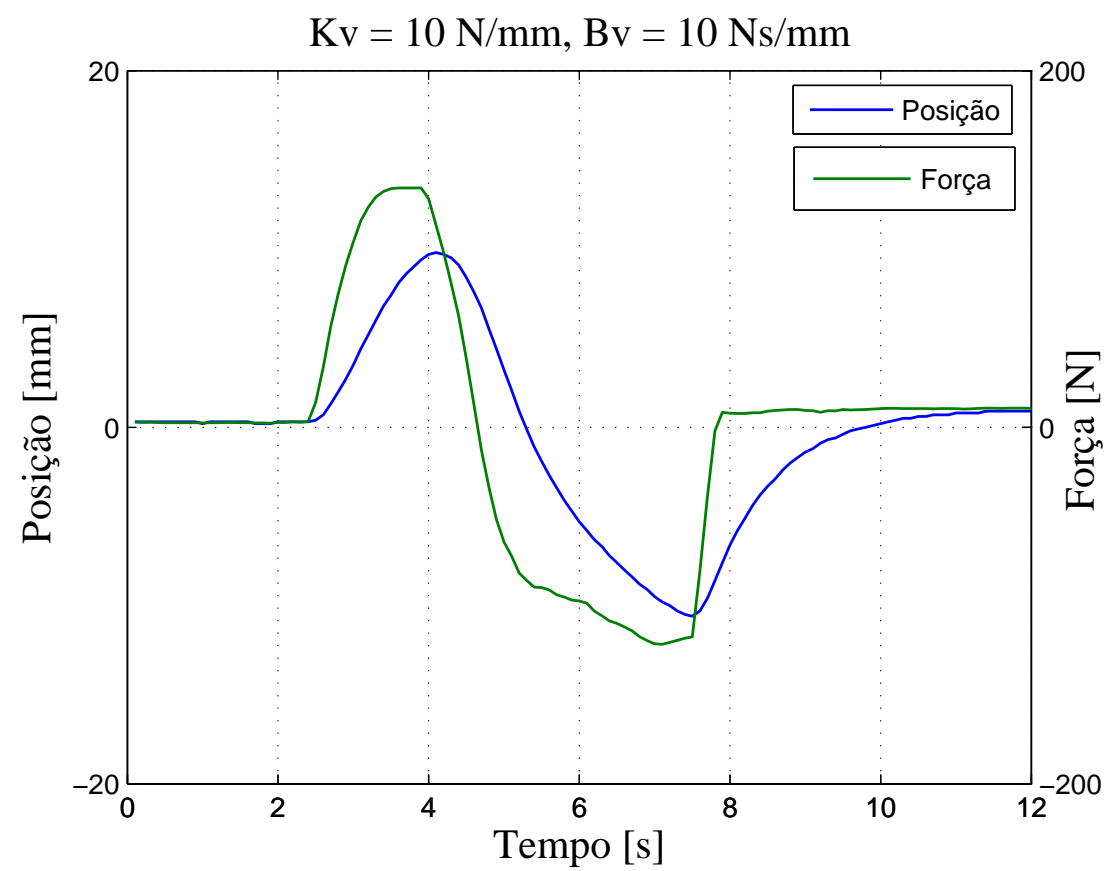

Figura 5.20: OTPA - Mola e Amortecedor Virtuais 


\section{Capítulo 6}

\section{Conclusão}

Este trabalho mostra a construção de um protótipo do atuador elástico em série e a utilização do mesmo em uma órtese tornozelo-pé ativa (OTPA). Na primeira fase foram projetados em Solid Edge e fabricados os componentes do atuador e da órtese. O atuador foi montado de acordo com modelos já existentes na literatura, salvo pequenos ajustes de projeto para o encaixe com a órtese. Após a montagem dos dispositivos, foi elaborada uma interface de controle dos mesmos, desenvolvida em Borland Builder $C++$. Os resultados experimentais obtidos para os controles implementados, controle de posição, força e controle de impedância, no atuador são satisfatórios e conferem com resultados encontrados na literatura. Dessa forma, pode-se implementar tal dispositivo, de forma confiável, no acionamento das demais juntas do exoesqueleto: joelho e quadril. 


\section{Referências Bibliográficas}

BLAYA, J. B. (2002). Force controllable ankle-foot orthosis (AFO) to assist drop foot gait. Master

Thesis for Massachusetts Institute of Technology, Department of Mechanical Engineering.

BLAYA, J. B.; HERR, H. (2004). Adaptative Control of a Variable-Impedance Ankle-Foot Orthosis to Assist Drop-Foot Gait. IEEE Transactions on Neural Systems and Rehabilitation Engineering, v.12, n.1, p.24-31.

DOLLAR, M.; HERR, H. (2008). Lower Extremity Exoskeletons and Active Orthoses: Challenges and State-of-the-Art. IEEE Transactions on Robotics, v.24, n.1, p.144-158.

ENDO, K.; HERR, H.; WALSH, C. J. (2007). A Quasepassive Leg Exoskeleton For Load Carrying Augmentation. International Journal of Humanoid Robotics, p. 4935-4939, March.

FERRIS, D. P.; SAWICKI, G. S.; DOMINGO, A. R. (2005). Powered Lower Limb Orthoses for Gait Rehabilitation. Top Signal Cord inj. Rehabilitation, v.11, n.2, p.34-49.

GUIZZO, E.; GOLDSTEIN, H. (2005). The rise of the body bots. IEEE Spectrum (INT), v.42, n.10, p.50-56, October.

HAYASHI, T.; KAWAMOTO, H.; SANKAY, Y. (2005). Control Method of Robot Suit HAL working as Operator's Muscle using Biological and Dynamical Information. In: Proceedings of the 2005 IEEE/RSJ International Conference on Intelligent Robots and Systems. 2005, volume 1, Edmonton,Canada, p. 3063-3068.

IBGE, I. B. D. G. E. E. (2003). Censo Demográfio 2000 - Características Gerais da População. JASPERS, P.; PETEGEM, W. V.; PERRE, G. V. D.; PEERAER, L. (1995). Optimisation Of a Combined Argo-Fes System: Adaptation Of The Knee Mechanism To Allow Flexion Of The Knee During The Swing Phase. Proceedings of the 17th Annual International Conference of the IEEE Engineering in Medicine and Biology Society, v.2p.1143-1144. 
JASPERS, P.; PETEGEM, W. V.; PERRE, G. V. D.; PEERAER, L. (1996). Design Of An Automatic Step Intention Detection System For a Hybrid Gait Orthosis. In: Proceedings of the 18th Annual International Conference of the IEEE Engineering in Medicine and Biology Society. 1996, volume 1, Amsterdam, Holanda, p. 457-458.

JAUKOVIC, N. (1981). Active Peroneal Orthosis. In: Proceedings of the International Symposium on External Control of Human Extremities. 1981, p. 13-20.

JEZERnIK, S.; COLOMBO, G.; KELlER, T.; FRUEH, H.; MORARI, M. (2003). Robotic Orthosis Lokomat: A Rehabilitation and Research Tool. Neuromodulation, v.6, n.2, p.108115.

JEZERNIK, S.; COLOMBO, G.; MORARI, M. (2004). Automatic Gait-Pattern Adaptation Algorithms for Rehabilitation With a 4-DOF Robotic Orthosis. IEEE Transactions on Robotics and Automation, v.20, n.3, p.574-582.

KAZEROONI, H. (2005). Exoskeletons for Human Power Augmentation. In: Proceedings of the 2005 IEEE/RSJ International Conference on Intelligent Robots and Systems. 2005, Edmonton,Canada, p. 3459-3464.

KIM, S.; ANWAR, G.; KAZEROONI, H. (2004). High-speed Communication Network for Controls with the Application on the Exoskeleton. In: Proceedings of the 2004 American Control Conference. 2004, volume 1, Boston, USA, p. 355-360.

KIM, S. H.; SANKAI, Y. (2005). Stair climbing task of humanoid robot by phase composition and phase sequence. In: Proceedings of the 2005 IEEE International Workshop on Robot and Human Interactive Communication. 2005, Nashville, TN, USA, p. 531-536.

KIM, S. H.; SANKAI, Y. (2005). Task generation for humanoid robot walking using human motion by phase sequence. In: Proceedings of the 2005 IEEE International Workshop on Robot and Human Interactive Communication. 2005, Nashville, TN, USA, p. 524-530.

KIRTLEY, C. (2007). CGA Normative Gait Database. Disponível em $<$ http://guardian.curtin.edu.au/cga/data/>. Acesso em out. $200 \%$.

LEE, S.; SANKAI, Y. (2002). Power Assist Control for Walking Aid with HAL-3 Based on EMG and Impedance Adjustment around Knee Joint. In: Proceedings of the 2002 IEEE/RSJ International Conference on Intelligent Robots and Systems. 2002, volume 2, Lausanne, Switzerland, p. 1499-1504. 
MORENO, J. C.; BRUNETTI, F. J.; PONS, J. L.; ROCON, E. (2007). Lower-Limb Wearable Exoskeleton. Rehabilitation Robotics, p. 471-498.

MOREnO, J. C.; LIMA, E. R.; RUÍZ, A. F.; BRUneTTI, F. J.; PONS, J. L. (2006). Design and implementation of an inertial measurement unit for control of artificial limbs: Application on leg orthoses. Rehabilitation Robotics, p. 333-337.

OGATA, K. (1993). Modern Control Engineering. Prentice-Hall, second edition.

OHTA, Y.; YOSHIDA, M.; KAWASHIMA, N.; NAKAZAWA, K. (2003). A Gait Orthosis For Paraplegics With a Motor-Driven Hip Joint. In: Proceedings of the XVI International Conference of the Society for Postural and Gait Research. 2003, Sydney, Australia.

PALUSKA, D.; HERR, H. (2006). Series Elastic Actuator and Power Output. In: Proceedings of IEEE International Conference on Robotics and Automation (ICRA). 2006, Orlando, Florida, p. $1830-1833$.

PALUSKA, D. J. (2000). Design of a Humanoid Biped for Walking Research. Master Thesis for Massachusetts Institute of Technology, Department of Mechanical Engineering.

PinotTi, M.; VIMieiro, C. B. S.; NAGEM, D. A. P.; NASCIMENTO, B. G. (2008). Hip Orthosis Powered By Pneumatic Artificial Muscle: Voluntary Activaction in Absence of Myoelectrical Signal. Artificial Organs, v.32p.317-322.

PRATT, G.; WILLIAMSON, M. (1995). Series elastic actuators. In: Proceedings of the 1995 IEEE/RSJ International Conference on Intelligent Robots and Systems. 1995, volume 1, Pittsburgh, p. 399-406.

PRATT, J.; DILWORTH, P.; PRATT, G. (1997). Virtual Model Control of a Biped Walking Robot. In: Proceedings of the 1997 IEEE International Conference on Robotics and Automation. 1997, volume 1, Albuquerque, New Mexico, USA, p. 193-198.

PRATT, J.; KRUPP, B. T.; MORSE, C. J. (2004). The RoboKnee: An Exoskeleton for Enhancing Strenght and Endurance During Walking. In: Proceedings of the 2004 IEEE International Conference on Robotics and Automation. 2004, New Orleans, LA, p. 2430-2435.

PRATT, J.; PRATT, G. (1998). Exploiting Natural Dynamics in the Control of a Planar Bipedal Walking Robot. In: Proceedings of the Thirty-Sixth Annual Allerton Conference on Communication, Control, and Computing. 1998, Urbana-Champaign, Illinois, p. 561-568. 
PRATT, J.; PRATT, G. (1999). Exploting Natural Dynamics in the Control of a 3D Bipedal Walking Simulation. In: Proceedings of the International Conference on Climbing and Walking Robots (CLAWAR99). 1999, Portsmouth,UK, p. 1-11.

PÉREZ-ORIVE, J.; MAYAGOITIA, R. E. (1994). A Closed-Loop Control System To Be Used With a Hybrid RGO System. In: Proceedings of the 16th Annual International Conference of the IEEE Engineering in Medicine and Biology Society. 1994, volume 1, Baltimore, MD, USA, p. $410-411$.

RIENER, R.; LÜNENBURGER, L.; JEZERNIK, S.; ANDERSCHITZ, M.; COLOMBO, G.; DIETZ., V. (2005). Patient-Cooperative Strategies for Robot-Aided Treadmill Training: First Experimental Results. IEEE Transactions on Neural Systems and Rehabilitation Engineering, v.13, n.2, p.380-394.

ROBInSON, D. W.; PRATT, J.; PALUSKA, D.; PRATT, G. (1999). Series Elastic Actuator Development for a Biomimetic Walking Robot. In: Proceedings of the 1999 IEEE/ASME International Conference on Advanced Intelligent Mechatronics. 1999, Atlanta, p. 561-568.

SAMUEL, K.; HERR, H. (2006). Initial Experimental Study on Dynamic Interaction Between an Amputee and a Powered Ankle-Foot Prostheses. In: Proceedings of the the ICRA 2006. 2006, Orlando - Flórida, p. 1-1.

SENSINGER, J. W.; WEIR, R. F. (2006). Improvements to Series Elastic Actuators. Mechatronic and Embedded Systems and Applications, p. 1-7.

TO, C. S.; KIRSCH, R. F.; KOBETIC, R.; TRIOLO, R. J. (2005). Simulation of a Functional Neuromuscular Stimulation Powered Mechanical Gait Orthosis With Coordinated Joint Locking. IEEE Transactions on Neural Systems and Rehabilitation Engineering, v.13, n.2, p.227235, June.

WALSH, C. J.; PALUSKA, D. J.; PASCH, K.; GRAND, W.; VALIENTE, A.; HERR, H. (2006). Development of a lightweight, underactuated exoskeleton for load-carrying augmentation. In: Proceedings of the 2006 IEEE International Conference on Robotics and Automation. 2006, Orlanda, Florida, p. 3485-3491.

YAKIMOVICH, T.; KOFMAN, J.; LEMAIRE, E. (2006). Design, Construction and Evaluation of an Electromechanical Stance-Control Knee-Ankle-Foot Orthosis. In: Proceedings of the 
2005 IEEE Engineering in Medicine an Biology 2rith Annual Conference. 2006, volume 14, Shanghai, China, p. 361-369.

ZOSS, A.; KAZEROONI, H.; CHU, A. (2005). On the Mechanical Design of the Berkeley Lower Extremity Exoskeleton (BLEEX). In: Proceedings of the 2005 IEEE/RSJ International Conference on Intelligent Robots and Systems. 2005, Edmonton, Canada, p. 3465-3472. 


\section{Apêndice A}

\section{Lista de Materiais}

Neste apêndice são apresentados os componentes utilizados na montagem do atuador elástico em série e da OTPA, respectivamente, nas Tabelas A.1 e A.2.

Tabela A.1: Componentes para a montagem do Atuador Elástico em Série

\begin{tabular}{|c|c|c|c|c|c|}
\hline Componentes & Material & Quantidade & Marca & Descrição & Preço $R \$$ \\
\hline Peças de Suporte & Duralumínio & 6 & - & Usinadas & 900,00 \\
\hline Buchas & Bronze-grafite & 4 & - & Usinadas & 200,00 \\
\hline Molas & Aço & 4 & - & Pré-fabricadas & 30,00 \\
\hline Rolamentos & Aço & 6 & - & Lineares & 95,00 \\
\hline Mancal & Aço & 1 & NSK & - & 333,00 \\
\hline Guias & Aço & 4 & NSK & Retificado & 53,00 \\
\hline Fuso & Aço & 1 & NSK & Retificado & 157,00 \\
\hline Castanha & - & 1 & NSK & Esferas Recirculantes & 213,00 \\
\hline Acoplamento & - & 1 & NSK & & 140,00 \\
\hline Potenciômetro & - & 1 & - & Linear Deslizante & 10,00 \\
\hline Motor & - & 1 & Maxon & RE40 - $150 \mathrm{~W}$ & 1500,00 \\
\hline Driver & - & 1 & Maxon & EPOS $70 / 10$ & 2880,00 \\
\hline Total & - & - & - & & 6511,00 \\
\hline
\end{tabular}


Tabela A.2: Componentes para a montagem da Órtese Tornozelo-Pé Ativa

\begin{tabular}{|c|c|c|c|c|c|}
\hline Componentes & Material & Quantidade & Marca & Descrição & Preço $R \$$ \\
\hline Peças de Suporte & Duralumínio & 10 & - & Usinadas & 2600,00 \\
\hline Plataforma de apoio (Pé) & Aço & 1 & - & Usinadas & 50,00 \\
\hline Bota Ortopédica & - & 1 & - & Pré-fabricadas & 100,00 \\
\hline Sensores & - & 4 & $F S R$ & SIC & 50,00 \\
\hline Total & - & - & - & - & 2800,00 \\
\hline
\end{tabular}

